\title{
A Library of Spirooxindoles Based on a Stereoselective Three-Component Coupling Reaction
}

\author{
Michael M.-C. Lo, Christopher S. Neumann, Satoshi Nagayama, Ethan O. Perlstein, \\ and Stuart L. Schreiber*
}

Contribution from the Program in Chemical Biology, Broad Institute of Harvard and MIT, and the Howard Hughes Medical Institute, Department of Chemistry and Chemical Biology, Harvard University, Cambridge, Massachusetts 02138

\section{Supporting Information}

\section{General}

${ }^{1} \mathrm{H}$ nuclear magnetic resonance spectra were recorded on Varian Mercury 400 (400MHz), Bruker Avance DMX500 (500MHz), or Varian Unity/Inova600 $(600 \mathrm{MHz})$ spectrometers. ${ }^{1} \mathrm{H}$ data are reported as follows: chemical shift in parts per million downfield from tetramethylsilane $(\delta$ scale $)$, multiplicity (s, singlet; d, doublet; t, triplet; q, quartet; sept, septet; m, multiplet; and br, broadened), integration, and coupling constant $(\mathrm{Hz}) . \quad{ }^{13} \mathrm{C}$ magnetic resonance spectra were recorded on Varian Mercury400 $(100 \mathrm{MHz})$ or Varian Unity/Inova500 $(125 \mathrm{MHz})$ spectrometers. ${ }^{13} \mathrm{C}$ chemical shifts are reported in parts per million downfield from tetramethylsilane $\left(\delta\right.$ scale). All ${ }^{13} \mathrm{C}$ spectra were determined with broadband ${ }^{1} \mathrm{H}$ decoupling.

All reactions were monitored by thin layer chromatography using glass plates precoated with Merck silica gel $60 \mathrm{~F}_{254}$ and visualized with either UV light or ceric ammonium molybdate. Analytical 


\section{General}

HPLC/MS was performed on a Gilson 322 - ThermoFinnigan AQA system using a Waters SymmetryShield $^{\mathrm{TM}} \mathrm{RP}_{8}$ column $(4.6 \times 100 \mathrm{~mm}, 3.5 \mu \mathrm{m})$ and electrospray ionization. Flash chromatography was performed either on EM Science silica gel 60 (230-400 mesh) or using a CombiFlash Companion system (Teledyne ISCO, Inc.) with pre-packed FLASH silica gel columns (Biotage, Inc.). Preparative HPLC was performed on an Agilent 1100 Series system with either a ZORBAX ${ }^{\circledR}$ Rx-SIL column $(9.4$ x $250 \mathrm{~mm}, 5 \mu \mathrm{m})$ in normal phase or a ZORBAX ${ }^{\circledR}$ Eclipse XDB-C18 column $(9.4 \times 250 \mathrm{~mm}, 5 \mu \mathrm{m})$ in reverse phase.

Dry solvents were dispensed from a solvent purification system that passes solvents through packed columns (THF and $\mathrm{CH}_{2} \mathrm{Cl}_{2}$ : dry neutral alumina; toluene: dry neutral alumina and Q5 reactant; DMF: activated molecular sieves). Anhydrous pyridine and trimethyl orthoformate were purchased from Aldrich. 2,6-Lutidine was distilled from $\mathrm{CaH}_{2}$ under nitrogen. Unless otherwise stated, all reagents were obtained from commercial sources and used without further purification. 5,6-Diphenyl-4morpholin-2-one was prepared from the Boc-protected compound according to the procedure of Williams. ${ }^{1}$

The 500-600 $\mu \mathrm{m}$ macrobeads used were prepared at the Institute of Chemistry and Chemical Biology according to published procedure. ${ }^{2}$ Before loading, the aldehydes were purified either by recrystallization or distillation under reduced pressure. Loading of aldehydes was carried out according to published procedure. ${ }^{3}$ To determine the loading level, a batch of 25 macrobeads was treated with the cleavage cocktail according to published procedure, ${ }^{3}$ and the amount of eluted compound was quantified by ${ }^{1} \mathrm{H}$ NMR using $\left(\mathrm{PhMe}_{2} \mathrm{Si}\right)_{2} \mathrm{O}$ as the internal standard.

Trace metal analysis was carried out at the West Coast Analytical Service, Sante Fe Springs, CA.

(1) Williams, R. M.; Zhai, W.; Aldous, D. J.; Aldous, S. C. J. Org. Chem. 1992, 57, 6527-6532. 
I. General

(2) Tallarico, J. A.; Depew, K. M.; Pelish, H. E.; Westwood, N. J.; Lindsley, C. W.; Shair, M. D.; Schreiber, S. L.; Foley, M. A. J. Comb. Chem. 2001, 3, 312-318.

(3) Clemons, P. A.; Koehler, A. N.; Wagner, B. K.; Sprigings, T. G.; Spring, D. R.; King, R. W.; Schreiber, S. L. Chem. Biol. 2001, 8, 1183-1195. 


\section{Synthesis of Dipolarophiles}
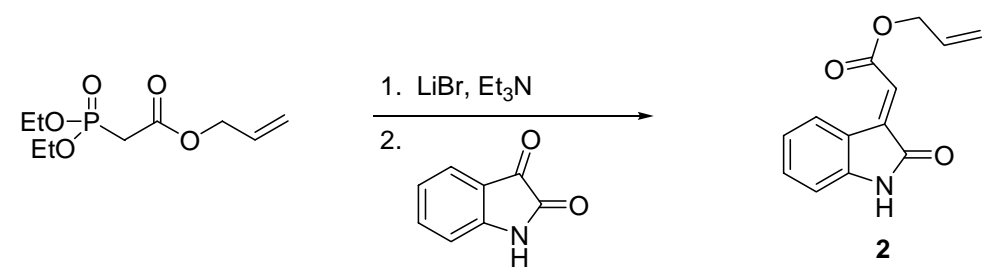

(E)-allyl 2-(2'-oxoindolin-3'-ylidene)acetate. To a 150-mL THF solution of $\operatorname{LiBr}(5.79 \mathrm{~g}, 66.7$ mmol) was added allyl diethylphosphonoacetate $(10.8 \mathrm{~mL}, 51.2 \mathrm{mmol})$ and $\mathrm{Et}_{3} \mathrm{~N}(9.25 \mathrm{~mL}, 66.4 \mathrm{mmol})$. After 30 minutes, isatin $(7.36 \mathrm{~g}, 50.0 \mathrm{mmol})$ was added. The reaction was monitored by TLC, and when the isatin was consumed, the reaction mixture was quenched with $200 \mathrm{~mL} 1 \mathrm{M} \mathrm{HCl}$. The mixture was then extracted with EtOAc $(3 \times 300 \mathrm{~mL})$, and the combined organic extracts were washed with brine, dried $\left(\mathrm{MgSO}_{4}\right)$, and concentrated in vacuo to afford an orange solid. The crude product was purified first by flash chromatography $(20 / 80$ EtOAc/hexanes $)$, followed by recrystallization from EtOAc/hexanes to afford an orange solid $(5.11 \mathrm{~g}, 44 \%$ yield $)$.

${ }^{1} \mathrm{H}$ NMR (500 MHz, $\mathrm{CDCl}_{3}$ ): $\delta 4.78(\mathrm{td}, 2 \mathrm{H}, J=1.1,5.7), 5.31$ (qd, $\left.1 \mathrm{H}, J=1.3,10.5\right), 5.41$ (qd, $1 \mathrm{H}$, $J=1.5,17.6), 6.01(\mathrm{tdd}, 1 \mathrm{H}, J=5.7,10.4,17.1), 6.86(\mathrm{~d}, 1 \mathrm{H}, J=7.8), 6.92(\mathrm{~s}, 1 \mathrm{H}), 7.05(\mathrm{dt}, 1 \mathrm{H}, J=$ 1.0, 7.8), $7.33(\mathrm{dt}, 1 \mathrm{H}, J=1.1,7.6), 8.3(\mathrm{~s} \mathrm{br}, 1 \mathrm{H}), 8.55(\mathrm{~d}, 1 \mathrm{H}, J=7.8) .{ }^{13} \mathrm{C}$ NMR $\left(101 \mathrm{MHz}, \mathrm{CDCl}_{3}\right)$ : $\delta 66.0,110.5,119.0,120.5,122.3,123.1,129.3,131.8,132.9,138.9,143.8,165.4,169.8$. HRMS-EI (m/z): $[\mathrm{M}]^{+}$calcd for $\mathrm{C}_{13} \mathrm{H}_{11} \mathrm{NO}_{3}, 229.0739$; found, 229.0746 . 


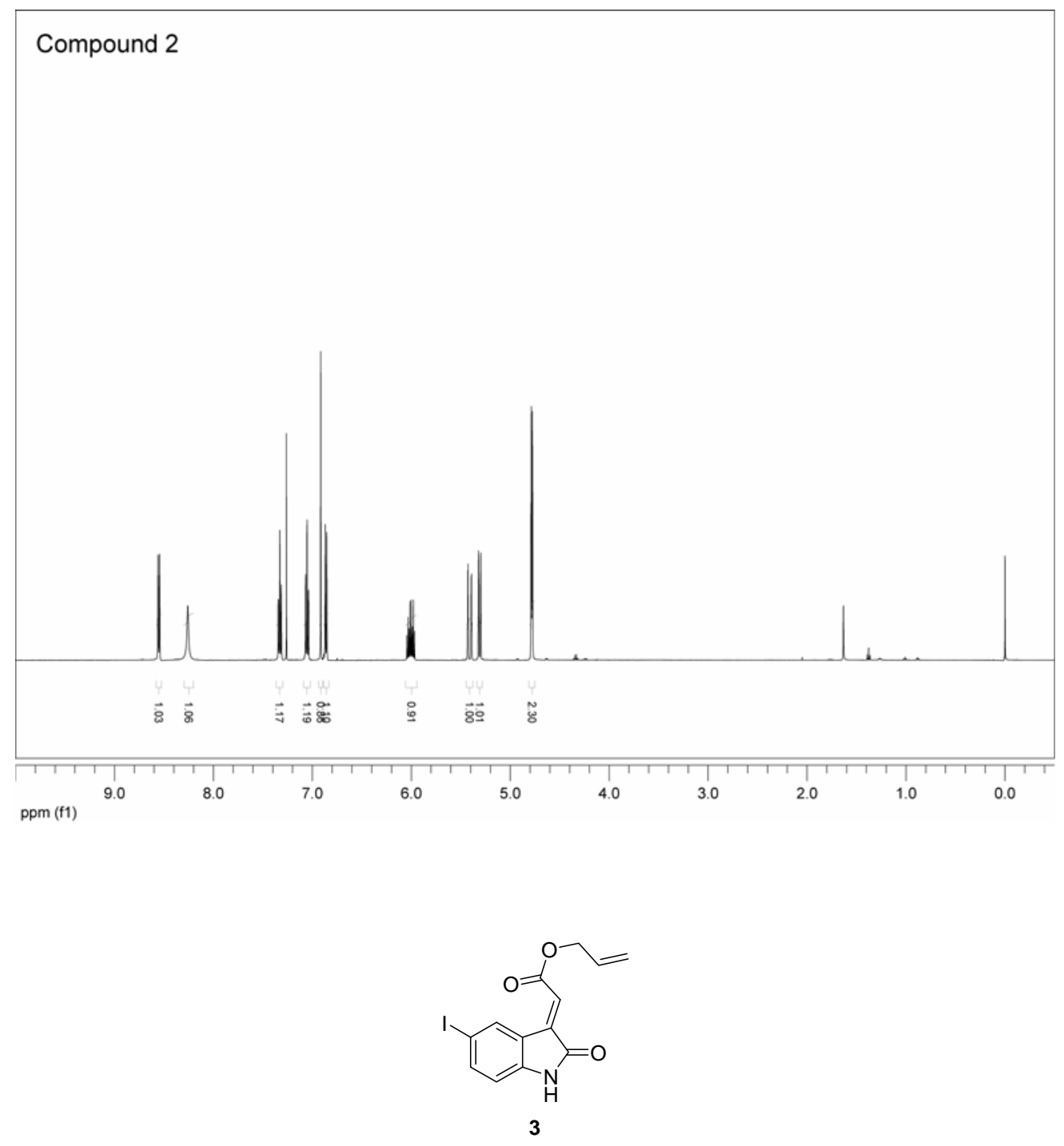

(E)-allyl 2-(5'-iodo-2'-oxoindolin-3'-ylidene)acetate. The title compound was synthesized similar to the procedure for $\mathbf{2}$, with 5 -iodoisatin replacing isatin. The crude product was first purified by flash chromatography (8/92 MeCN/benzene), followed by recrystallization from $\mathrm{CH}_{2} \mathrm{Cl}_{2} /$ hexanes to afford an orange solid ( $37 \%$ yield).

${ }^{1} \mathrm{H}$ NMR (500 MHz, $\left.\mathrm{CDCl}_{3}\right): \delta 4.80(\mathrm{td}, 2 \mathrm{H}, J=1.5,5.9), 5.34(\mathrm{qd}, 1 \mathrm{H}, J=1.0,10.3), 5.43(\mathrm{qd}, 1 \mathrm{H}$, $J=1.2,17.3), 6.02(\mathrm{tdd}, 1 \mathrm{H}, J=5.8,10.6,17.1), 6.66(\mathrm{~d}, 1 \mathrm{H}, J=8.3), 6.92(\mathrm{~s}, 1 \mathrm{H}), 7.65(\mathrm{dd}, 1 \mathrm{H}, J=$ 1.7, 8.1), 8.20 (s br, 1H), $8.89(\mathrm{~d}, 1 \mathrm{H}, J=1.0) .{ }^{13} \mathrm{C} \mathrm{NMR}\left(100 \mathrm{MHz}, \mathrm{CDCl}_{3}\right): \delta 66.1,85.4,112.1,119.2$, 
II. Synthesis of Dipolarophiles

$122.3,123.6,131.4,137.1,137.5,141.1,142.7,164.8,168.4$. HRMS-EI $(m / z):[M]^{+}$calcd for $\mathrm{C}_{13} \mathrm{H}_{10} \mathrm{INO}_{3}, 354.9705$; found, 354.9702 .

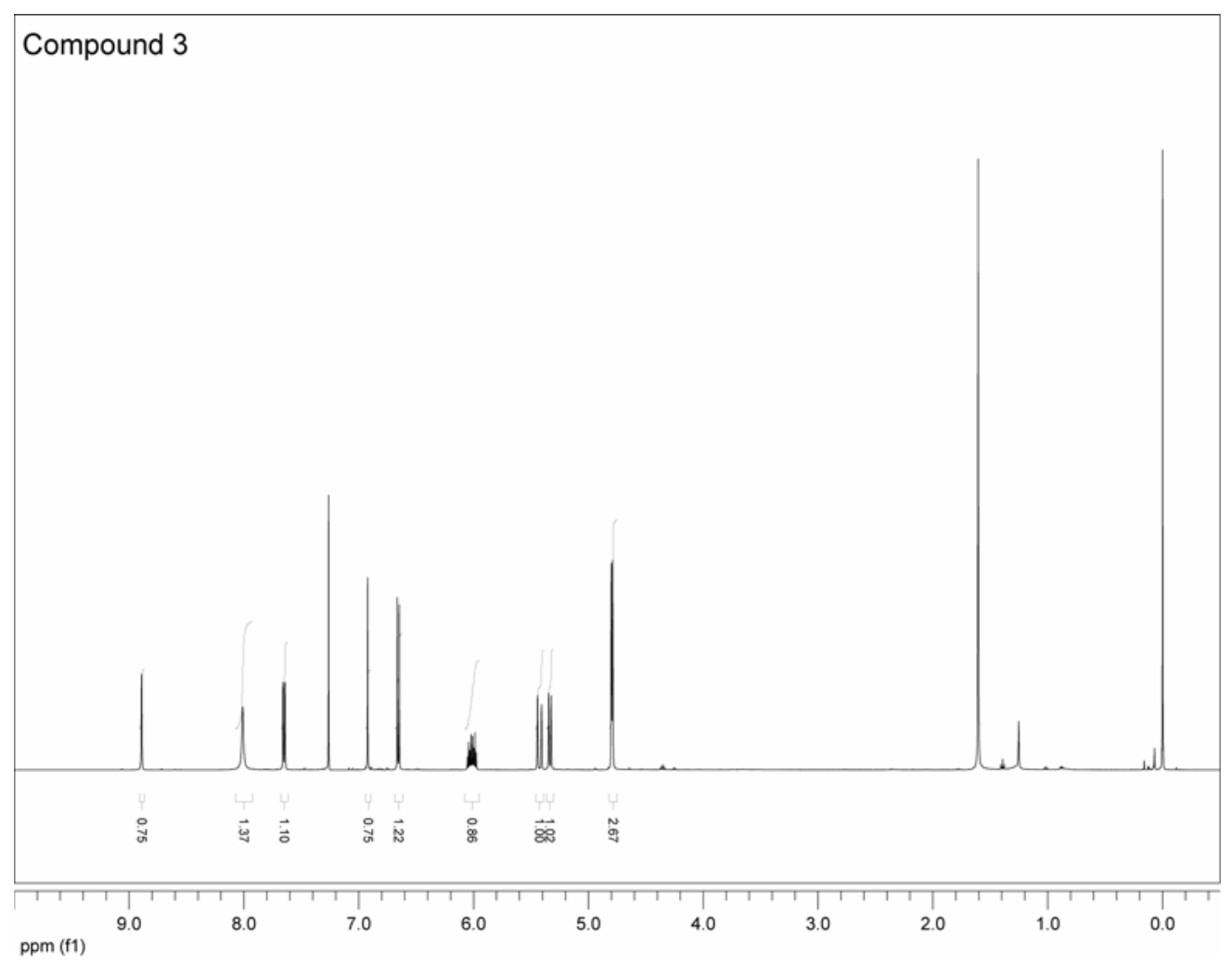




\section{Lewis Acid-Mediated 3CR (Table 1)}

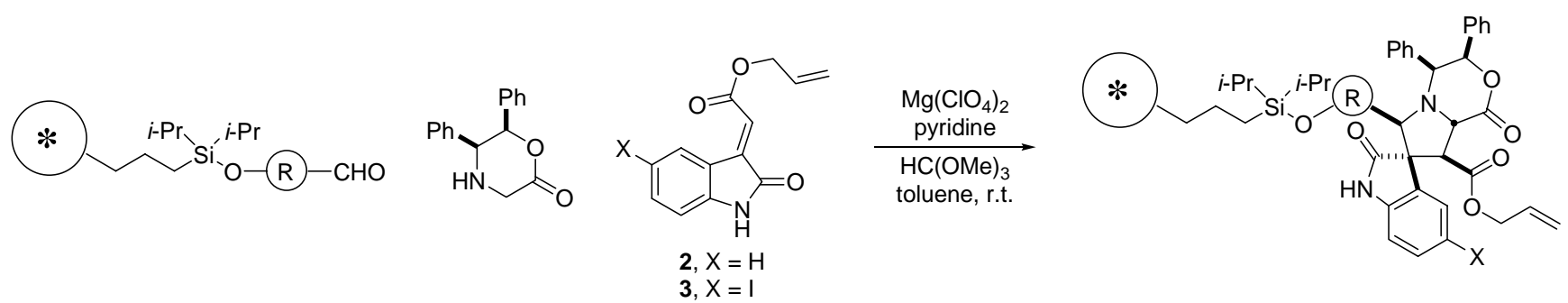

General procedure. To a $20-\mathrm{mL}$ vial was added the macrobead-supported aldehyde $(50.0 \mathrm{mg})$, enantiomerically pure 5,6-diphenyl-4-morpholin-2-one $(50 \mathrm{mg}, 0.20 \mathrm{mmol})$, dipolarophile $(0.20 \mathrm{mmol})$, $\mathrm{Mg}\left(\mathrm{ClO}_{4}\right)_{2}(20.2 \mathrm{mg}, 0.0905 \mathrm{mmol})$, pyridine $(25 \mu \mathrm{L}, 0.31 \mathrm{mmol})$, and trimethyl orthoformate $(50 \mu \mathrm{L}$, $0.46 \mathrm{mmol}$ ). The vial was purged with Ar, charged with $5 \mathrm{~mL}$ toluene, and tumbled for 3 days at room temperature. The beads were then filtered, washed with $\mathrm{CH}_{2} \mathrm{Cl}_{2}$ ( $\left.3 \times 10 \mathrm{~min}\right)$, THF ( $\left.3 \times 10 \mathrm{~min}\right)$, DMF ( $3 \times 10 \mathrm{~min})$, THF ( $3 \times 10 \mathrm{~min}), \mathrm{CH}_{2} \mathrm{Cl}_{2}(3 \times 10 \mathrm{~min})$, and dried in vacuo. To obtain the crude compound for analysis and characterization, the macrobeads were treated with the cleavage cocktail according to published procedure.

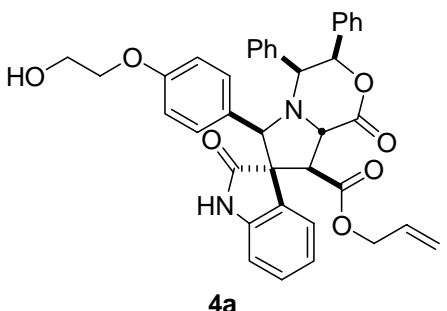

Table 1, entry 1. The reaction was carried out using macrobead-supported 4-(2hydroxyethoxy)benzaldehyde, (5S,6R)-5,6-diphenyl-4-morpholin-2-one, and the dipolarophile 2. NMR analysis showed that the conversion was $89 \%$, and the product was a $88: 12$ diastereomeric mixture. The crude product was purified by flash chromatography (50/50 EtOAc/hexanes $\rightarrow 60 / 40)$, followed by $\operatorname{HPLC}(65 / 35$ acetonitrile/water). 
4a. ${ }^{1} \mathrm{H}$ NMR (500 MHz, $\left.\mathrm{CD}_{3} \mathrm{CN}\right): \delta 2.9(\mathrm{~s} \mathrm{br}, 1 \mathrm{H}), 3.71(\mathrm{t}, 2 \mathrm{H}, J=4.2), 3.86(\mathrm{t}, 2 \mathrm{H}, J=4.6), 4.05$ (d, 1H, $J=8.3), 4.12(\mathrm{dd}, 1 \mathrm{H}, J=5.4,13.2), 4.13(\mathrm{~d}, 1 \mathrm{H}, J=2.9), 4.17(\mathrm{dd}, 1 \mathrm{H}, J=5.9,13.2), 4.99$ (dd, $1 \mathrm{H}, J=1.2,11.5), 5.02(\mathrm{dd}, 1 \mathrm{H}, J=1.2,17.3), 5.05(\mathrm{~s}, 1 \mathrm{H}), 5.09(\mathrm{~d}, 1 \mathrm{H}, J=8.3), 5.33(\mathrm{tdd}, 1 \mathrm{H}, J=5.8$, $10.3,17.3), 6.33(\mathrm{~d}, 1 \mathrm{H}, J=2.9), 6.64(\mathrm{~d}, 1 \mathrm{H}, J=7.8), 6.65$ (d, $2 \mathrm{H}, J=8.3), 6.89$ (dt, $1 \mathrm{H}, J=1.0,6.8)$, 7.07-7.09 (m, 7H), 7.17-7.25 (m, 7H), 8.5 (s br, 1H). $\left.{ }^{13} \mathrm{C} \mathrm{NMR} \mathrm{(101} \mathrm{MHz,} \mathrm{CD}_{3} \mathrm{CN}\right): \delta 55.4,58.1,60.9$ $61.2,61.9,66.6,70.3,75.0,77.5,110.4,114.8,118.9,122.4,126.46,126.54,127.3,127.6,128.7,129.2$ $129.3,129.79,129.82,130.3,132.3,137.36,137.38,142.6,160.0,169.0,171.9,176.6$. HRMS-ESI $^{+}$ (m/z): $[\mathrm{M}+\mathrm{H}]^{+}$calcd for $\mathrm{C}_{38} \mathrm{H}_{35} \mathrm{~N}_{2} \mathrm{O}_{7}, 631.2444$; found, 631.2446 .

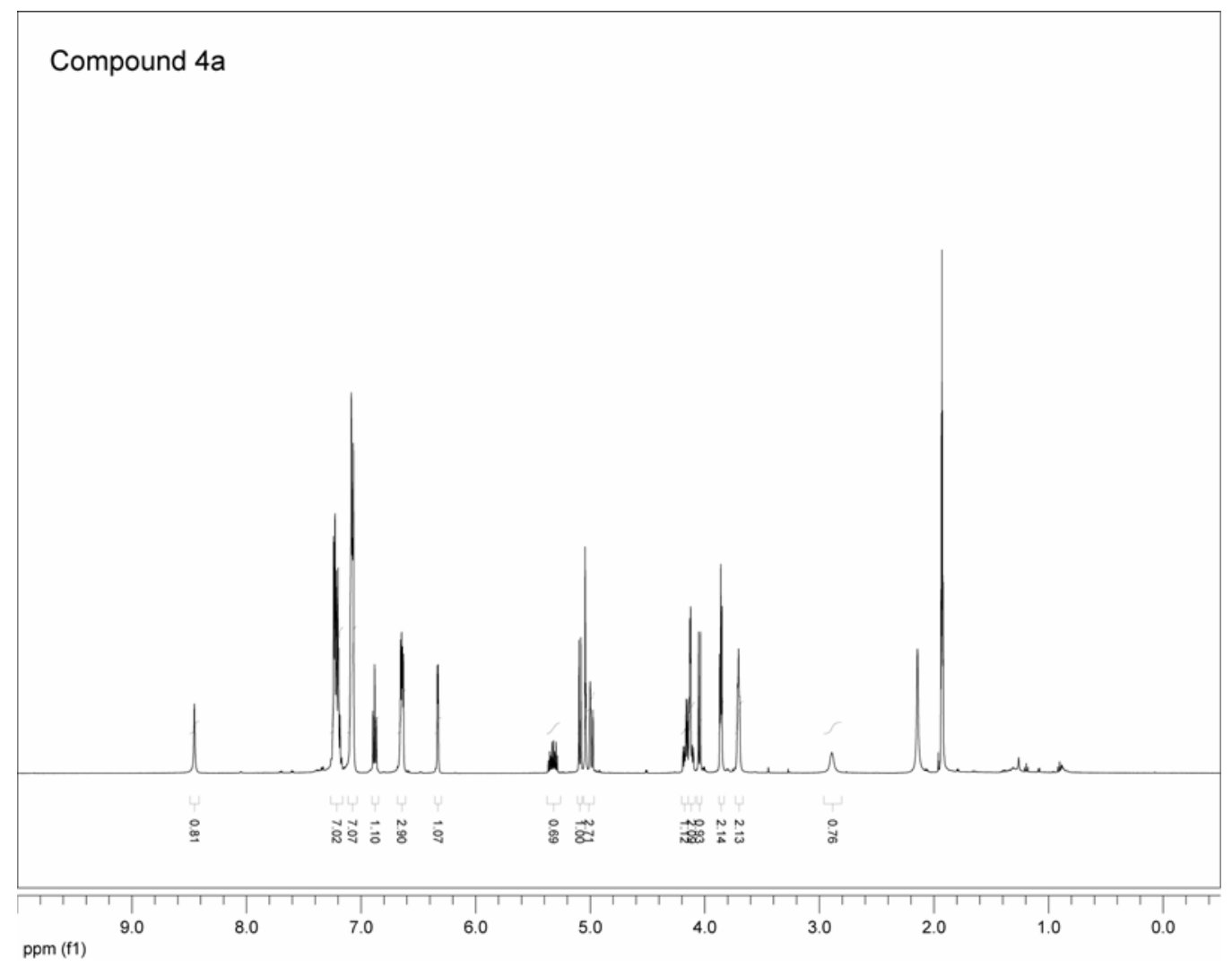




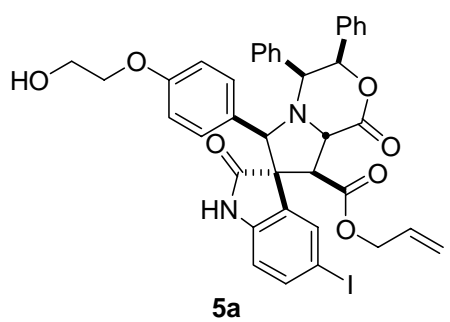

Table 1, entry 2. The reaction was carried out using macrobead-supported 4-(2hydroxyethoxy)benzaldehyde, $(5 S, 6 R)-5,6$-diphenyl-4-morpholin-2-one, and the dipolarophile 3 . NMR analysis showed that the conversion was $89 \%$, and the product was predominantly one major diastereomer. The crude product was purified by flash chromatography (40/60 EtOAc/hexanes $\rightarrow$ 60/40), followed by HPLC (10/90 $i-\mathrm{PrOH} /$ hexanes $\rightarrow$ 30/70).

5a. ${ }^{1} \mathrm{H}$ NMR (500 MHz, $\left.\mathrm{CD}_{3} \mathrm{CN}\right): \delta 2.9(\mathrm{~s} \mathrm{br}, 1 \mathrm{H}), 3.72(\mathrm{t}, 2 \mathrm{H}, J=4.6), 3.88(\mathrm{t}, 2 \mathrm{H}, J=4.6), 4.04$ $(\mathrm{d}, 1 \mathrm{H}, J=8.3), 4.14(\mathrm{~d}, 1 \mathrm{H}, J=3.4), 4.19(\mathrm{dd}, 1 \mathrm{H}, J=5.9,13.2), 4.22(\mathrm{dd}, 1 \mathrm{H}, J=5.9,13.2), 4.99-$ $5.06(\mathrm{~m}, 4 \mathrm{H}), 5.34(\mathrm{tdd}, 1 \mathrm{H}, J=5.9,10.3,17.1), 6.30(\mathrm{~d}, 1 \mathrm{H}, J=3.4), 6.47(\mathrm{~d}, 1 \mathrm{H}, J=8.3), 6.70(\mathrm{~d}, 2 \mathrm{H}$, $J=8.3), 7.04-7.11(\mathrm{~m}, 6 \mathrm{H}), 7.18-7.26(\mathrm{~m}, 6 \mathrm{H}), 7.42(\mathrm{dd}, 1 \mathrm{H}, J=2.0,8.3), 7.45(\mathrm{~d}, 1 \mathrm{H}, J=2.0), 8.5(\mathrm{~s}$ br, $1 \mathrm{H}) .{ }^{13} \mathrm{C} \mathrm{NMR}\left(101 \mathrm{MHz}, \mathrm{CD}_{3} \mathrm{CN}\right): \delta 55.2,57.9,60.6,61.2,61.9,66.8,70.4,74.9,77.6,84.0$, 112.7, 115.0, 119.3, 126.5, 126.8, 128.6, 128.8, 129.2, 129.3, 129.4, 129.8, 130.2, 132.1, 135.9, 137.3,

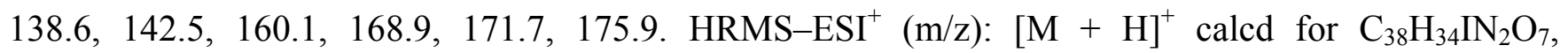
757.1411; found, 757.1415. 

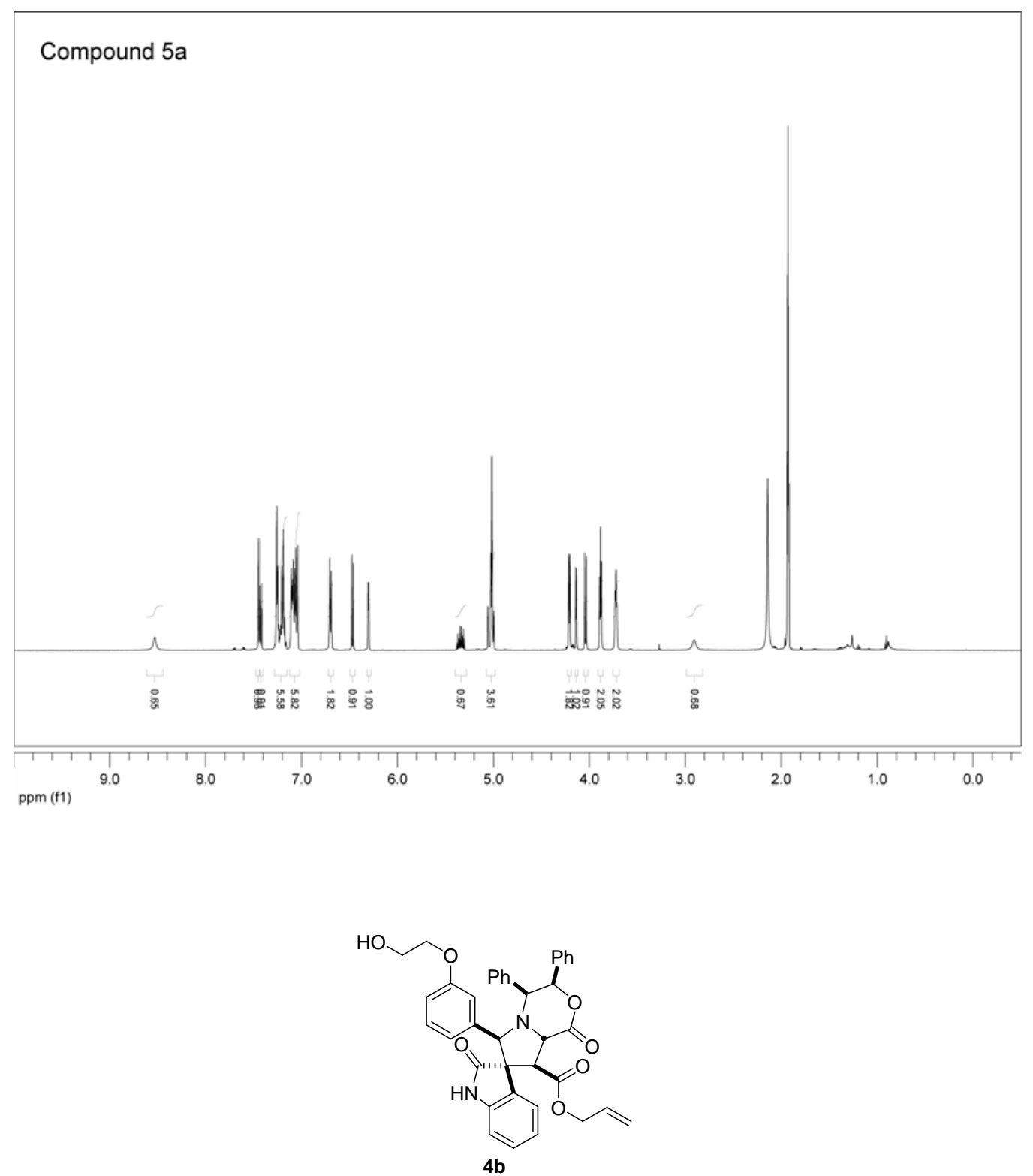

Table 1, entry 3. The reaction was carried out using macrobead-supported 3-(2hydroxyethoxy)benzaldehyde, $(5 S, 6 R)$-5,6-diphenyl-4-morpholin-2-one, and the dipolarophile 2. NMR analysis did not show any residual aldehyde, and the product was predominantly one major diastereomer. The crude product was purified by flash chromatography $(50 / 50 \mathrm{EtOAc} / \mathrm{hexanes} \rightarrow$ 65/35), followed by HPLC (55/45 acetonitrile/water).

4b. ${ }^{1} \mathrm{H}$ NMR (500 MHz, $\left.\mathrm{CD}_{3} \mathrm{CN}\right): \delta 2.9(\mathrm{~s} \mathrm{br}, 1 \mathrm{H}), 3.6-3.7(\mathrm{~m} \mathrm{br}, 4 \mathrm{H}), 4.09(\mathrm{~d}, 1 \mathrm{H}, J=8.8), 4.13$ (tdd, $1 \mathrm{H}, J=1.4,5.7,13.2), 4.15(\mathrm{~d}, 1 \mathrm{H}, J=3.9), 4.18(\mathrm{tdd}, 1 \mathrm{H}, J=1.3,6.0,13.2), 5.00(\mathrm{qd}, 1 \mathrm{H}, J=$ 
1.3, 10.5), $5.04(\mathrm{qd}, 1 \mathrm{H}, J=1.6,17.4), 5.10(\mathrm{~s}, 1 \mathrm{H}), 5.16(\mathrm{~d}, 1 \mathrm{H}, J=8.8), 5.35(\mathrm{tdd}, 1 \mathrm{H}, J=5.8,10.6$, 17.2), $6.34(\mathrm{~d}, 1 \mathrm{H}, J=2.9), 6.63-6.70(\mathrm{~m}, 3 \mathrm{H}), 6.75(\mathrm{~d}, 1 \mathrm{H}, J=6.8), 6.88(\mathrm{dt}, 1 \mathrm{H}, J=1.1,7.7), 7.00-$ $7.11(\mathrm{~m}, 6 \mathrm{H}), 7.19-7.25(\mathrm{~m}, 7 \mathrm{H}), 8.5(\mathrm{~s} \mathrm{br}, 1 \mathrm{H}) .{ }^{13} \mathrm{C} \mathrm{NMR}\left(101 \mathrm{MHz}, \mathrm{CD}_{3} \mathrm{CN}\right): \delta 55.6,58.3,61.1,61.4$, $61.8,66.6,70.3,75.3,77.7,110.5,118.9,122.4,126.3,126.7,127.7,128.66,128.71,129.2,129.3$,

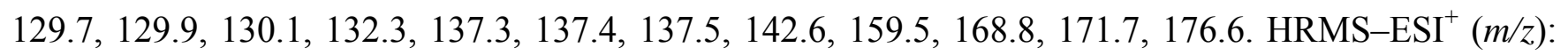
$[\mathrm{M}+\mathrm{H}]^{+}$calcd for $\mathrm{C}_{38} \mathrm{H}_{35} \mathrm{~N}_{2} \mathrm{O}_{7}, 631.2444$; found, 631.2437.
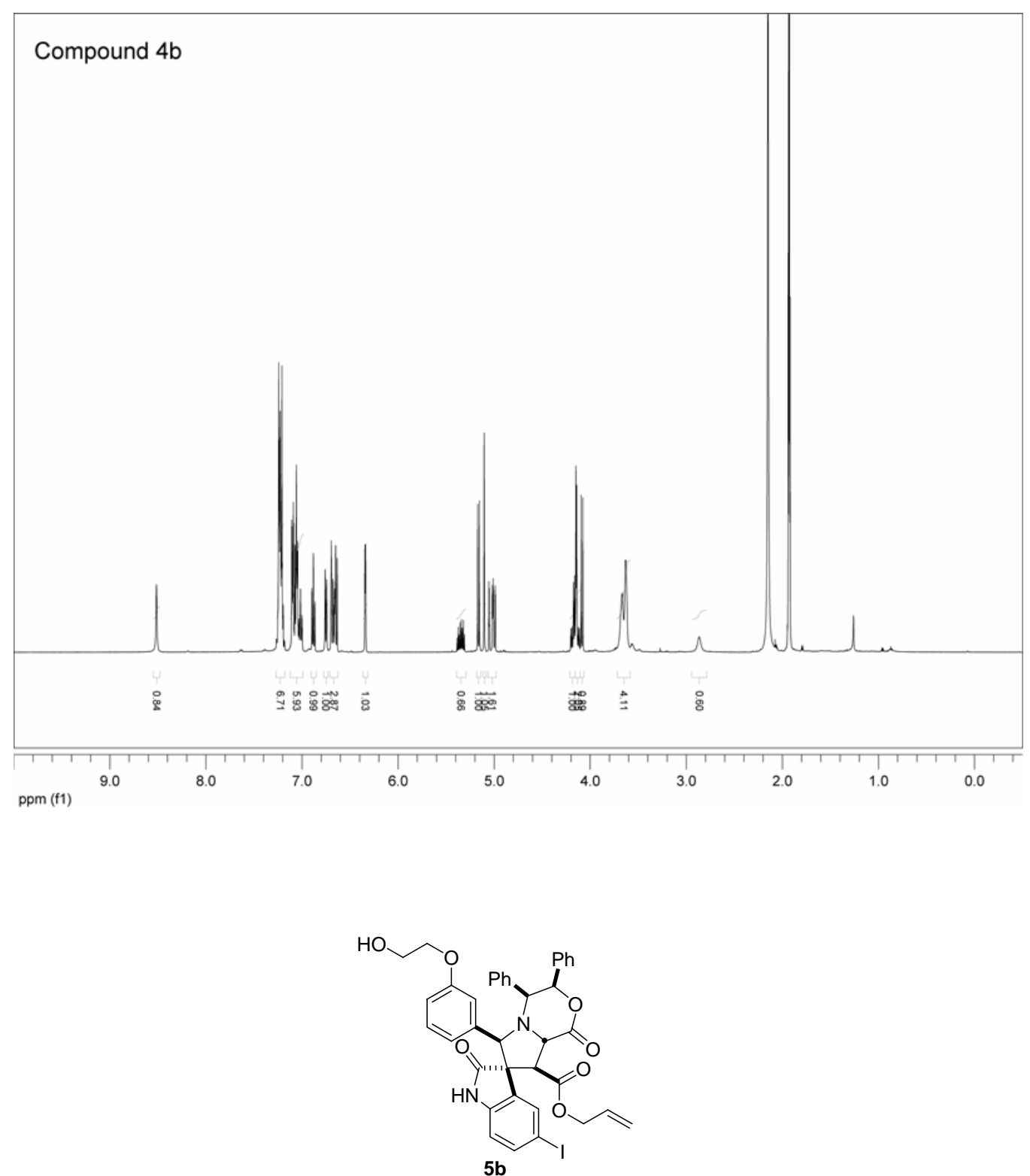
Table 1, entry 4. The reaction was carried out using macrobead-supported 3-(2hydroxyethoxy)benzaldehyde, (5S,6R)-5,6-diphenyl-4-morpholin-2-one, and the dipolarophile 3 . NMR analysis did not show any residual aldehyde, and the product was predominantly one major diastereomer. The crude product was purified by flash chromatography (32/68 EtOAc/hexanes $\rightarrow$ $50 / 50)$.

5b. ${ }^{1} \mathrm{H}$ NMR (500 MHz, $\left.\mathrm{CD}_{3} \mathrm{CN}\right): \delta 2.87(\mathrm{t}, 1 \mathrm{H}, J=5.1), 3.62-3.74(\mathrm{~m} \mathrm{br}, 4 \mathrm{H}), 4.09(\mathrm{~d}, 1 \mathrm{H}, J=$ 8.8), $4.16(\mathrm{~d}, 1 \mathrm{H}, J=3.4), 4.21(\mathrm{dd}, 1 \mathrm{H}, J=5.9,13.2), 4.24(\mathrm{dd}, 1 \mathrm{H}, J=5.9,12.7), 5.01(\mathrm{dd}, 1 \mathrm{H}, J=$ $1.2,10.5), 5.05$ (dd, $1 \mathrm{H}, J=1.5,17.1), 5.08(\mathrm{~s}, 1 \mathrm{H}), 5.09(\mathrm{~d}, 1 \mathrm{H}, J=8.8), 5.36(\mathrm{tdd}, 1 \mathrm{H}, J=5.9,10.5$, 17.2), $6.32(\mathrm{~d}, 1 \mathrm{H}, J=3.4), 6.47(\mathrm{~d}, 1 \mathrm{H}, J=8.3), 6.67(\mathrm{~d}, 1 \mathrm{H}, J=1.5), 6.71(\mathrm{dd}, 1 \mathrm{H}, J=1.7,8.1), 6.74$ (d, 1H, $J=7.8), 7.05-7.10(\mathrm{~m}, 5 \mathrm{H}), 7.19-7.26(\mathrm{~m}, 6 \mathrm{H}), 7.41(\mathrm{dd}, 1 \mathrm{H}, J=1.7,8.1), 7.48(\mathrm{~d}, 1 \mathrm{H}, J=2.0)$, 8.5 (s br, $1 \mathrm{H}) .{ }^{13} \mathrm{C} \mathrm{NMR}\left(101 \mathrm{MHz}, \mathrm{CD}_{3} \mathrm{CN}\right): \delta 55.3,58.1,61.1,61.2,61.8,66.8,70.5,75.2,77.8,84.0$, $112.8,119.3,126.6,128.7,128.8,129.18,129.22,129.3,129.8,130.2,132.1,136.0,136.9,137.2,137.3$,

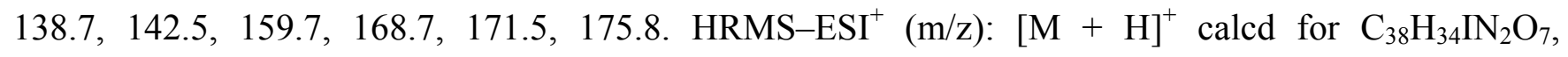
757.1411; found, 757.1413. 

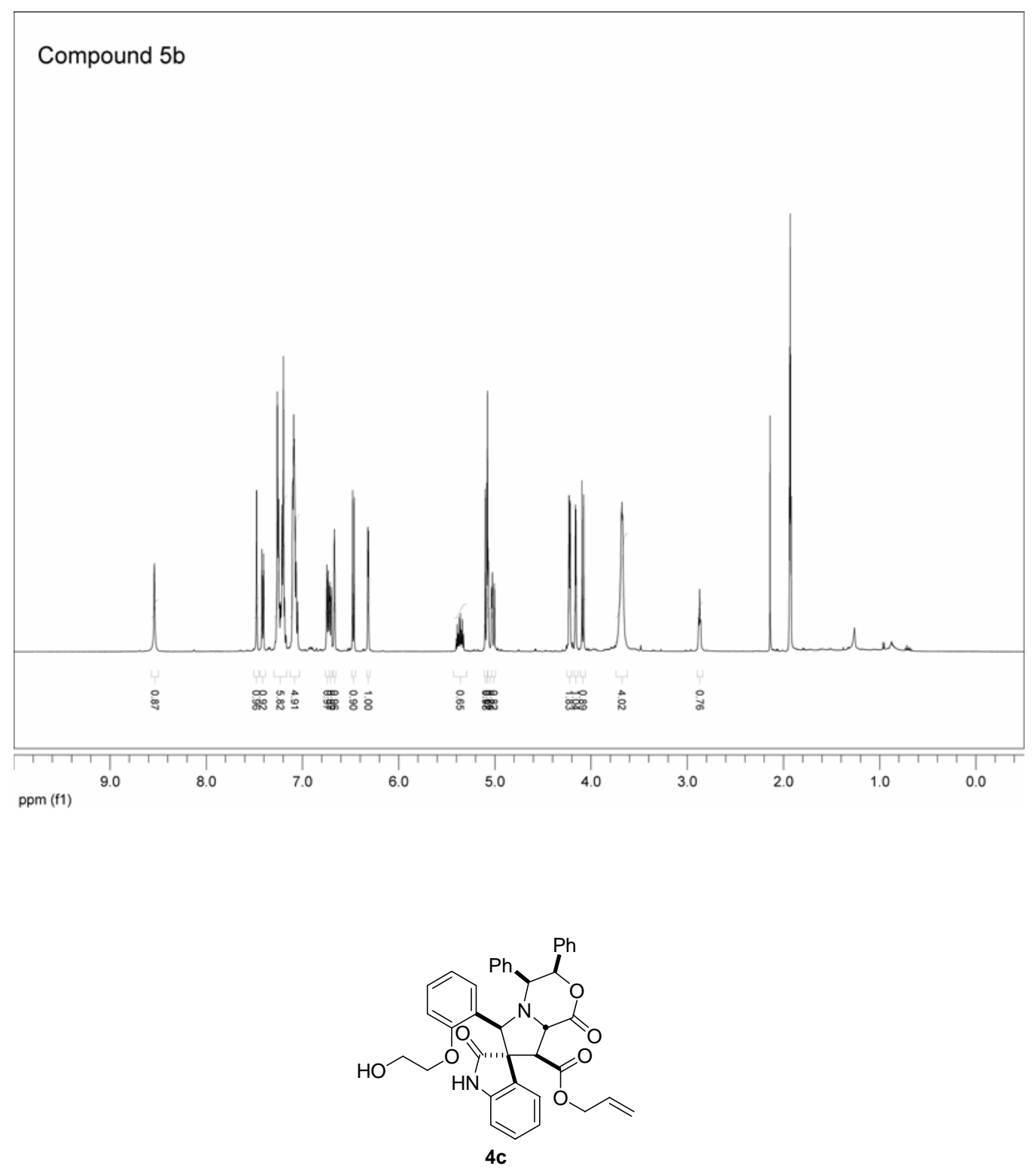

Table 1, entry 5. The reaction was carried out using macrobead-supported 2-(2hydroxyethoxy)benzaldehyde, (5S,6R)-5,6-diphenyl-4-morpholin-2-one, and the dipolarophile 2. NMR analysis showed that the conversion was $>95 \%$, and the product was predominantly one major diastereomer. The crude product was purified by flash chromatography $(40 / 60$ EtOAc/hexanes $\rightarrow$ $60 / 40)$.

4c. ${ }^{1} \mathrm{H}$ NMR (500 MHz, $\left.\mathrm{CD}_{3} \mathrm{CN}\right): \delta 3.75-3.81(\mathrm{~m}, 1 \mathrm{H}), 3.86-3.97(\mathrm{~m}, 3 \mathrm{H}), 4.09(\mathrm{~d}, 1 \mathrm{H}, J=3.4)$, 4.10-4.17 (m, 3H), $4.18(\mathrm{~d}, 1 \mathrm{H}, J=8.8), 4.99(\mathrm{dd}, 1 \mathrm{H}, J=1.5,10.3), 5.03(\mathrm{qd}, 1 \mathrm{H}, J=1.5,17.3), 5.23$ 
(d, 1H, $J=8.8), 5.33(\mathrm{tdd}, 1 \mathrm{H}, J=5.8,10.6,17.2), 5.61(\mathrm{~s}, 1 \mathrm{H}), 6.29(\mathrm{~d}, 1 \mathrm{H}, J=3.4), 6.55(\mathrm{t}, 1 \mathrm{H}, J=$ 7.6), $6.65(\mathrm{~d}, 1 \mathrm{H}, J=7.8), 6.77(\mathrm{~d}, 1 \mathrm{H}, J=8.3), 6.83(\mathrm{dd}, 1 \mathrm{H}, J=1.0,7.8), 7.00-7.08(\mathrm{~m}, 6 \mathrm{H}), 7.18-$ $7.24(\mathrm{~m}, 8 \mathrm{H}), 8.6(\mathrm{~s} \mathrm{br}, 1 \mathrm{H}) .{ }^{13} \mathrm{C} \mathrm{NMR}\left(101 \mathrm{MHz}, \mathrm{CD}_{3} \mathrm{CN}\right): \delta 56.0,59.0,61.2,61.6,62.1,66.5,68.9$, $71.4,78.2,110.5,111.8,118.8,120.6,122.5,124.0,126.8,127.0,127.6,128.6,128.7,129.18,129.22$ $129.67,129.73,130.1,130.3,132.3,137.2,142.5,158.3,168.8,171.7,178.5 . \operatorname{HRMS}_{-}$ESI $^{+}(m / z):[\mathrm{M}+$ $\mathrm{H}]^{+}$calcd for $\mathrm{C}_{38} \mathrm{H}_{35} \mathrm{~N}_{2} \mathrm{O}_{7}, 631.2444$; found, 631.2447 .

Table 1, entry 6. The reaction was carried out using macrobead-supported 2-(2hydroxyethoxy)benzaldehyde, (5S,6R)-5,6-diphenyl-4-morpholin-2-one, and the dipolarophile 3 . NMR analysis showed that the conversion was $>95 \%$, and the product was predominantly one major diastereomer. The crude product was purified by flash chromatography (40/60 EtOAc/hexanes $\rightarrow$ 70/30).

5c. ${ }^{1} \mathrm{H}$ NMR $\left(500 \mathrm{MHz}, \mathrm{CD}_{3} \mathrm{CN}\right): \delta 3.74-3.78(\mathrm{~m}, 1 \mathrm{H}), 3.84-3.93(\mathrm{~m}, 4 \mathrm{H}), 4.14(\mathrm{~d}, 1 \mathrm{H}, J=3.4)$, $4.18(\mathrm{~d}, 1 \mathrm{H}, J=8.8), 4.21(\mathrm{td}, 2 \mathrm{H}, J=1.5,5.9), 5.01(\mathrm{qd}, 1 \mathrm{H}, J=1.3,10.4), 5.05$ (qd, $1 \mathrm{H}, J=1.5,17.2)$, $5.21(\mathrm{~d}, 1 \mathrm{H}, J=8.8), 5.35(\mathrm{tdd}, 1 \mathrm{H}, J=5.9,10.4,17.4), 5.55(\mathrm{~s}, 1 \mathrm{H}), 6.24(\mathrm{~d}, 1 \mathrm{H}, J=3.4), 6.47(\mathrm{dd}, 1 \mathrm{H}$, $J=1.0,7.3), 6.64(\mathrm{t}, 1 \mathrm{H}, J=7.6), 6.76(\mathrm{~d}, 1 \mathrm{H}, J=7.8), 7.00(\mathrm{~m}, 2 \mathrm{H}), 7.05-7.09(\mathrm{~m}, 3 \mathrm{H}), 7.19-7.24(\mathrm{~m}$, 7H), 7.36-7.37 (m, 2H), 8.7 (s br, 1H). ${ }^{13} \mathrm{C}$ NMR (101 MHz, $\left.\mathrm{CD}_{3} \mathrm{CN}\right): \delta 55.9,59.1,61.1,61.5,62.2$, $66.7,69.2,71.4,78.6,84.2,112.0,112.7,119.2,120.6,124.0,126.9,128.7,128.8,129.1,129.2,129.8$ 130.0, 130.2, 132.1, 135.9, 137.07, 137.13, 138.4, 142.4, 158.2, 168.7, 171.4, 177.9. HRMS-ESI ${ }^{+}(\mathrm{m} / \mathrm{z}):$ $[\mathrm{M}+\mathrm{H}]^{+}$calcd for $\mathrm{C}_{38} \mathrm{H}_{34} \mathrm{IN}_{2} \mathrm{O}_{7}, 757.1411$; found, 757.1410. 


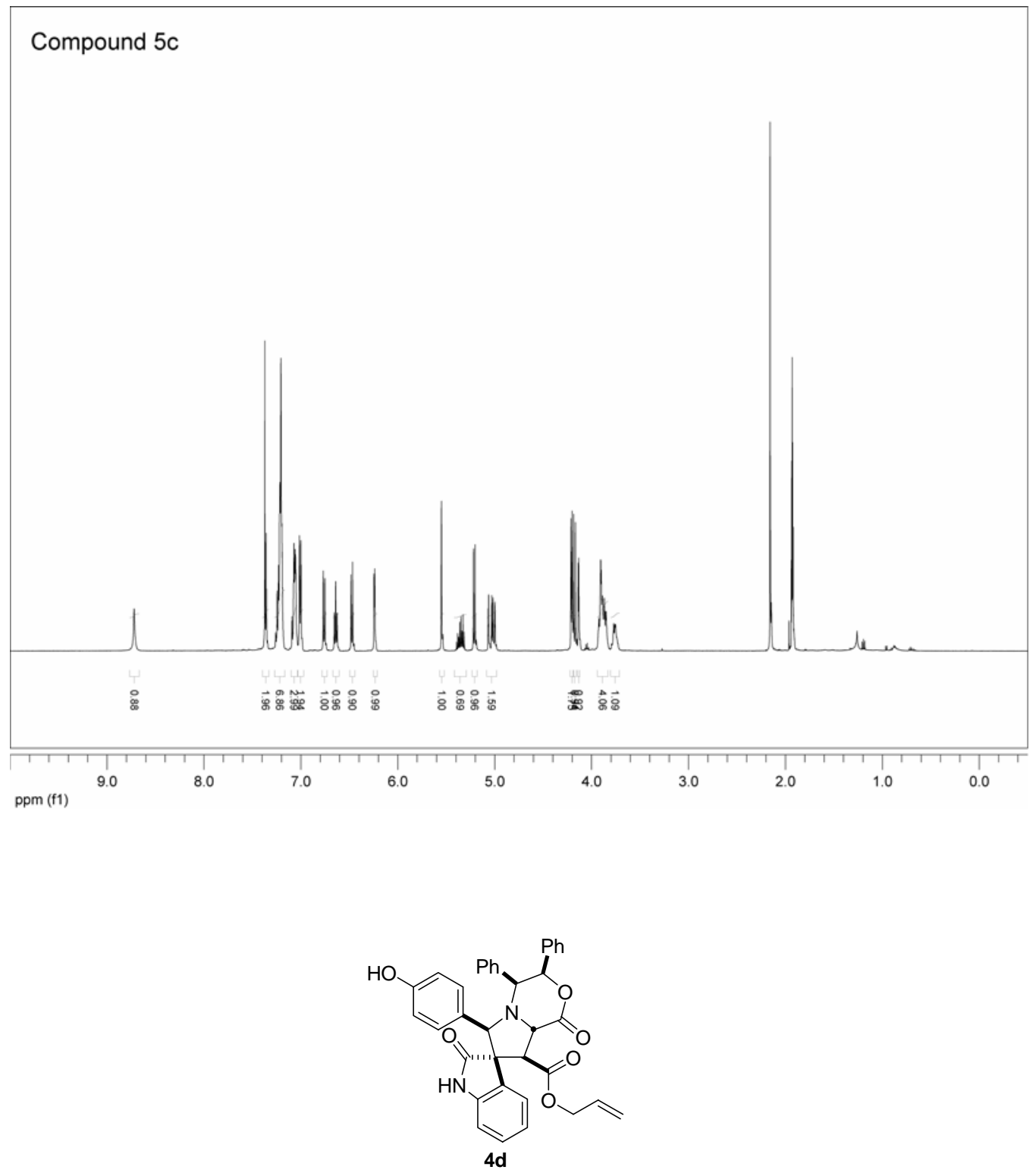

Table 1, entry 7. The reaction was carried out using macrobead-supported 4-hydroxybenzaldehyde, (5S,6R)-5,6-diphenyl-4-morpholin-2-one, and the dipolarophile 2. NMR analysis showed that the conversion was $>95 \%$, and the product was a 91:9 diastereomeric mixture. The crude product was purified by flash chromatography (32/68 EtOAc/hexanes $\rightarrow 50 / 50)$, followed by HPLC (5/95 i$\mathrm{PrOH} /$ hexanes $\rightarrow$ 25/75).

4d. ${ }^{1} \mathrm{H}$ NMR (500 MHz, $\mathrm{CD}_{3} \mathrm{CN}$ ): $\delta 4.03$ (d, $1 \mathrm{H}, J=8.3$ ), 4.12 (tdd, $\left.1 \mathrm{H}, J=1.5,5.4,13.2\right), 4.14$ (d, $1 \mathrm{H}, J=3.4), 4.17(\mathrm{tdd}, 1 \mathrm{H}, J=1.3,6.1,13.2), 4.97-5.04(\mathrm{~m}, 3 \mathrm{H}), 5.07$ (d, $1 \mathrm{H}, J=8.3), 5.32$ (tdd, $1 \mathrm{H}, J$ 
$=5.8,10.4,17.3), 6.32(\mathrm{~d}, 1 \mathrm{H}, J=3.4), 6.52(\mathrm{~d}, 2 \mathrm{H}, J=8.3), 6.65(\mathrm{~d}, 1 \mathrm{H}, J=7.8), 6.88(\mathrm{dt}, 1 \mathrm{H}, J=1.0$ 7.6), $6.99(\mathrm{~d}, 2 \mathrm{H}, J=8.3), 7.06-7.11(\mathrm{~m}, 5 \mathrm{H}), 7.16-7.24(\mathrm{~m}, 7 \mathrm{H}), 8.4(\mathrm{~s} \mathrm{br}, 1 \mathrm{H}) .{ }^{13} \mathrm{C} \mathrm{NMR}(101 \mathrm{MHz}$, $\left.\mathrm{CD}_{3} \mathrm{CN}\right): \delta 55.3,58.1,60.7,61.9,66.6,75.1,77.4,110.4,115.6,118.9,122.3,126.3,126.51,126.54$ 127.6, 128.6, 129.2, 129.3, 129.77, 129.80, 130.4, 132.3, 137.4, 142.6, 158.0, 169.0, 172.0, 176.7 . HRMS-ESI ${ }^{+}(m / z):[M+H]^{+}$calcd for $\mathrm{C}_{36} \mathrm{H}_{31} \mathrm{~N}_{2} \mathrm{O}_{6}, 587.2182$; found, 587.2175.
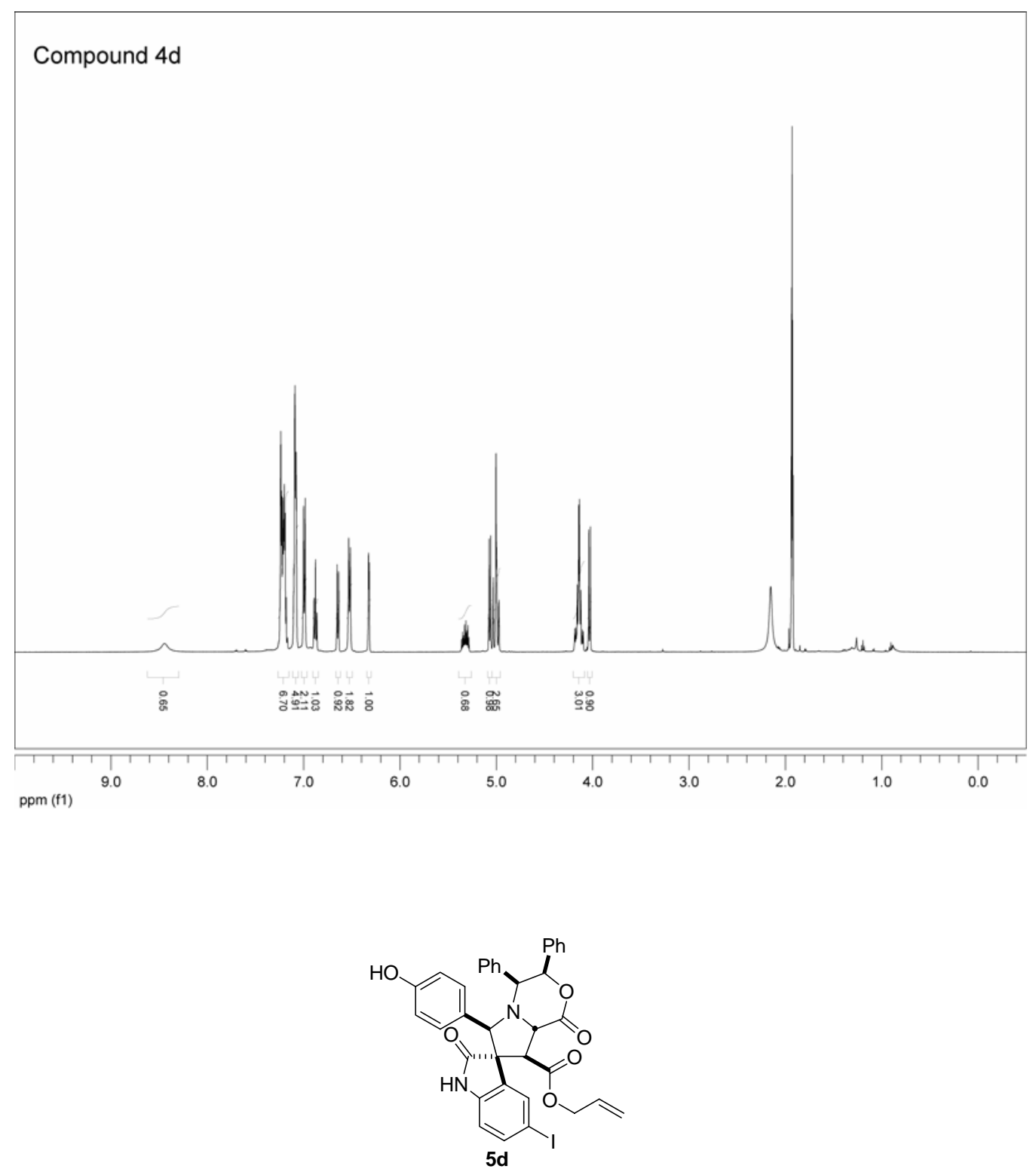

Table 1, entry 8. The reaction was carried out using macrobead-supported 4-hydroxybenzaldehyde, (5S,6R)-5,6-diphenyl-4-morpholin-2-one, and the dipolarophile 3. NMR analysis did not show any 
residual aldehyde, and the product was a 92:8 diastereomeric mixture. The crude product was purified by flash chromatography (50/50 EtOAc/hexanes $\rightarrow$ 60/40), followed by HPLC (5/95 i-PrOH/hexanes $\rightarrow$ 25/75).

5d. ${ }^{1} \mathrm{H}$ NMR (500 MHz, $\left.\mathrm{CD}_{3} \mathrm{CN}\right): \delta 4.02(\mathrm{~d}, 1 \mathrm{H}, J=8.3), 4.15(\mathrm{~d}, 1 \mathrm{H}, J=3.4), 4.19(\mathrm{dd}, 1 \mathrm{H}, J=$ 6.3, 13.2), $4.22(\mathrm{dd}, 1 \mathrm{H}, J=5.9,13.2), 4.96-5.06(\mathrm{~m}, 4 \mathrm{H}), 5.34(\mathrm{tdd}, 1 \mathrm{H}, J=5.9,10.3,17.1), 6.29(\mathrm{~d}$, $1 \mathrm{H}, J=3.4), 6.47(\mathrm{~d}, 1 \mathrm{H}, J=8.8), 6.57(\mathrm{~d}, 2 \mathrm{H}, J=8.3), 6.97(\mathrm{~d}, 2 \mathrm{H}, J=8.8), 7.07-7.12(\mathrm{~m}, 4 \mathrm{H}), 7.16-$ $7.27(\mathrm{~m}, 6 \mathrm{H}), 7.43(\mathrm{~d}, 1 \mathrm{H}, J=1.5), 7.43(\mathrm{dd}, 1 \mathrm{H}, J=1.7,8.5), 8.5(\mathrm{~s} \mathrm{br}, 1 \mathrm{H}) .{ }^{13} \mathrm{C}$ NMR $(101 \mathrm{MHz}$ $\left.\mathrm{CD}_{3} \mathrm{CN}\right): \delta 55.1,57.8,60.5,61.9,66.7,75.0,77.5,84.0,112.6,115.8,119.3,125.7,126.5,128.6,128.7$, $129.2,129.38,129.40,129.8,130.3,132.1,135.9,137.3,138.6,142.5,158.1,168.9,171.8,176.0$. HRMS-ESI ${ }^{+}(\mathrm{m} / \mathrm{z}):[\mathrm{M}+\mathrm{H}]^{+}$calcd for $\mathrm{C}_{36} \mathrm{H}_{30} \mathrm{IN}_{2} \mathrm{O}_{6}, 713.1149$; found, 713.1151 .

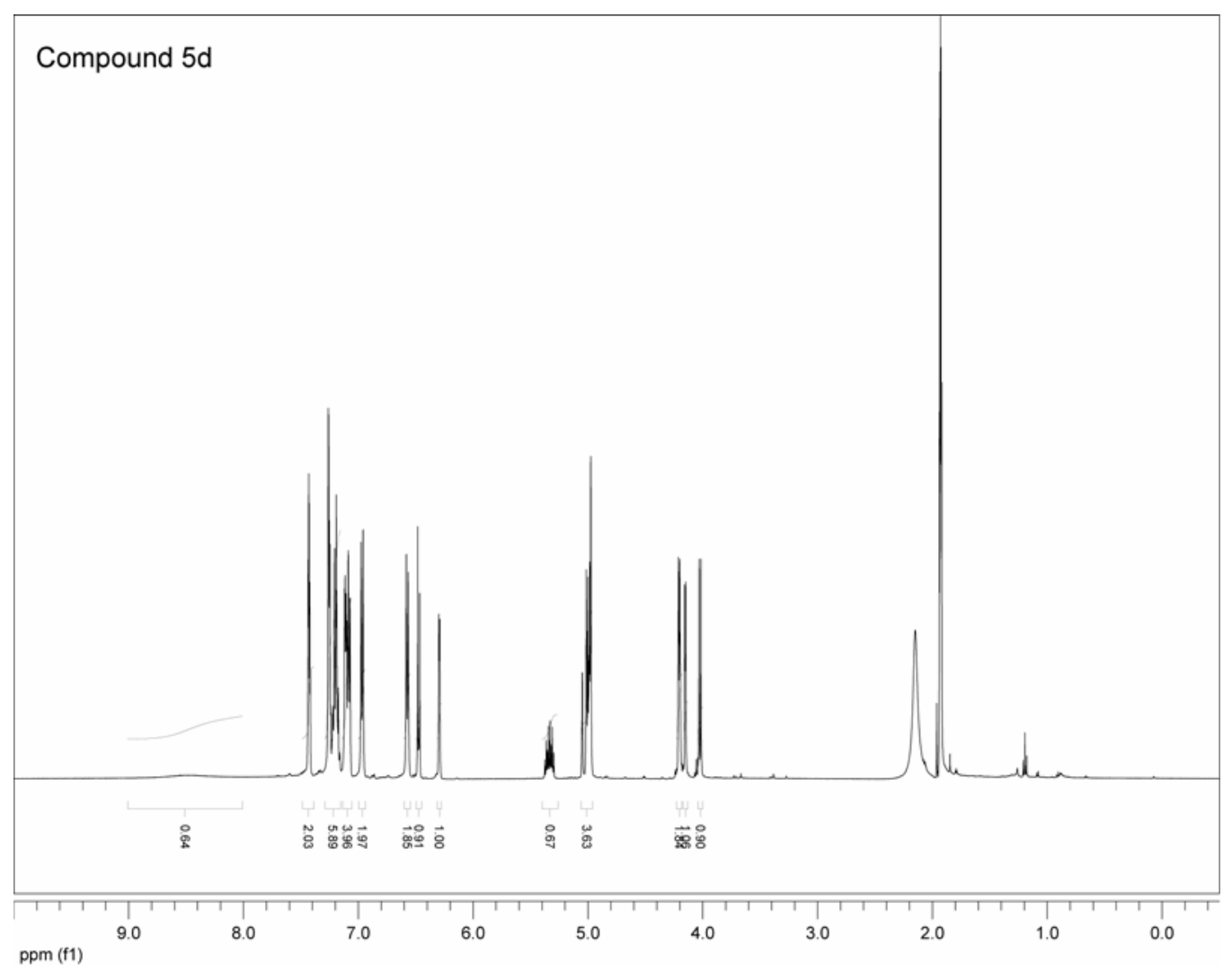




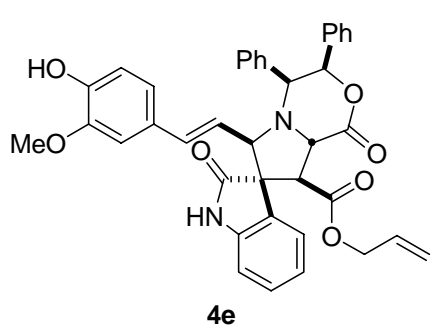

Table 1, entry 9. The reaction was carried out using macrobead-supported 4-hydroxy-3methoxycinnamaldehyde, $(5 S, 6 R)$-5,6-diphenyl-4-morpholin-2-one, and the dipolarophile 2 . NMR analysis did not show any residual aldehyde, and the product was a 77:23 diastereomeric mixture. The crude product was purified by flash chromatography (35/65 EtOAc/hexanes $\rightarrow 50 / 50)$, followed by HPLC (4/96 i-PrOH/hexanes $\rightarrow$ 10/90).

4e. ${ }^{1} \mathrm{H}$ NMR (500 MHz, $\left.\mathrm{CD}_{3} \mathrm{CN}\right): \delta 3.68(\mathrm{~s}, 3 \mathrm{H}), 4.01(\mathrm{~d}, 1 \mathrm{H}, J=7.3), 4.12(\mathrm{tdd}, 1 \mathrm{H}, J=1.5,5.4$, 13.2), 4.17 (tdd, $1 \mathrm{H}, J=1.3,5.9,13.2), 4.19$ (d, $1 \mathrm{H}, J=8.3), 4.52$ (d, $1 \mathrm{H}, J=3.9), 4.88$ (d, 1H, $J=7.3$ ), $4.99(\mathrm{dd}, 1 \mathrm{H}, J=1.2,10.5), 5.01$ (dd, $1 \mathrm{H}, J=1.5,17.1), 5.21(\mathrm{dd}, 1 \mathrm{H}, J=8.8,17.3), 5.32$ (tdd, $1 \mathrm{H}, J=$ 5.9, 10.7, 17.1), $6.14(\mathrm{~d}, 1 \mathrm{H}, J=3.9), 6.42-6.45(\mathrm{~m}, 3 \mathrm{H}), 6.5(\mathrm{~s} b r, 1 \mathrm{H}), 6.59(\mathrm{~d}, 1 \mathrm{H}, J=8.8), 6.83(\mathrm{~d}$, $1 \mathrm{H}, J=7.8), 7.05(\mathrm{dt}, 1 \mathrm{H}, J=1.0,7.6), 7.14-7.34(\mathrm{~m}, 12 \mathrm{H}), 8.54(\mathrm{~s}, 1 \mathrm{H}) .{ }^{13} \mathrm{C}$ NMR $(101 \mathrm{MHz}$, $\left.\mathrm{CD}_{3} \mathrm{CN}\right): \delta 54.4,56.6,59.0,61.0,62.7,66.6,76.3,80.3,110.4,110.7,115.5,118.8,120.8,123.0,123.3$ 126.6, 127.2, 127.9, 128.5, 129.1, 129.4, 130.0, 132.3, 135.8, 136.9, 138.1, 142.9, 147.4, 148.0, 169.3,

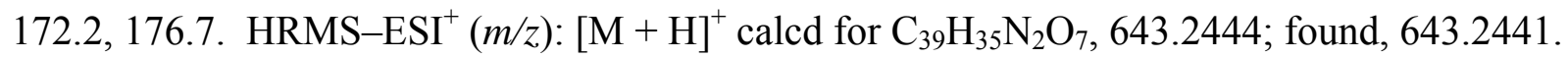



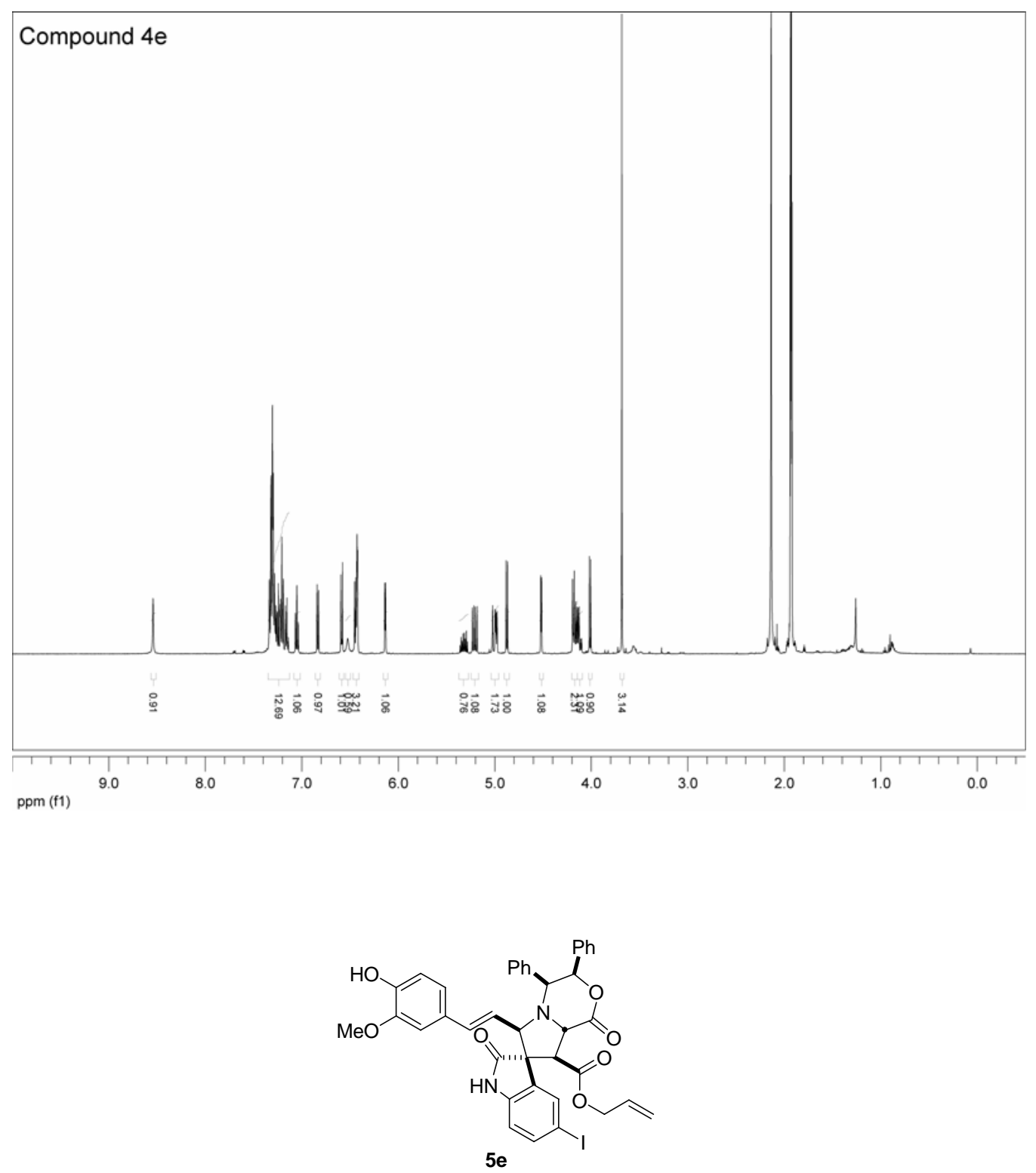

Table 1, entry 10. The reaction was carried out using macrobead-supported 4-hydroxy-3methoxycinnamaldehyde, $(5 S, 6 R)$-5,6-diphenyl-4-morpholin-2-one, and the dipolarophile 3. NMR analysis did not show any residual aldehyde, and the product was a 72:28 diastereomeric mixture. The crude product was purified by flash chromatography (50/50 EtOAc/hexanes $\rightarrow 60 / 40)$, followed by HPLC (4/96 i-PrOH/hexanes $\rightarrow$ 10/90).

5e. ${ }^{1} \mathrm{H}$ NMR (500 MHz, $\left.\mathrm{CD}_{3} \mathrm{CN}\right): \delta 3.73(\mathrm{~s}, 3 \mathrm{H}), 3.98(\mathrm{~d}, 1 \mathrm{H}, J=7.3), 4.18-4.24(\mathrm{~m}, 3 \mathrm{H}), 4.53(\mathrm{~d}$, $1 \mathrm{H}, J=3.9), 4.75(\mathrm{~d}, 1 \mathrm{H}, J=7.3), 5.01(\mathrm{qd}, 1 \mathrm{H}, J=1.2,10.3), 5.03(\mathrm{qd}, 1 \mathrm{H}, J=1.5,17.1), 5.27(\mathrm{dd}$, 
$1 \mathrm{H}, J=8.8,16.1), 5.34(\mathrm{tdd}, 1 \mathrm{H}, J=5.9,10.3,17.1), 6.17(\mathrm{~d}, 1 \mathrm{H}, J=3.9), 6.50(\mathrm{~d}, 1 \mathrm{H}, J=16.1), 6.52-$ $6.54(\mathrm{~m}, 2 \mathrm{H}), 6.6(\mathrm{~s} \mathrm{br}, 1 \mathrm{H}), 6.63(\mathrm{~d}, 1 \mathrm{H}, J=8.8), 6.67(\mathrm{~d}, 1 \mathrm{H}, J=8.3), 7.18-7.32(\mathrm{~m}, 10 \mathrm{H}), 7.55(\mathrm{~d}$, $1 \mathrm{H}, J=1.5), 7.58(\mathrm{dd}, 1 \mathrm{H}, J=1.7,8.1), 8.62(\mathrm{~s}, 1 \mathrm{H}) .{ }^{13} \mathrm{C} \mathrm{NMR}\left(101 \mathrm{MHz}, \mathrm{CD}_{3} \mathrm{CN}\right): \delta 54.3,56.6,58.4$, $61.0,61.8,66.8,75.6,79.7,84.7,110.6,112.9,115.5,119.2,121.1,122.3,127.5,128.6,129.0,129.18$ $129.22,129.3,130.0,130.1,132.1,135.1,136.6,137.0,137.9,138.7,142.8,147.5,148.1,169.1,171.9$ 176.0. HRMS-ESI ${ }^{+}(\mathrm{m} / \mathrm{z}):[\mathrm{M}+\mathrm{H}]^{+}$calcd for $\mathrm{C}_{39} \mathrm{H}_{34} \mathrm{IN}_{2} \mathrm{O}_{7}, 769.1411$; found, 769.1417.
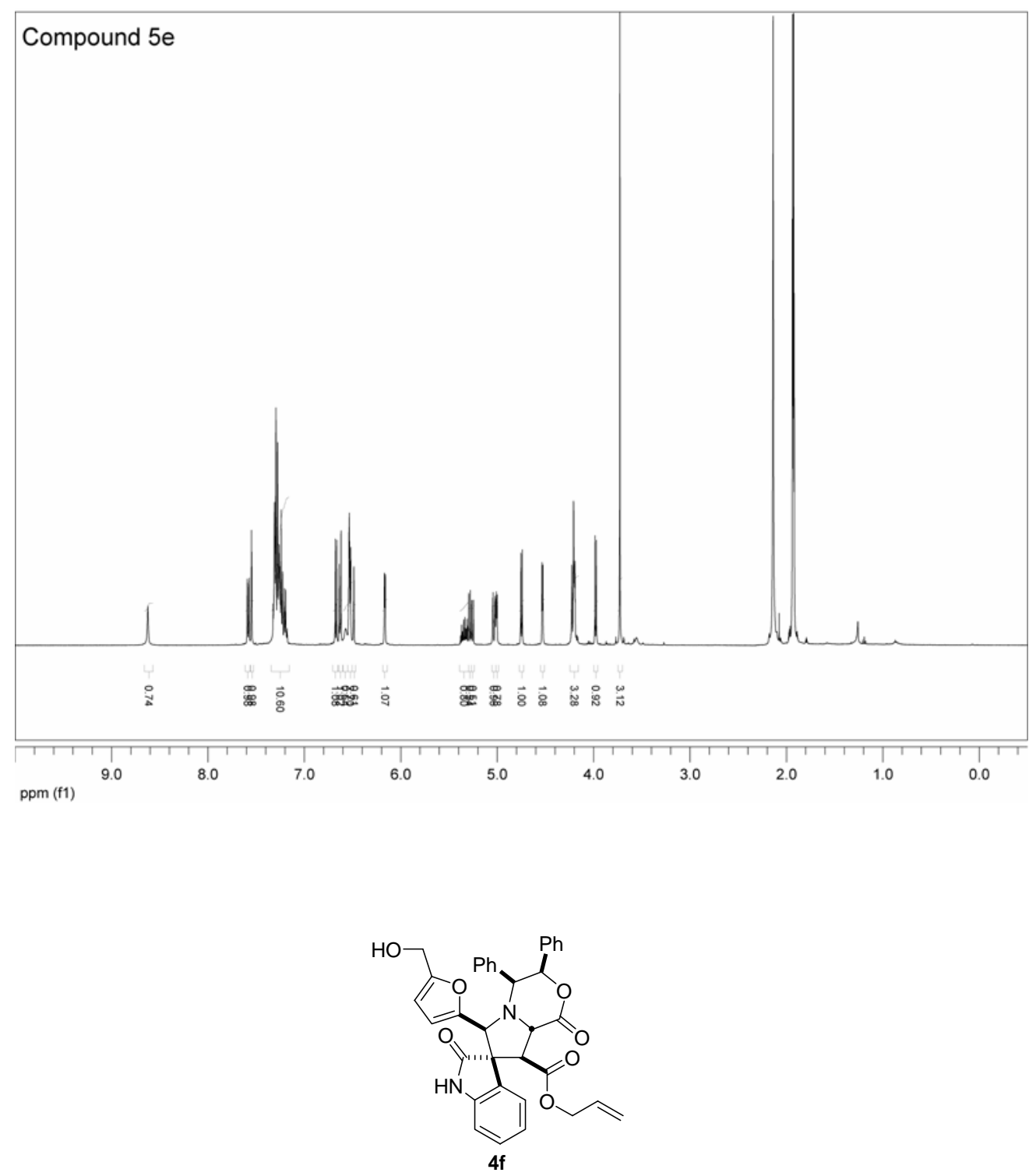
Table 1, entry 11. The reaction was carried out using macrobead-supported 5(hydroxymethyl)furfural, (5S,6R)-5,6-diphenyl-4-morpholin-2-one, and the dipolarophile 2. NMR analysis showed that the conversion was $>95 \%$, and the product was a $82: 18$ diastereomeric mixture. The crude product was purified by flash chromatography ( $45 / 55 \mathrm{EtOAc} /$ hexanes $\rightarrow 65 / 35$ ) followed by $\operatorname{HPLC}\left(50 / 50 \mathrm{H}_{2} \mathrm{O} / \mathrm{MeCN}\right)$.

4f. ${ }^{1} \mathrm{H}$ NMR (500 MHz, $\left.\mathrm{CD}_{3} \mathrm{CN}\right): \delta 3.01(\mathrm{~s} b r, 1 \mathrm{H}), 4.04(\mathrm{~d}, 1 \mathrm{H}, J=8.3), 4.13(\operatorname{tdd}, 1 \mathrm{H}, J=1.3,5.5$, 13.2), 4.16-4.21 (m, 3H), $4.36(\mathrm{~d}, 1 \mathrm{H}, J=3.4), 4.96(\mathrm{~d}, 1 \mathrm{H}, J=8.3), 4.99-5.06(\mathrm{~m}, 3 \mathrm{H}), 5.36$ (tdd, $1 \mathrm{H}, J$ $=5.8,10.3,17.2), 5.69(\mathrm{~d}, 1 \mathrm{H}, J=2.9), 5.88(\mathrm{~d}, 1 \mathrm{H}, J=2.9), 6.27(\mathrm{~d}, 1 \mathrm{H}, J=3.4), 6.78(\mathrm{~d}, 1 \mathrm{H}, J=7.8)$, $6.94(\mathrm{dt}, 1 \mathrm{H}, J=1.0,7.6), 7.09-7.13(\mathrm{~m}, 2 \mathrm{H}), 7.15-7.20(\mathrm{~m}, 4 \mathrm{H}), 7.21-7.30(\mathrm{~m}, 6 \mathrm{H}), 8.7(\mathrm{~s} \mathrm{br}, 1 \mathrm{H}) .{ }^{13} \mathrm{C}$ NMR (101 MHz, $\left.\mathrm{CD}_{3} \mathrm{CN}\right): \delta 55.1,56.9,58.3,60.1,62.1,66.6,69.9,78.9,108.4,110.6,110.8,118.9$, 122.6, 126.9, 127.1, 127.4, 128.5, 128.9, 129.1, 129.3, 129.8, 130.1, 132.3, 137.1, 137.2, 142.8, 149.8, 156.1, 168.8, 171.5, 176.3. HRMS-ESI ${ }^{+}(\mathrm{m} / \mathrm{z}):[\mathrm{M}+\mathrm{H}]^{+}$calcd for $\mathrm{C}_{35} \mathrm{H}_{31} \mathrm{~N}_{2} \mathrm{O}_{7}, 591.2131$; found, 591.2125 . 

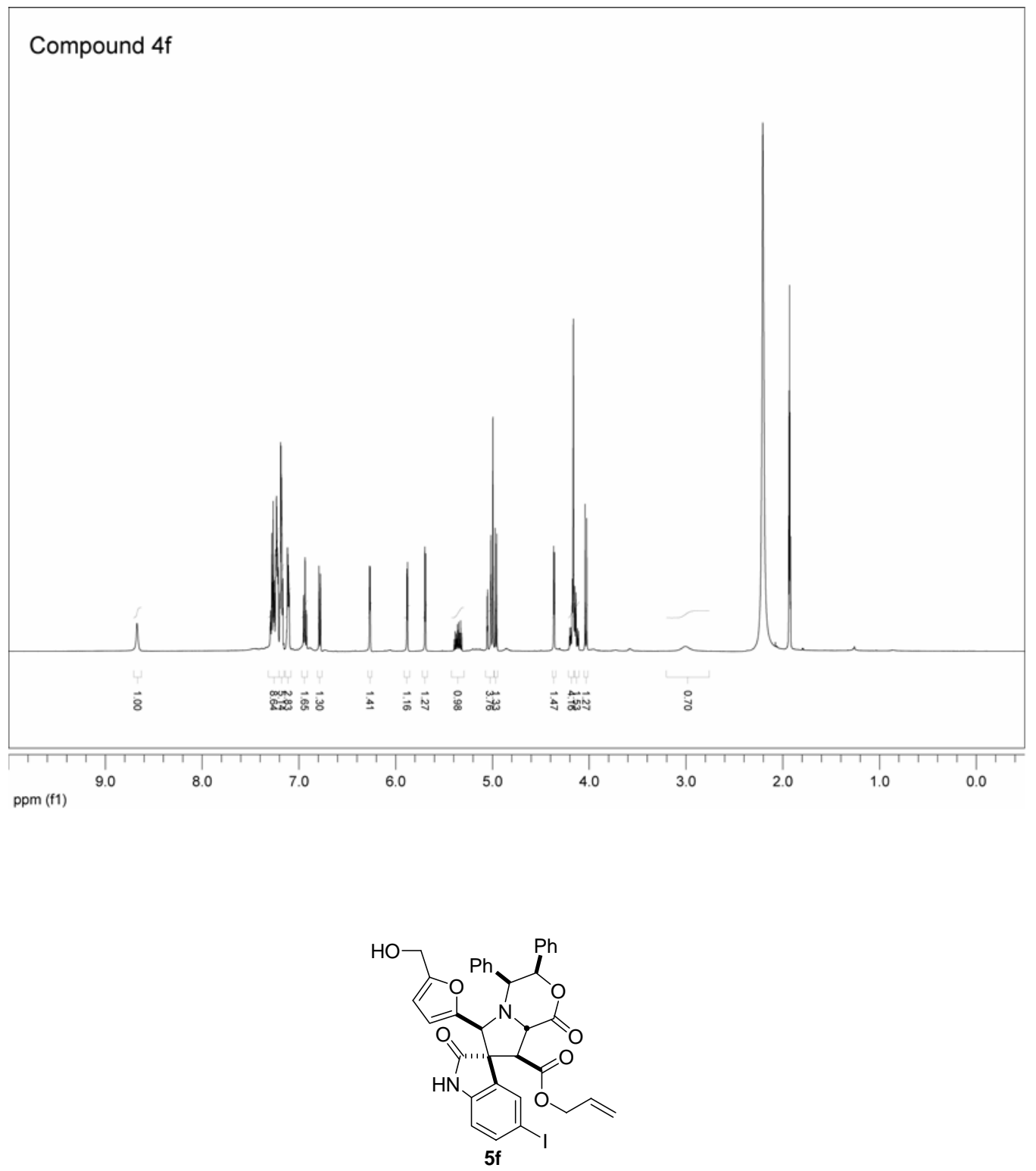

Table 1, entry 12. The reaction was carried out using 5-(hydroxymethyl)furfural, (5S,6R)-5,6diphenyl-4-morpholin-2-one, and the dipolarophile 3. NMR analysis showed that the conversion was $>95 \%$, and the product was a $85: 15$ diastereomeric mixture. The crude product was purified by flash chromatography (40/60 EtOAc/hexanes $\rightarrow$ 60/40).

5f. ${ }^{1} \mathrm{H}$ NMR $\left(500 \mathrm{MHz}, \mathrm{CD}_{3} \mathrm{CN}\right): \delta 2.96(\mathrm{t}, 1 \mathrm{H}, J=6.1), 4.02(\mathrm{~d}, 1 \mathrm{H}, J=7.8), 4.18-4.23(\mathrm{~m}, 4 \mathrm{H})$, $4.38(\mathrm{~d}, 1 \mathrm{H}, J=3.4), 4.86(\mathrm{~d}, 1 \mathrm{H}, J=8.3), 4.99(\mathrm{~s}, 1 \mathrm{H}), 5.02(\mathrm{qd}, 1 \mathrm{H}, J=1.3,10.3), 5.05(\mathrm{qd}, 1 \mathrm{H}, J=$ $1.5,17.1), 5.37$ (tdd $1 \mathrm{H}, J=5.9,10.3,17.1), 5.82(\mathrm{~d}, 1 \mathrm{H}, J=3.4), 5.95(\mathrm{~d}, 1 \mathrm{H}, J=3.4), 6.25(\mathrm{~d}, 1 \mathrm{H}, J=$ 
3.4), $6.61(\mathrm{~d}, 1 \mathrm{H}, J=8.3), 7.14-7.19(\mathrm{~m}, 2 \mathrm{H}), 7.21-7.30(\mathrm{~m}, 8 \mathrm{H}), 7.48(\mathrm{~d}, 1 \mathrm{H}, J=1.5), 7.51(\mathrm{dd}, 1 \mathrm{H}, J$ $=1.7,8.1), 8.6(\mathrm{~s} \mathrm{br}, 1 \mathrm{H}) .{ }^{13} \mathrm{C} \mathrm{NMR}\left(101 \mathrm{MHz}, \mathrm{CD}_{3} \mathrm{CN}\right): \delta 54.9,57.0,58.0,60.2,61.4,66.8,69.5,78.8$, $84.1,108.4,111.2,112.8,119.3,126.9,128.6,128.9,129.2,129.3,129.6,129.9,132.1,135.9,137.0$ 137.1, 138.8, 142.6, 149.2, 156.5, 168.7, 171.3, 175.6. HRMS-ESI $^{+}(\mathrm{m} / \mathrm{z}):[\mathrm{M}+\mathrm{H}]^{+}$calcd for $\mathrm{C}_{35} \mathrm{H}_{30} \mathrm{IN}_{2} \mathrm{O}_{7}, 717.1098$; found, 717.1097 .






\section{Reaction Survey and Building Block Selection}

\section{A. Sonogashira Coupling}

Alkyne Building Blocks. All alkyne building blocks that are commercially available were used as received. The preparation of the other alkyne building blocks screened is described as follows. The yields reported are unoptimized.
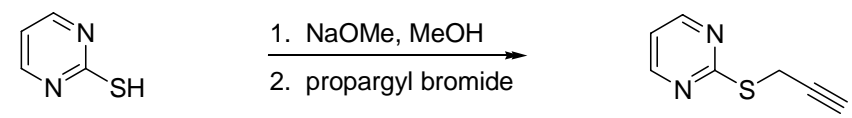

2-(propargylthio)pyrimidine. To a 100-mL round-bottom flask was added a suspension of 2mercaptopyrimidine $(1.12 \mathrm{~g}, 10.0 \mathrm{mmol})$ in $50 \mathrm{~mL} \mathrm{MeOH}$. A $0.5 \mathrm{M}$ solution of $\mathrm{NaOMe}(22.0 \mathrm{~mL}, 11.0$ mmol) was added to the reaction mixture, and the suspended solid dissolved to form a yellow solution. Propargyl bromide $(1.60 \mathrm{~mL}, 10.8 \mathrm{mmol})$ was added, and the reaction mixture turned brown. After 18 hours, the reaction mixture was poured into $\mathrm{Et}_{2} \mathrm{O}(100 \mathrm{~mL})$, and $1.0 \mathrm{M} \mathrm{HCl}(50 \mathrm{~mL})$ was added. The aqueous layer was removed, basified with $\mathrm{KOH}$, and extracted with $\mathrm{Et}_{2} \mathrm{O}(3 \times 100 \mathrm{~mL})$. The combined organic extracts were dried $\left(\mathrm{K}_{2} \mathrm{CO}_{3}\right)$ and concentrated in vacuo to afford a yellow solid. The crude product was purified by flash chromatography (10/90 EtOAc/hexanes $\rightarrow 15 / 85)$ to afford a white solid (232.2 mg, 15\% yield).

${ }^{1} \mathrm{H}$ NMR (500 MHz, $\left.\mathrm{CDCl}_{3}\right): \delta 2.20(\mathrm{t}, 1 \mathrm{H}, J=2.7), 3.94(\mathrm{~d}, 2 \mathrm{H}, J=2.9), 7.02(\mathrm{t}, 1 \mathrm{H}, J=4.9), 8.57$ $(\mathrm{d}, 2 \mathrm{H}, J=4.9) .{ }^{13} \mathrm{C}$ NMR $\left(100 \mathrm{MHz}, \mathrm{CDCl}_{3}\right): \delta 19.2,70.5,79.5,116.8,157.3,170.6 . \mathrm{HRMS}_{-} \mathrm{CI}^{+}$ $(\mathrm{m} / \mathrm{z}):[\mathrm{M}+\mathrm{H}]^{+}$calcd for $\mathrm{C}_{7} \mathrm{H}_{7} \mathrm{~N}_{2} \mathrm{~S}, 151.0330$; found, 151.0330 . 


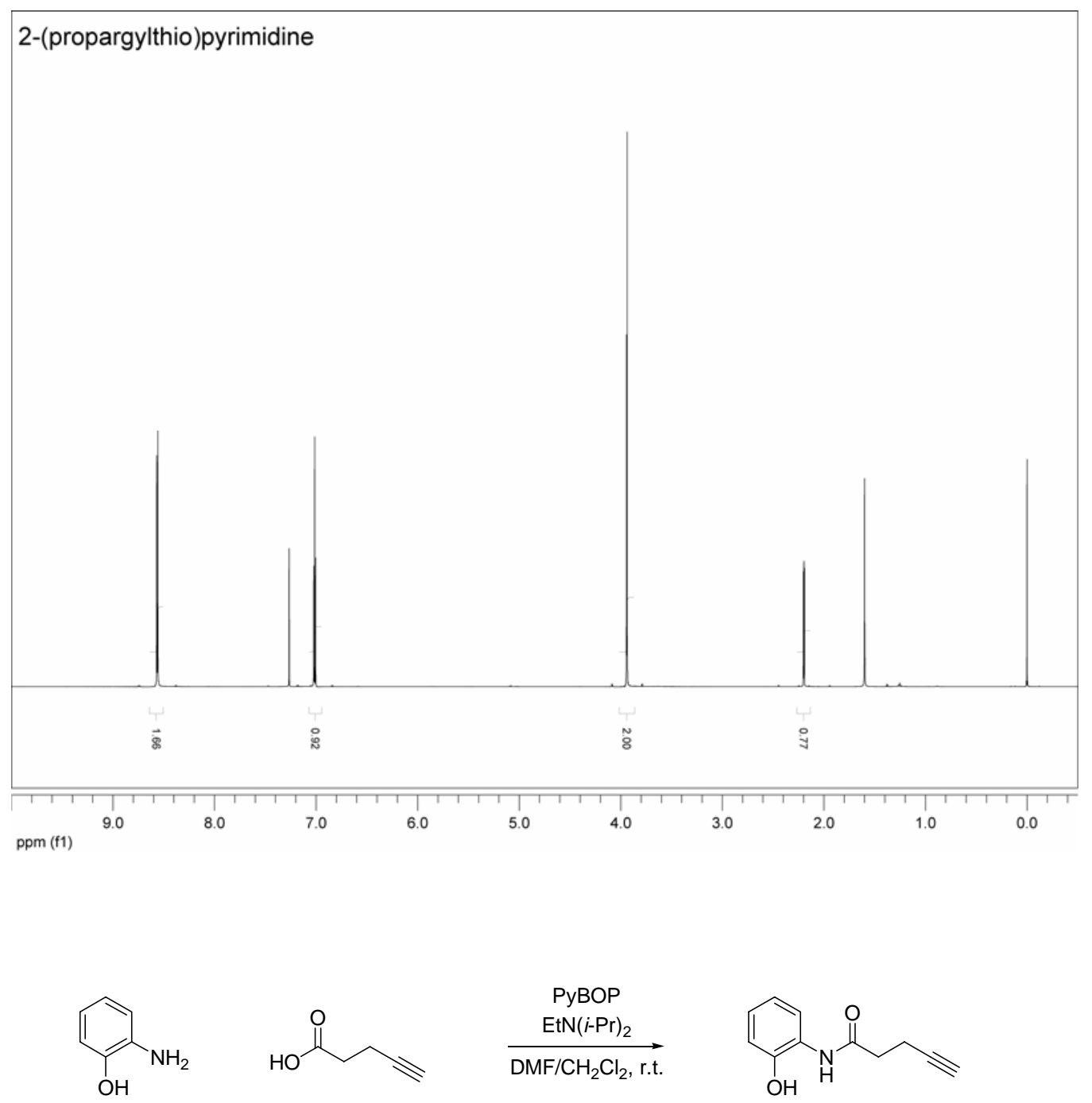

$N$-(2-hydroxyphenyl)pent-4-ynamide. To a 500-mL round-bottom flask was added pent-4-ynoic acid (2.32 g, $23.6 \mathrm{mmol})$ and PyBOP (10.6 g, $23.9 \mathrm{mmol})$. The mixture was dissolved in $180 \mathrm{~mL}$ DMF/60 mL CH $\mathrm{Cl}_{2}$ and charged with 2-aminophenol (3.59 g, $\left.32.9 \mathrm{mmol}\right)$. $\operatorname{EtN}(i-\mathrm{Pr})_{2}(9.00 \mathrm{~mL}, 51.7$ mmol) was finally added, and the reaction mixture was stirred for 12 hours. The reaction mixture was poured into a mixture of $\mathrm{Et}_{2} \mathrm{O}$ and water. The aqueous layer was extracted with $\mathrm{Et}_{2} \mathrm{O}(3 \times 100 \mathrm{~mL})$, and the combined organic extracts were washed with water $(3 \times 100 \mathrm{~mL})$, brine $(100 \mathrm{~mL})$, dried $\left(\mathrm{MgSO}_{4}\right)$, and concentrated in vacuo to afford a brown liquid. The crude product was purified by flash chromatography $(20 / 80$ EtOAc/hexanes $\rightarrow 25 / 75)$ to afford a pale yellow solid, which was then recrystallized from $\mathrm{CH}_{2} \mathrm{Cl}_{2}$ /hexanes to afford colorless crystals ( $3.12 \mathrm{~g}, 70 \%$ yield). 
${ }^{1} \mathrm{H}$ NMR $\left(500 \mathrm{MHz}, \mathrm{CDCl}_{3}\right): \delta 2.11(\mathrm{t}, 1 \mathrm{H}, J=2.4), 2.63-2.71(\mathrm{~m}, 4 \mathrm{H}), 6.87(\mathrm{dt}, 1 \mathrm{H}, J=1.5,7.5)$, $7.02(\mathrm{dd}, 1 \mathrm{H}, J=1.5,8.3), 7.04(\mathrm{dd}, 1 \mathrm{H}, J=1.7,8.1), 7.14(\mathrm{ddd}, 1 \mathrm{H}, J=1.5,7.1,8.3), 7.7(\mathrm{~s} b r, 1 \mathrm{H})$, 8.5 (s br, $1 \mathrm{H}) .{ }^{13} \mathrm{C}$ NMR $\left(100 \mathrm{MHz}, \mathrm{CDCl}_{3}\right): \delta 15.0,35.6,70.3,82.2,119.6,120.5,122.2,125.4,127.2$, $148.5,171.2$.

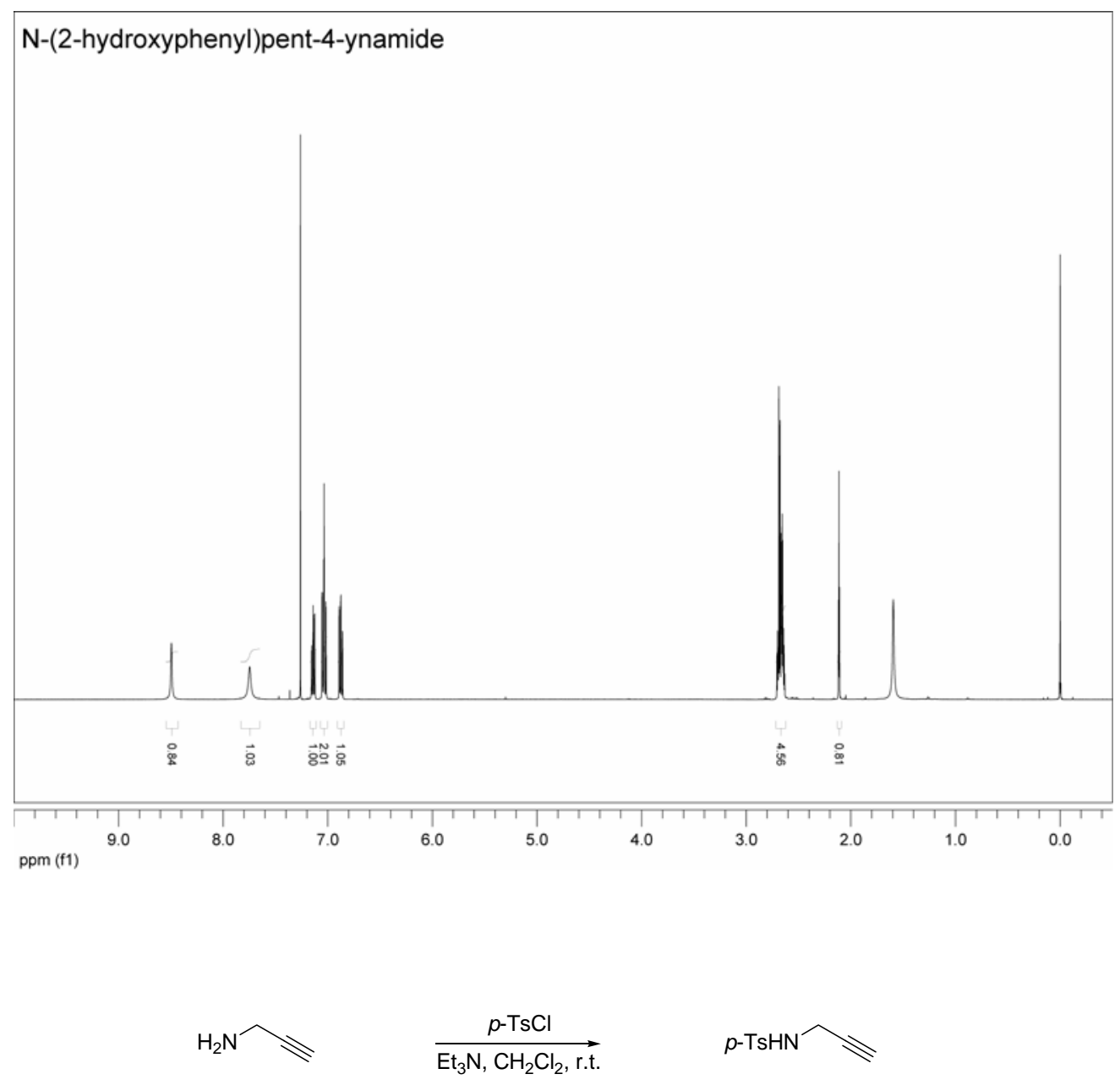

$N$-(propargyl)-p-toluenesulfonamide. To a $40 \mathrm{~mL} \mathrm{CH}_{2} \mathrm{Cl}_{2}$ solution of $p$-toluenesulfonyl chloride $(1.91 \mathrm{~g}, 10.0 \mathrm{mmol})$ was added propargylamine $(0.70 \mathrm{~mL}, 10.2 \mathrm{mmol})$, followed by $\mathrm{Et}_{3} \mathrm{~N}(3.0 \mathrm{~mL}, 22$ mmol). After 12 hours, the reaction mixture was diluted with $\mathrm{CH}_{2} \mathrm{Cl}_{2}$ and washed with $1 \mathrm{M} \mathrm{HCl}(50$ 
$\mathrm{mL})$. The combined organic extracts were dried $\left(\mathrm{MgSO}_{4}\right)$ and concentrated in vacuo to afford a white solid (1.99 g, 95\% yield). The ${ }^{1} \mathrm{H}$ NMR spectrum of the product matched the literature data. ${ }^{1}$
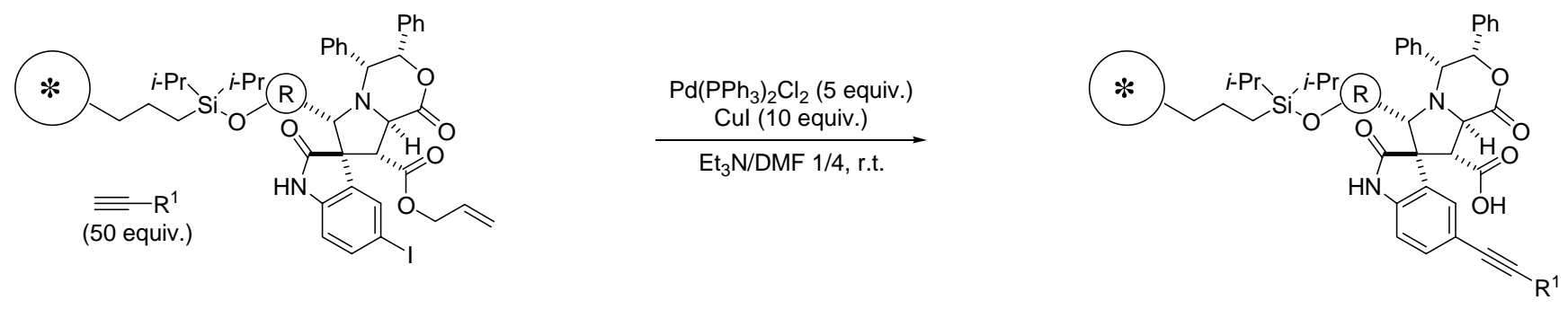

General procedure. To a $20-\mathrm{mL}$ Teflon-septum vial was added the macrobead-supported spirooxindole (30 $\mathrm{mg}, 18 \mu \mathrm{mol}), \mathrm{CuI}(34.2 \mathrm{mg}, 0.180 \mathrm{mmol})$, and the alkyne (50 equiv) if the alkyne is a solid at room temperature. The vial was capped and purged with Ar, and the liquid alkyne (50 equiv) was introduced into the vial. Solvent $\left(\mathrm{Et}_{3} \mathrm{~N} / \mathrm{DMF} 1 / 4,7.5 \mathrm{~mL}\right)$ was added before the suspension of $\operatorname{Pd}\left(\mathrm{PPh}_{3}\right)_{2} \mathrm{Cl}_{2}(61.8 \mathrm{mg}, 88.0 \mu \mathrm{mol})$ in $7.5 \mathrm{~mL}$ solvent was slowly added.

The reaction mixture was tumbled for 3 days, and the solution was removed by filtration. The macrobeads were separated from other insoluble solid by suspending them in $\mathrm{CH}_{2} \mathrm{Cl}_{2}$. In a polypropylene tube, the recovered beads was washed with a $0.1 \mathrm{M}$ DMF solution of glyoxal bis(semithiocarbazone) $(3 \times 1 \mathrm{~h}, 1 \times 10 \mathrm{~h}, 1 \times 1 \mathrm{~h})$. Additional washing with the scavenger solution is carried out if the color of the last wash indicates that there is still residual palladium or copper. The beads were then filtered, washed with $\mathrm{CH}_{2} \mathrm{Cl}_{2}$ ( $\left.3 \times 10 \mathrm{~min}\right)$, THF ( $\left.3 \times 10 \mathrm{~min}\right)$, DMF ( $\left.3 \times 10 \mathrm{~min}\right)$, THF (3 $\times 10 \mathrm{~min}), \mathrm{CH}_{2} \mathrm{Cl}_{2}(3 \times 10 \mathrm{~min})$, and dried in vacuo.

(1) Ince, J.; Ross, T. M.; Shipman, M.; Slawin, A. M. Z.; Ennis, D. S. Tetrahedron 1996, 52, 70377044. 

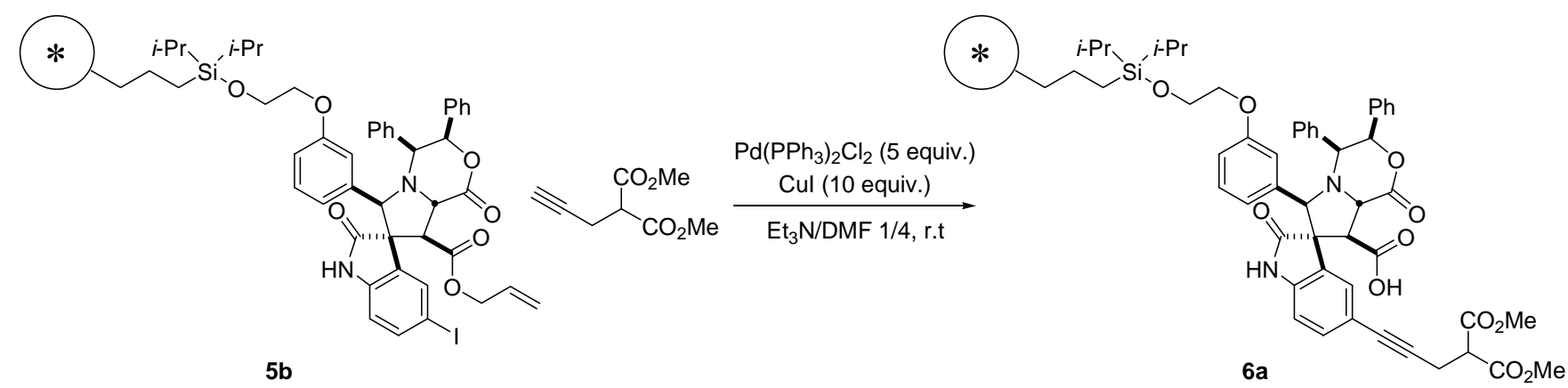

Deprotection of allylic ester, with concomitant Sonogashira coupling The general procedure for

Sonogashira coupling was followed, with macrobead-supported spirooxindole $\mathbf{5 b}$ as the substrate and dimethyl propargylmalonate as the alkyne. The crude product was purified by reverse phase flash chromatography $\left(0.1 \% \mathrm{HCO}_{2} \mathrm{H} / 59.9 \% \mathrm{H}_{2} \mathrm{O} / 40 \% \mathrm{MeCN}\right)$ to afford a white solid.

6a. ${ }^{1} \mathrm{H}$ NMR (500 MHz, $\left.\mathrm{CD}_{3} \mathrm{CN}\right): \delta 2.89(\mathrm{~d}, 2 \mathrm{H}, J=7.8), 3.64-3.73(\mathrm{~m}, 11 \mathrm{H}), 4.06(\mathrm{~d}, 1 \mathrm{H}, J=8.8)$, $4.11(\mathrm{~d}, 1 \mathrm{H}, J=3.4), 5.10(\mathrm{~s}, 1 \mathrm{H}), 5.10(\mathrm{~d}, 1 \mathrm{H}, J=8.8), 6.33(\mathrm{~d}, 1 \mathrm{H}, J=2.9), 6.60(\mathrm{~d}, 1 \mathrm{H}, J=8.3)$, 6.65-6.72 (m, 3H), 7.01-7.09 (m, 6H), 7.14-7.26 (m, 7H), 8.61 (s, 1H). ${ }^{13} \mathrm{C}$ NMR (101 MHz, $\left.\mathrm{CD}_{3} \mathrm{CN}\right)$ : $\delta 19.9,51.7,53.3,55.1,58.4,61.2,61.5,61.6,70.3,75.5,77.8,82.7,85.7,110.6,116.9,126.6,127.0$ 128.7, 128.8, 129.2, 129.4, 129.7, 130.1, 130.4, 133.5, 137.1, 137.3, 142.5, 159.6, 169.5, 171.9, 176.4 . HRMS-ESI ${ }^{+}(m / z):[M+H]^{+}$calcd for $\mathrm{C}_{43} \mathrm{H}_{39} \mathrm{~N}_{2} \mathrm{O}_{11}, 759.2554$; found, 759.2546 . 

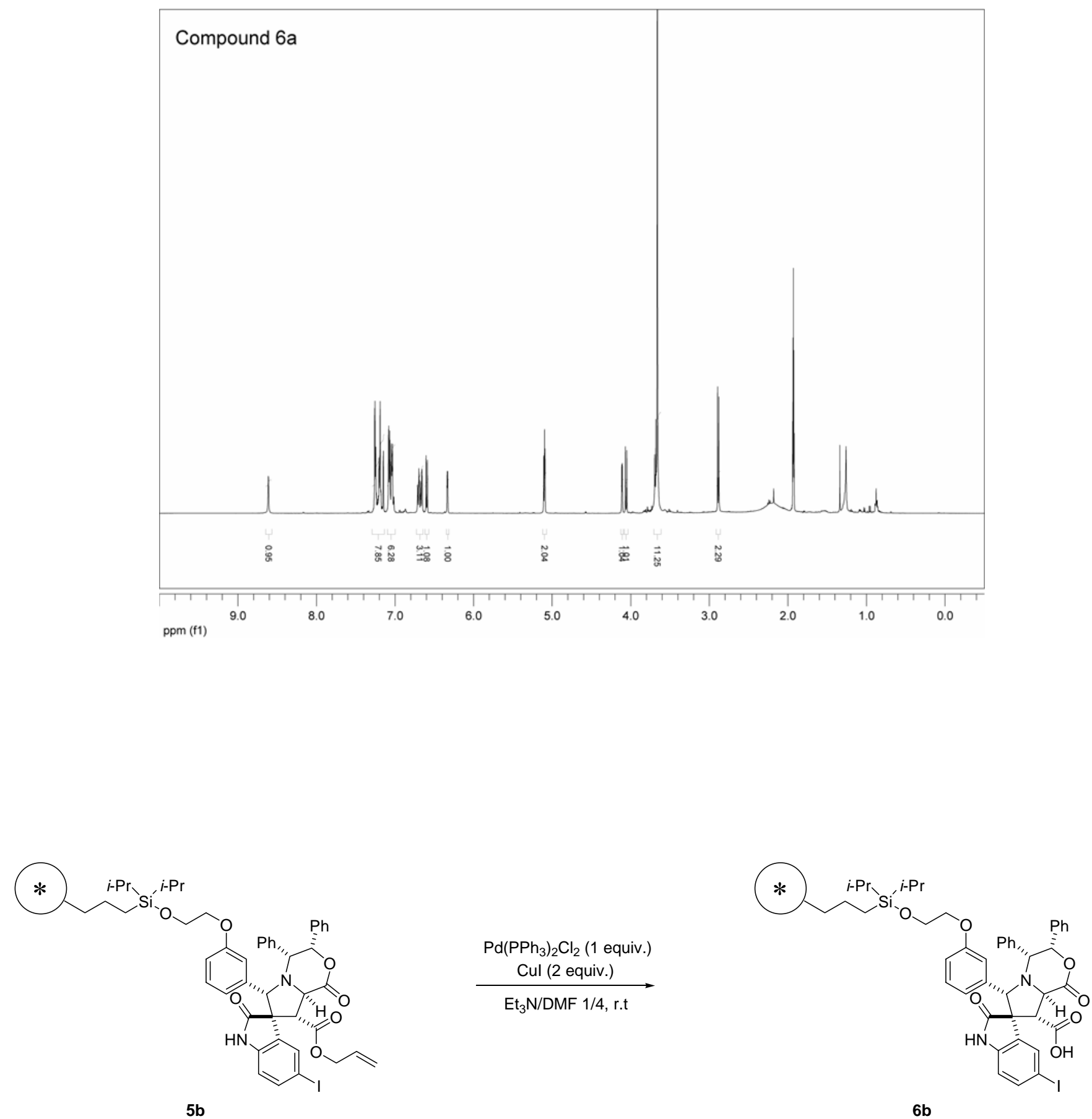

Deprotection of allylic ester, with aromatic iodide intact. To a $20-\mathrm{mL}$ Teflon-septum vial was added the macrobead-supported spirooxindole $(105.7 \mathrm{mg}, 70 \mu \mathrm{mol})$ and $\mathrm{CuI}(27.0 \mathrm{mg}, 142 \mu \mathrm{mol})$. The vial was capped and purged with $\mathrm{Ar}$, and a suspension of $\mathrm{Pd}\left(\mathrm{PPh}_{3}\right)_{2} \mathrm{Cl}_{2}(51.5 \mathrm{mg}, 73.3 \mu \mathrm{mol})$ in $7.5 \mathrm{~mL}$ solvent (Et $\left.{ }_{3} \mathrm{~N} / \mathrm{DMF} 1 / 4\right)$ was slowly added. 
The reaction mixture was tumbled for 3 days, and the solution was removed by filtration. The recovered beads was washed with a $0.1 \mathrm{M}$ DMF solution of glyoxal bis(semithiocarbazone) ( $3 \times 1 \mathrm{~h}, 1 \mathrm{x}$ $10 \mathrm{~h}, 1 \times 1 \mathrm{~h}$ ). Additional washing with the scavenger solution is carried out if the color of the last wash indicates that there is still residual palladium or copper. The beads were then filtered, washed with $\mathrm{CH}_{2} \mathrm{Cl}_{2}$ (3 $\left.\times 10 \mathrm{~min}\right)$, THF ( $\left.3 \times 10 \mathrm{~min}\right), \mathrm{DMF}$ ( $\left.3 \times 10 \mathrm{~min}\right)$, THF ( $\left.3 \times 10 \mathrm{~min}\right), \mathrm{CH}_{2} \mathrm{Cl}_{2}(3 \times 10 \mathrm{~min})$, and dried in vacuo. The crude product was purified by reverse phase flash chromatography $(0.1 \%$ $\mathrm{HCO}_{2} \mathrm{H} / 59.9 \% \mathrm{H}_{2} \mathrm{O} / 40 \% \mathrm{MeCN}$ ) to afford a white solid.

6b. ${ }^{1} \mathrm{H}$ NMR (500 MHz, $\left.\mathrm{CD}_{3} \mathrm{CN}\right): \delta 3.7(\mathrm{~s} \mathrm{br}, 4 \mathrm{H}), 4.07(\mathrm{~d}, 1 \mathrm{H}, J=8.8), 4.15(\mathrm{~d}, 1 \mathrm{H}, J=3.4), 5.07$ $(\mathrm{d}, 1 \mathrm{H}, J=8.8), 5.08(\mathrm{~s}, 1 \mathrm{H}), 6.33(\mathrm{~d}, 1 \mathrm{H}, J=3.4), 6.49(\mathrm{~d}, 1 \mathrm{H}, J=8.3), 6.65(\mathrm{~s}, 1 \mathrm{H}), 6.68-6.74(\mathrm{~m}$, 2H), 7.03-7.10 (m, 5H), 7.16-7.29 (m, 6H), $7.42(\mathrm{dd}, 1 \mathrm{H}, J=1.7,8.1), 7.52(\mathrm{~d}, 1 \mathrm{H}, J=1.5), 8.6(\mathrm{~s} b r$, 1H). ${ }^{13} \mathrm{C}$ NMR $\left(101 \mathrm{MHz}, \mathrm{CD}_{3} \mathrm{CN}\right): \delta 54.9,58.1,61.16,61.20,61.6,70.4,75.3,77.9,84.1,112.7$, $126.6,128.7,129.2,129.3,129.7,130.2,136.1,136.9,137.1,137.3,138.6,142.4,159.6,169.4,171.9$,

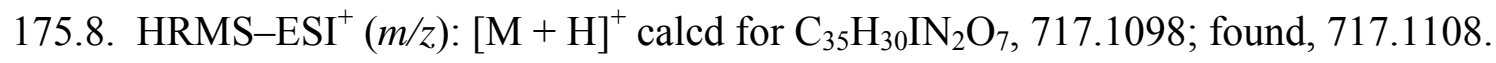




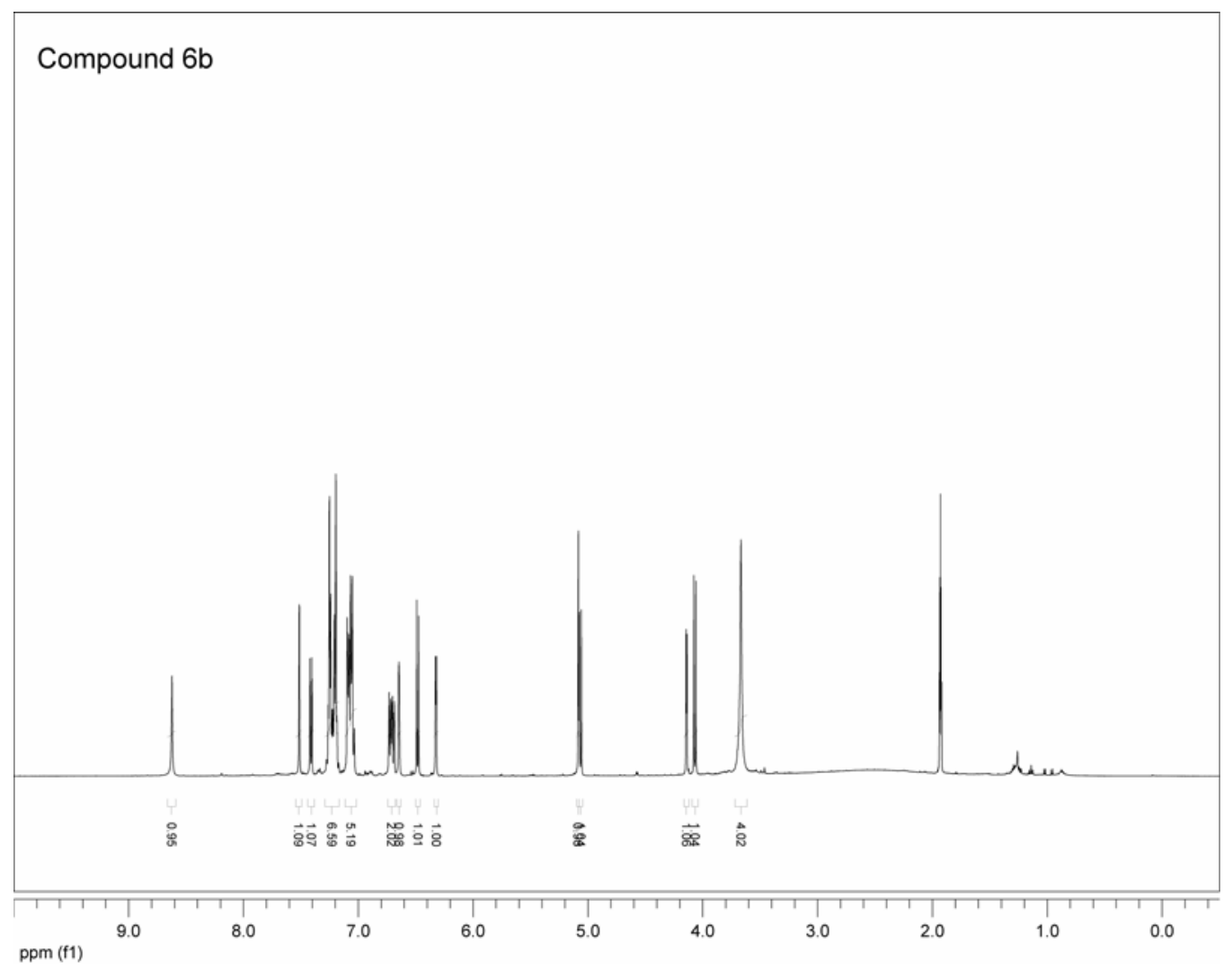

\section{B. Amide Formation}

Amine Building Blocks. All amine building blocks that are commercially available were used as received. The preparation of the other amine building blocks screened is described as follows. The yields reported are unoptimized.

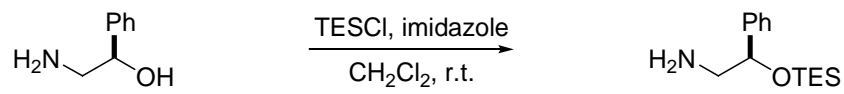

(R)-2-phenyl-2-(triethylsilyloxy)ethylamine. In a 100-mL round-bottom flask was added $(R)-2$ amino-1-phenylethanol $(2.75 \mathrm{~g}, 20.0 \mathrm{mmol})$ and imidazole $(6.97 \mathrm{~g}, 103 \mathrm{mmol})$. It was dissolved in $\mathrm{CH}_{2} \mathrm{Cl}_{2}(60 \mathrm{~mL})$ and charged with chlorotriethylsilane $(8.40 \mathrm{~mL}, 50.0 \mathrm{mmol})$. After 12 hours, the reaction mixture was poured into $\mathrm{CH}_{2} \mathrm{Cl}_{2}$ and washed with water. The organic layer was washed with 
saturated brine, dried $\left(\mathrm{K}_{2} \mathrm{CO}_{3}\right)$, and concentrated in vacuo to afford a colorless liquid. The crude product was distilled twice under high vaccum to afford the desired product as a colorless liquid (b.p. $=$ $\left.117^{\circ} \mathrm{C}\right)$

${ }^{1} \mathrm{H}$ NMR (500 MHz, $\left.\mathrm{C}_{6} \mathrm{D}_{6}\right): \delta 0.52$ (qd, 3H, $\left.J=7.9,15.6\right), 0.55$ (qd, 3H, $\left.J=7.7,15.4\right), 0.9$ (s br, 2H), $0.92(\mathrm{t}, 9 \mathrm{H}, J=7.7), 2.74(\mathrm{dd}, 1 \mathrm{H}, J=4.4,13.2), 2.83(\mathrm{dd}, 1 \mathrm{H}, J=6.6,12.9), 4.51(\mathrm{dd}, 1 \mathrm{H}, J=4.4$, 6.3), 7.07 (tt, $1 \mathrm{H}, J=1.6,7.3), 7.16(\mathrm{t}, 2 \mathrm{H}, J=7.6), 7.26(\mathrm{~d}, 2 \mathrm{H}, J=7.6) .{ }^{13} \mathrm{C} \mathrm{NMR}\left(101 \mathrm{MHz}, \mathrm{C}_{6} \mathrm{D}_{6}\right)$ : $\delta 5.6,7.4,52.1,77.8,126.8,127.9,128.7,144.4$.

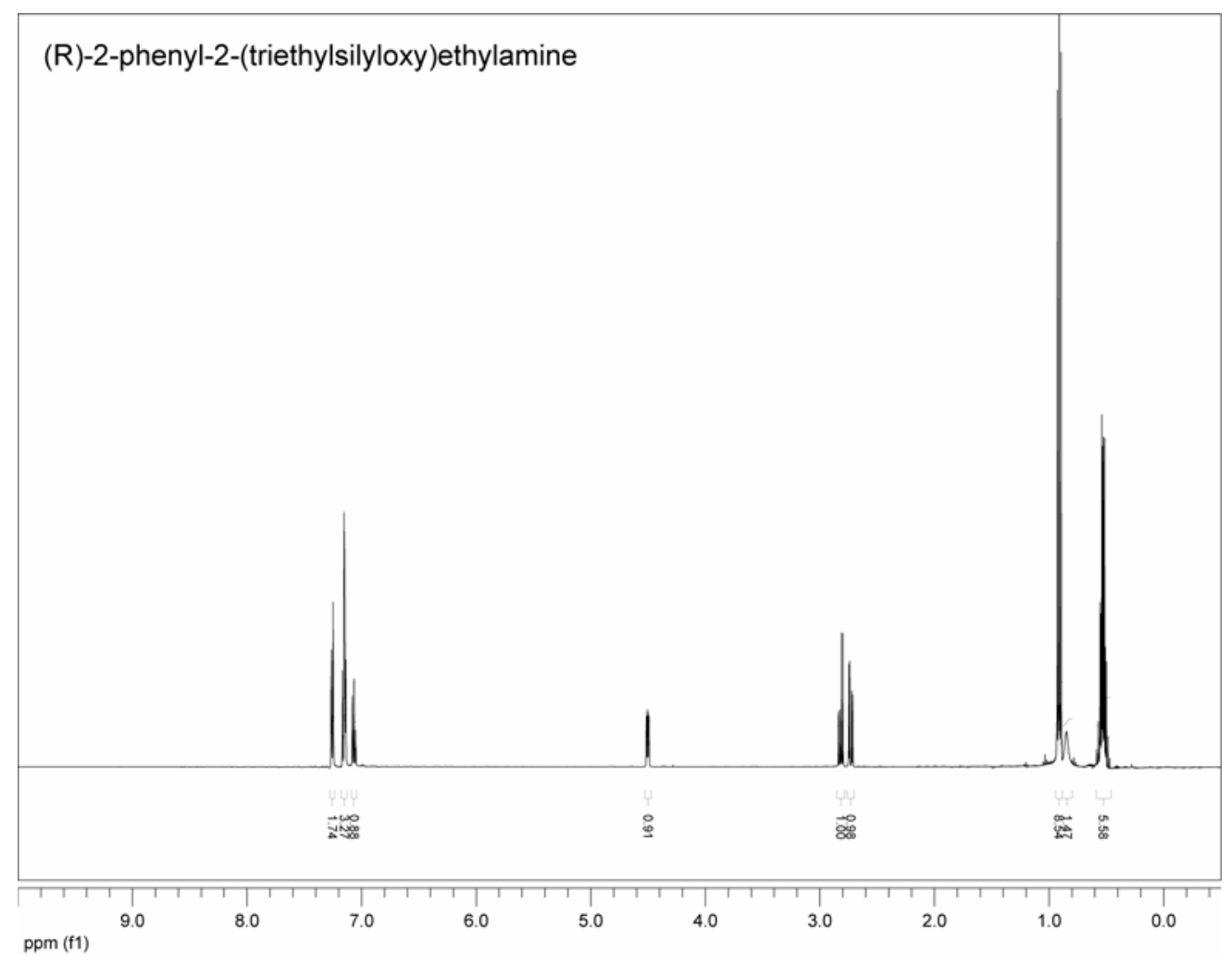

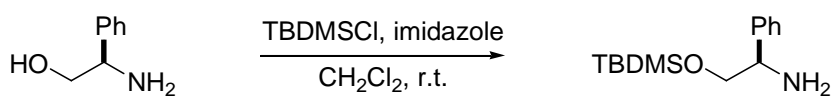


(R)-2-(t-butyldimethylsilyloxy)-1-phenylethylamine. To a $\mathrm{CH}_{2} \mathrm{Cl}_{2}$ solution $(30 \mathrm{~mL})$ of $(R)-2-$ phenylglycinol (506 mg, $3.69 \mathrm{mmol})$ and imidazole $(1.23 \mathrm{~g}, 18.1 \mathrm{mmol})$ was added with a $\mathrm{CH}_{2} \mathrm{Cl}_{2}(10$ $\mathrm{mL})$ solution of $t$-butyldimethylsilyl chloride $(1.35 \mathrm{~g}, 8.96 \mathrm{mmol})$. After 12 hours, the reaction mixture was quenched with saturated $\mathrm{NaHCO}_{3}$ and extracted with $\mathrm{CH}_{2} \mathrm{Cl}_{2}$. The combined organic extracts were dried $\left(\mathrm{K}_{2} \mathrm{CO}_{3}\right)$ and concentrated in vacuo to afford a colorless liquid. The crude product was purified twice by flash chromatography $\left(\mathrm{CH}_{2} \mathrm{Cl}_{2} \rightarrow 1 / 4 / 95 \mathrm{Et}_{3} \mathrm{~N} / \mathrm{MeOH} / \mathrm{CH}_{2} \mathrm{Cl}_{2}\right)$ to afford a slightly colorless liquid (678 mg, 73\% yield).

${ }^{1} \mathrm{H}$ NMR $\left(500 \mathrm{MHz}, \mathrm{CDCl}_{3}\right): \delta 0.02$ (s, 3H), 0.03 (s, 3H), 0.90 (s, 9H), $1.86(\mathrm{~s} \mathrm{br}, 2 \mathrm{H}), 3.52(\mathrm{dd}, 1 \mathrm{H}$, $\mathrm{J}=8.3,9.8), 3.72(\mathrm{dd}, 1 \mathrm{H}, J=3.9,9.8), 4.07$ (dd, $1 \mathrm{H}, J=3.9,8.3), 7.26(\mathrm{tt}, 1 \mathrm{H}, J=1.5,7.1), 7.32(\mathrm{~m}, 2 \mathrm{H})$, $7.37(\mathrm{~m}, 2 \mathrm{H}) .{ }^{13} \mathrm{C}$ NMR $\left(125 \mathrm{MHz}, \mathrm{CDCl}_{3}\right): \delta-5.50,-5.52,18.2,25.8,57.5,69.4,126.8,127.2,128.2$, 142.5. $\operatorname{HRMS}-\mathrm{ESI}^{+}(\mathrm{m} / \mathrm{z}):[\mathrm{M}+\mathrm{H}]^{+}$calcd for $\mathrm{C}_{14} \mathrm{H}_{26} \mathrm{NOSi}, 252.1784$; found, 252.1784 .

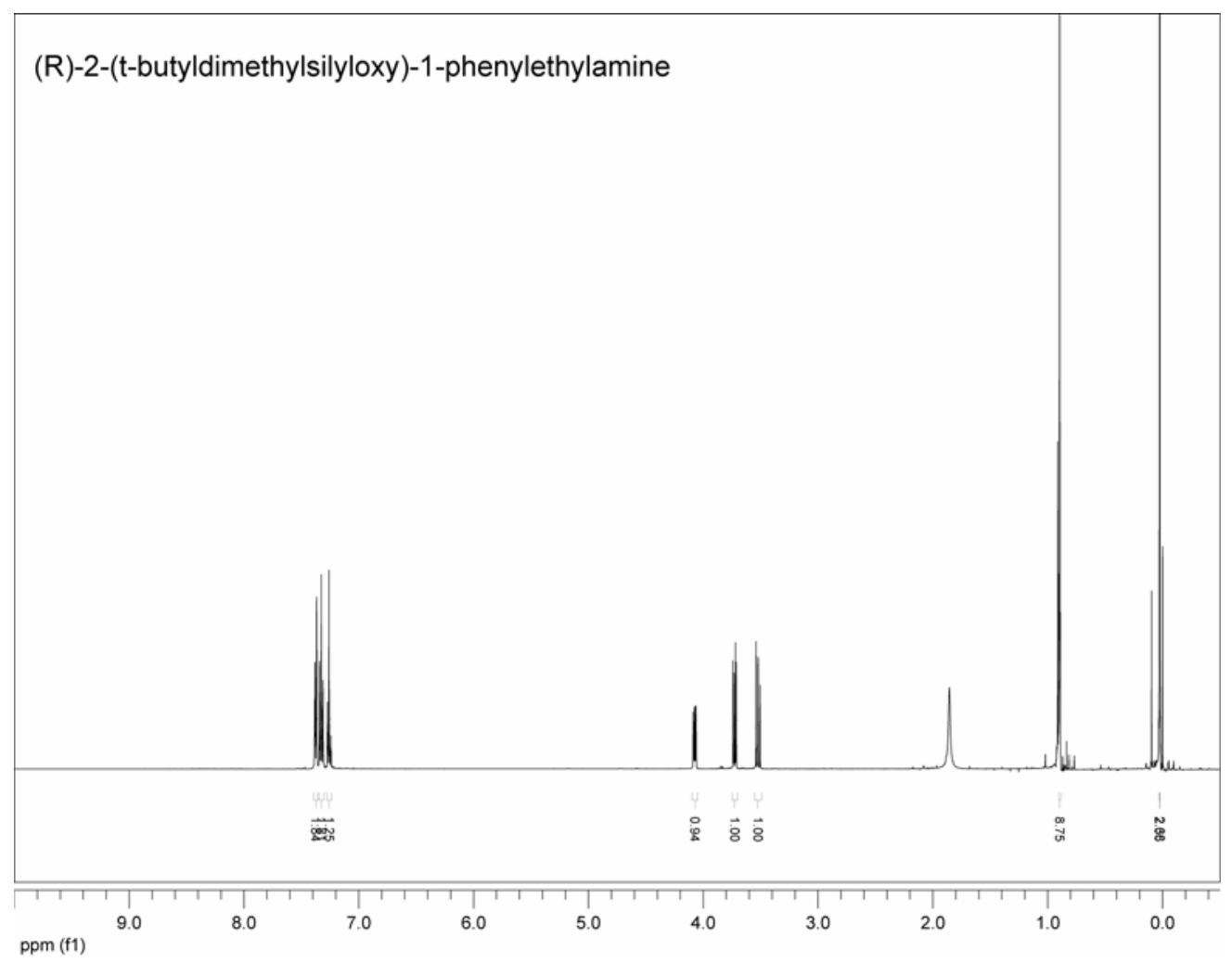



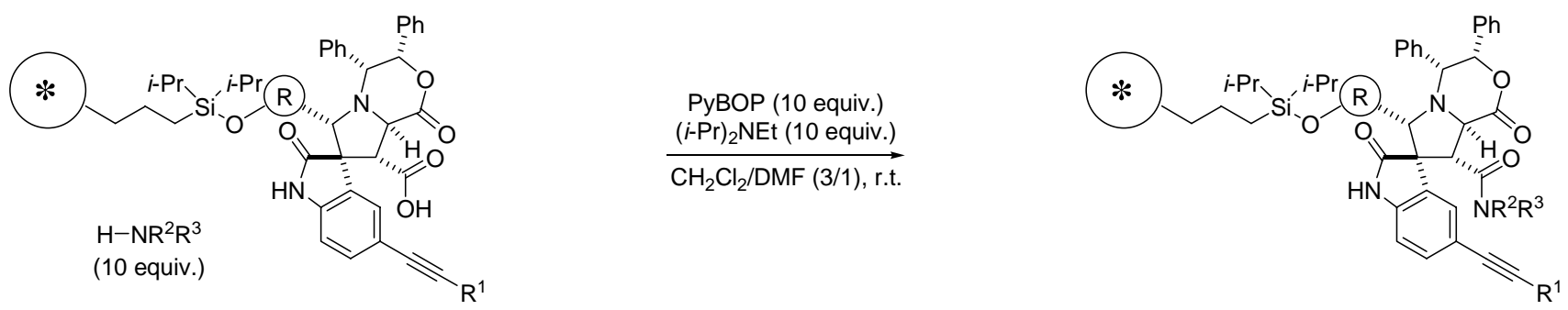

General procedure. To a 4-mL vial containing the macrobead-supported spirooxindole (30 mg, 18 $\mu$ mol) was added a DMF solution $(0.5 \mathrm{~mL})$ of (benzotriazol-1-yloxy)tripyrrolidinophosphonium hexafluorophosphate (PyBOP, $0.18 \mathrm{mmol}), \mathrm{CH}_{2} \mathrm{Cl}_{2}$ solution $(0.5 \mathrm{~mL})$ of $(i-\operatorname{Pr}){ }_{2} \mathrm{NEt}(0.18 \mathrm{mmol})$ and a $\mathrm{CH}_{2} \mathrm{Cl}_{2}$ solution $(1.0 \mathrm{~mL})$ of the amine (10 equiv). ${ }^{2}$ The reaction mixture was tumbled for 1 day, and the solution was removed by filtration. The macrobeads were washed with $\mathrm{CH}_{2} \mathrm{Cl}_{2}(3 \times 10 \mathrm{~min})$, THF $(3 \mathrm{x}$ $10 \mathrm{~min}), \mathrm{DMF}$ ( $3 \times 10 \mathrm{~min}), \mathrm{THF}(3 \times 10 \mathrm{~min}), \mathrm{CH}_{2} \mathrm{Cl}_{2}$ ( $\left.3 \times 10 \mathrm{~min}\right)$, and dried in vacuo.

\section{N-Acylation of $\gamma$-Lactams.}
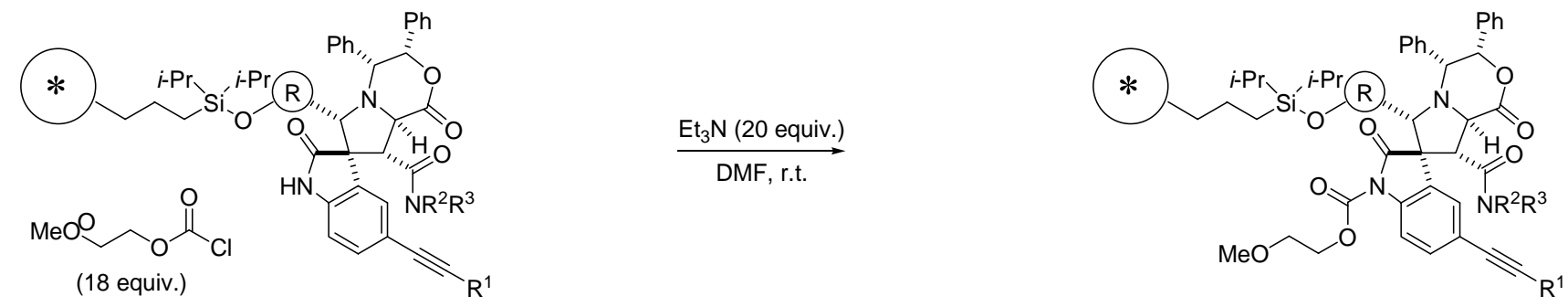

General procedure. To an oven-dried 20-mL Teflon-septum vial was added macrobead-supported spirooxindole $(0.125 \mathrm{mmol})$. The vial was purged with nitrogen, then charged with dry DMF $(9.0 \mathrm{~mL})$.

(2) For amines that are commercially available as salts with acids, the free bases were generated by first mixing the salts (1.0 equiv) with (i-Pr) $)_{2} \mathrm{NEt}$ (2.0 equiv) and dissolving the resultant mixture in DMF. 
$\mathrm{Et}_{3} \mathrm{~N}$ (348 $\mu \mathrm{L}, 2.50 \mathrm{mmol}, 20$ equiv) was added via syringe, followed by methoxyethyl chloroformate (311 $\mu \mathrm{L}, 2.25 \mathrm{mmol}, 18$ equiv). The reaction mixture was tumbled for 48 hours, and the solution was removed by filtration. The macrobeads were washed with DMF ( 3 × 30 min), THF ( 3 × $30 \mathrm{~min})$, $\mathrm{CH}_{2} \mathrm{Cl}_{2}$ (3 x $\left.30 \mathrm{~min}\right)$, and dried in vacuo.
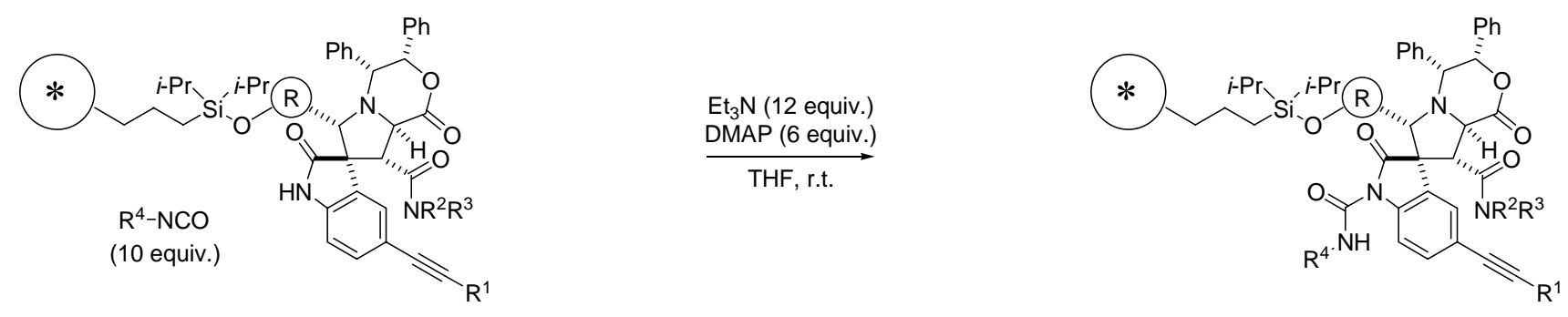

General procedure. To an oven-dried 20-mL Teflon-septum vial was added macrobead-supported spirooxindole $(0.125 \mathrm{mmol})$ and 4-(dimethylamino)pyridine $(92 \mathrm{mg}, 0.75 \mathrm{mmol}, 6.0$ equiv). The vial was purged with nitrogen, then charged with dry THF $(9.0 \mathrm{~mL}) . \mathrm{Et}_{3} \mathrm{~N}(209 \mu \mathrm{L}, 1.50 \mathrm{mmol}, 12$ equiv) was added via syringe, followed by the isocyanate $(1.25 \mathrm{mmol}, 10.0$ equiv). The reaction mixture was tumbled for 48 hours, and the solution was removed by filtration. The macrobeads were washed with THF (6 x $30 \mathrm{~min}), \mathrm{CH}_{2} \mathrm{Cl}_{2}(3 \times 30 \mathrm{~min})$, and dried in vacuo. 


\section{Demonstration Compound Synthesis}

Compounds were synthesized on solid phase using procedures described above. ${ }^{1} \mathrm{H}-\mathrm{NMR}$ spectra of crude material are shown to indicate degree of purity of final library members.

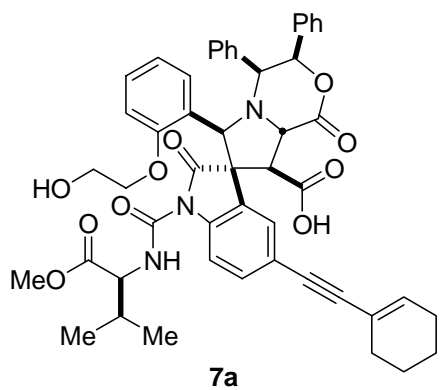

7a. Purification: Flash chromatography (40/60 EtOAc/hexanes $\rightarrow 65 / 35) .{ }^{1} \mathrm{H}$ NMR (500 MHz, $\left.\mathrm{CD}_{3} \mathrm{CN}\right): \delta 1.00(\mathrm{~d}, 3 \mathrm{H}, J=6.8), 1.01(\mathrm{~d}, 3 \mathrm{H}, J=6.8), 1.57-1.62(\mathrm{~m}, 2 \mathrm{H}), 1.64-1.69(\mathrm{~m}, 2 \mathrm{H}), 2.11-2.18$ (m, 4H), 2.25 (d sept, 1H, $J=4.9,6.8), 3.1(\mathrm{~s} \mathrm{br}, 1 \mathrm{H}), 3.72$ (s, 3H), 3.75 (ddd, 1H, $J=3.4,5.4,12.2$ ), $3.82(\mathrm{ddd}, 1 \mathrm{H}, J=3.4,6.3,12.2), 3.92(\mathrm{ddd}, 1 \mathrm{H}, J=3.5,6.5,10.1), 3.98(\mathrm{ddd}, 1 \mathrm{H}, J=3.9,5.9,10.3)$, $4.13(\mathrm{~d}, 1 \mathrm{H}, J=3.4), 4.31(\mathrm{~d}, 1 \mathrm{H}, J=8.8), 4.41(\mathrm{dd}, 1 \mathrm{H}, J=4.9,7.8), 5.19(\mathrm{~d}, 1 \mathrm{H}, J=8.8), 5.72(\mathrm{~s}, 1 \mathrm{H})$, $6.16(\mathrm{~m}, 1 \mathrm{H}), 6.30(\mathrm{~d}, 1 \mathrm{H}, J=3.4), 6.63(\mathrm{t}, 1 \mathrm{H}, J=7.6), 6.80(\mathrm{~d}, 1 \mathrm{H}, J=7.8), 7.00(\mathrm{~d}, 2 \mathrm{H}, J=6.8)$, 7.06-7.11 (m, 4H), 7.17-7.27 (m, 8H), $7.83(\mathrm{~d}, 1 \mathrm{H}, J=9.3), 8.87(\mathrm{~d}, 1 \mathrm{H}, J=7.8) .{ }^{13} \mathrm{C}$ NMR $(101 \mathrm{MHz}$, $\left.\mathrm{CD}_{3} \mathrm{CN}\right): \delta 18.4,19.2,22.1,23.0,26.4,29.8,31.8,52.9,56.2,58.8,59.3,61.3,61.5,62.2,69.3,71.9$, $78.7,86.8,92.2,113.7,116.3,120.0,121.2,121.4,124.1,126.4,126.9,128.80,128.82,129.1,129.27$, $129.30,129.7,129.8,130.5,133.1,136.5,136.9,140.8,152.1,158.2,169.1,171.6,172.6,178.9$. HRMS-ESI ${ }^{+}(\mathrm{m} / \mathrm{z}):[\mathrm{M}+\mathrm{H}]^{+}$calcd for $\mathrm{C}_{50} \mathrm{H}_{50} \mathrm{~N}_{3} \mathrm{O}_{10}, 852.3496$; found, 852.3497 . 
IV. Reaction Survey and Building Block Selection
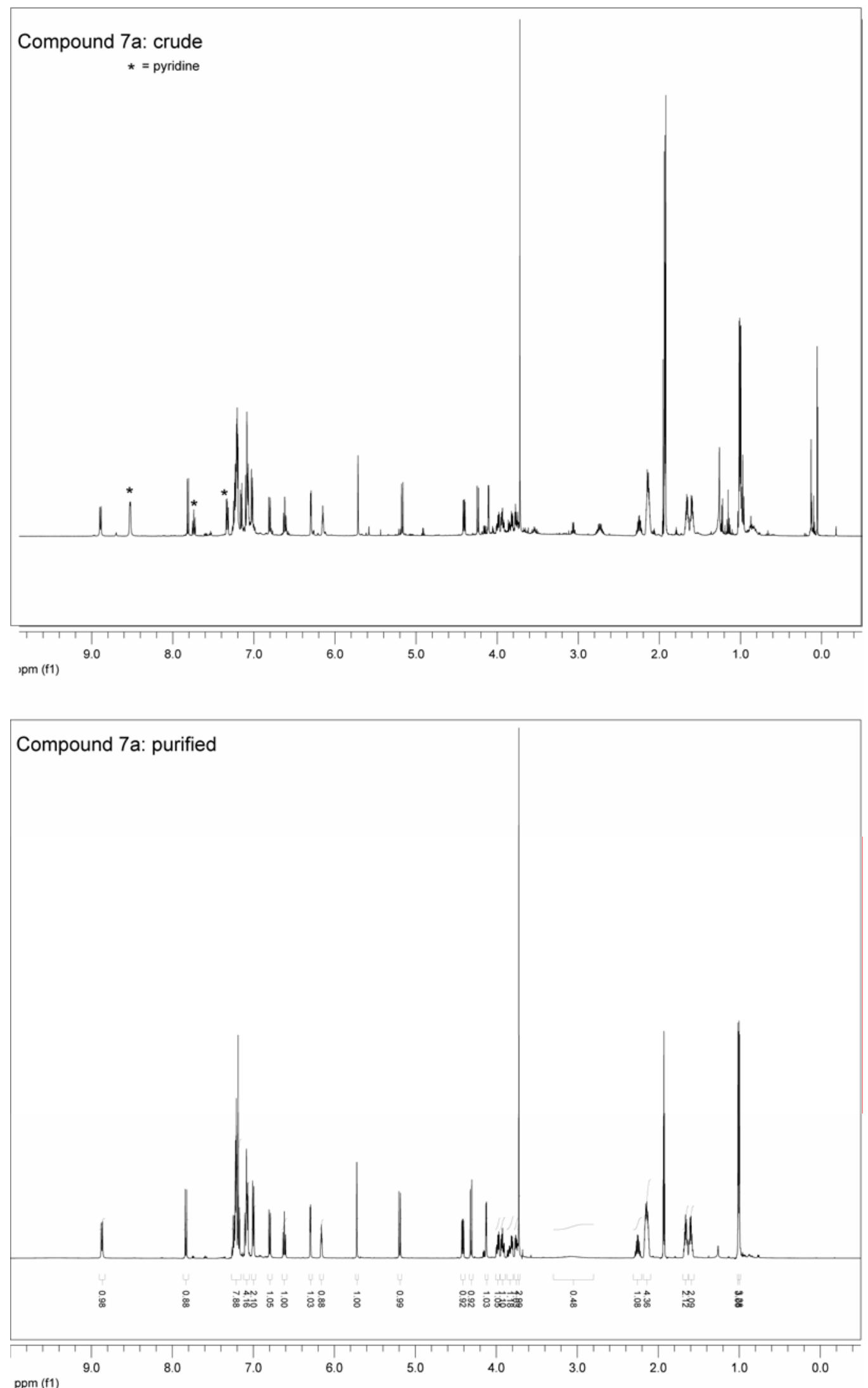
IV. Reaction Survey and Building Block Selection

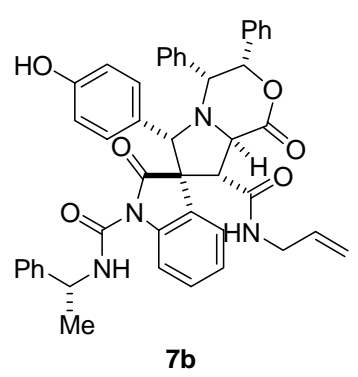

7b. Purification: Flash chromatography (25/75 EtOAc/hexanes $\rightarrow 75 / 25)$, followed by HPLC (75/25 acetonitrile/water). ${ }^{1} \mathrm{H}$ NMR (500 MHz, $\left.\mathrm{CD}_{3} \mathrm{CN}\right): \delta 1.58$ (d, $\left.3 \mathrm{H}, J=6.8\right), 3.51$ (tdd, $1 \mathrm{H}, J=1.7$, 5.2, 16.2), $3.63(\mathrm{tddd}, 1 \mathrm{H}, J=1.5,4.8,6.5,16.3), 4.11(\mathrm{~d}, 1 \mathrm{H}, J=2.9), 4.24(\mathrm{~d}, 1 \mathrm{H}, J=10.3), 4.90(\mathrm{qd}$, $1 \mathrm{H}, J=1.5,10.5), 4.93(\mathrm{qd}, 1 \mathrm{H}, J=1.7,17.2), 5.02$ (quintet, $1 \mathrm{H}, J=7.0), 5.12(\mathrm{~s}, 1 \mathrm{H}), 5.27(\mathrm{~d}, 1 \mathrm{H}, J=$ 10.7), 5.55 (tdd, $1 \mathrm{H}, J=5.2,10.4,17.3), 6.41(\mathrm{~d}, 1 \mathrm{H}, J=2.9), 6.46$ (d, $2 \mathrm{H}, J=8.3), 6.90$ (d, 2H, $J=$ 8.3), $6.94(\mathrm{~d}, 2 \mathrm{H}, J=7.3), 7.04(\mathrm{dt}, 1 \mathrm{H}, J=1.0,7.6), 7.07-7.11(\mathrm{~m}, 2 \mathrm{H}), 7.13(\mathrm{dt}, 1 \mathrm{H}, J=1.5,7.8)$, 7.18-7.30 (m, 6H), 7.34-7.42 (m, 4H), 7.52 (t, 1H, $J=5.6), 7.83$ (t, 1H, $J=7.8), 8.92$ (d, 1H, $J=6.8)$. ${ }^{13} \mathrm{C}$ NMR (101 MHz, $\left.\mathrm{CD}_{3} \mathrm{CN}\right): \delta 22.9,42.2,50.9,57.4,58.2,62.0,62.6,74.9,78.2,115.6,115.7,116.0$, $124.7,126.2,126.4,126.5,126.8,126.9,128.3,128.7,128.9,129.19,129.22,129.5,129.7,129.8,135.1$ $136.9,137.1,141.7,144.8,151.6,158.0,167.3,173.3,179.2 . \operatorname{HRMS}_{-} \mathrm{ESI}^{+}(\mathrm{m} / \mathrm{z}):[\mathrm{M}+\mathrm{H}]^{+}$calcd for $\mathrm{C}_{45} \mathrm{H}_{41} \mathrm{~N}_{4} \mathrm{O}_{6}, 733.3026$; found, 733.3016 . 
IV. Reaction Survey and Building Block Selection
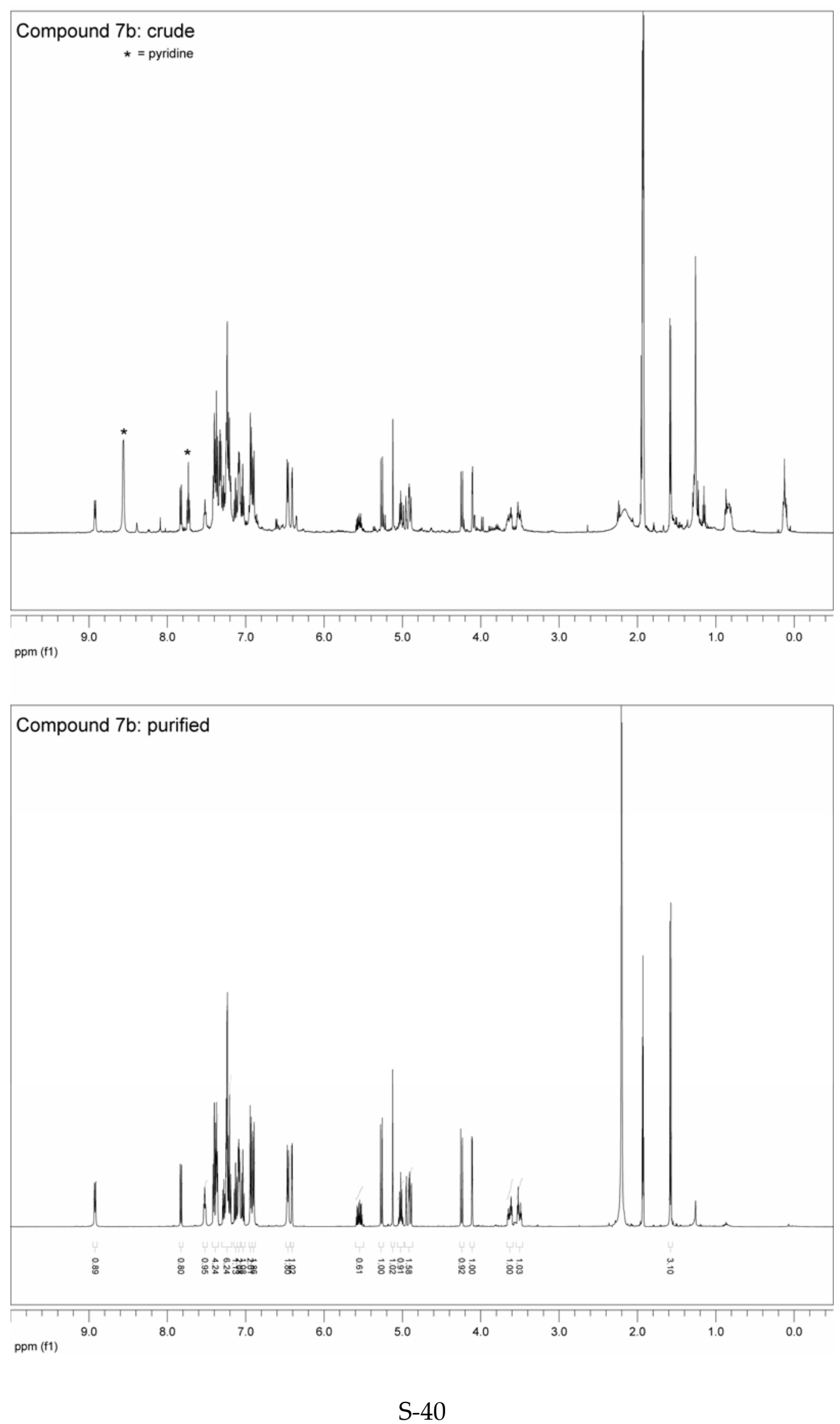


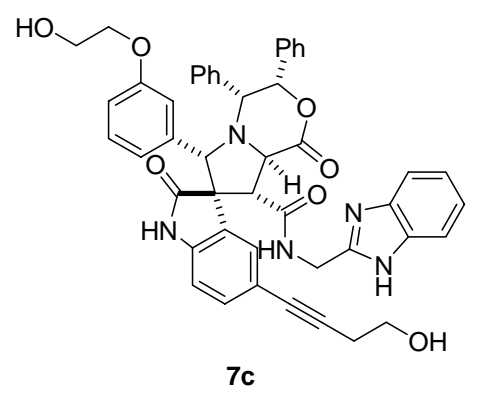

7c. Purification: Flash chromatography (10/90 i-PrOH/CH $\left.\mathrm{Cl}_{2} \rightarrow 20 / 80\right)$, follow by $\mathrm{HPLC}(35 / 65 i-$ $\mathrm{PrOH} /$ hexanes $\rightarrow 70 / 30) . \quad{ }^{1} \mathrm{H}$ NMR (500 MHz, $\left.\mathrm{CD}_{3} \mathrm{OD}\right): \delta 2.57$ (t, $\left.2 \mathrm{H}, J=6.6\right), 3.56-3.72(\mathrm{~m} \mathrm{br}, 4 \mathrm{H})$, $3.69(\mathrm{t}, 2 \mathrm{H}, J=6.8), 4.10(\mathrm{~d}, 1 \mathrm{H}, J=2.9), 4.24(\mathrm{~d}, 1 \mathrm{H}, J=9.8), 4.40(\mathrm{~d}, 1 \mathrm{H}, J=15.6), 4.46(\mathrm{~d}, 1 \mathrm{H}, J=$ 15.6), $5.13(\mathrm{~s}, 1 \mathrm{H}), 5.57$ (d, $1 \mathrm{H}, J=9.8), 6.25$ (d, $1 \mathrm{H}, J=7.8), 6.44$ (d, $1 \mathrm{H}, J=2.4), 6.65(\mathrm{~d}, 1 \mathrm{H}, J=$ 8.3), 6.69-6.73 (m, 2H), $6.82(\mathrm{~d}, 1 \mathrm{H}, J=7.8), 6.95-6.99(\mathrm{~m}, 3 \mathrm{H}), 7.07$ (d, 2H, $J=7.8), 7.18-7.26(\mathrm{~m}$, 8H), 7.38 (s, 1H), 7.47-7.49 (m, 2H). ${ }^{13} \mathrm{C}$ NMR (126 MHz, $\left.\mathrm{CD}_{3} \mathrm{OD}\right): \delta 24.4,38.6,56.9,59.3,61.7$, $62.0,63.3,70.60,70.63,76.1,79.1,82.7,87.0,110.7,118.3,121.6,123.6,127.2,127.5,129.0,129.2$ $129.5,130.0,130.2,131.2,133.5,137.4,137.7,137.8,142.7,152.6,160.2,169.9,174.3,178.7$. HRMS$\operatorname{ESI}^{+}(m / z):[\mathrm{M}+\mathrm{H}]^{+}$calcd for $\mathrm{C}_{47} \mathrm{H}_{42} \mathrm{~N}_{5} \mathrm{O}_{7}, 788.3084$; found, 788.3084. 
IV. Reaction Survey and Building Block Selection

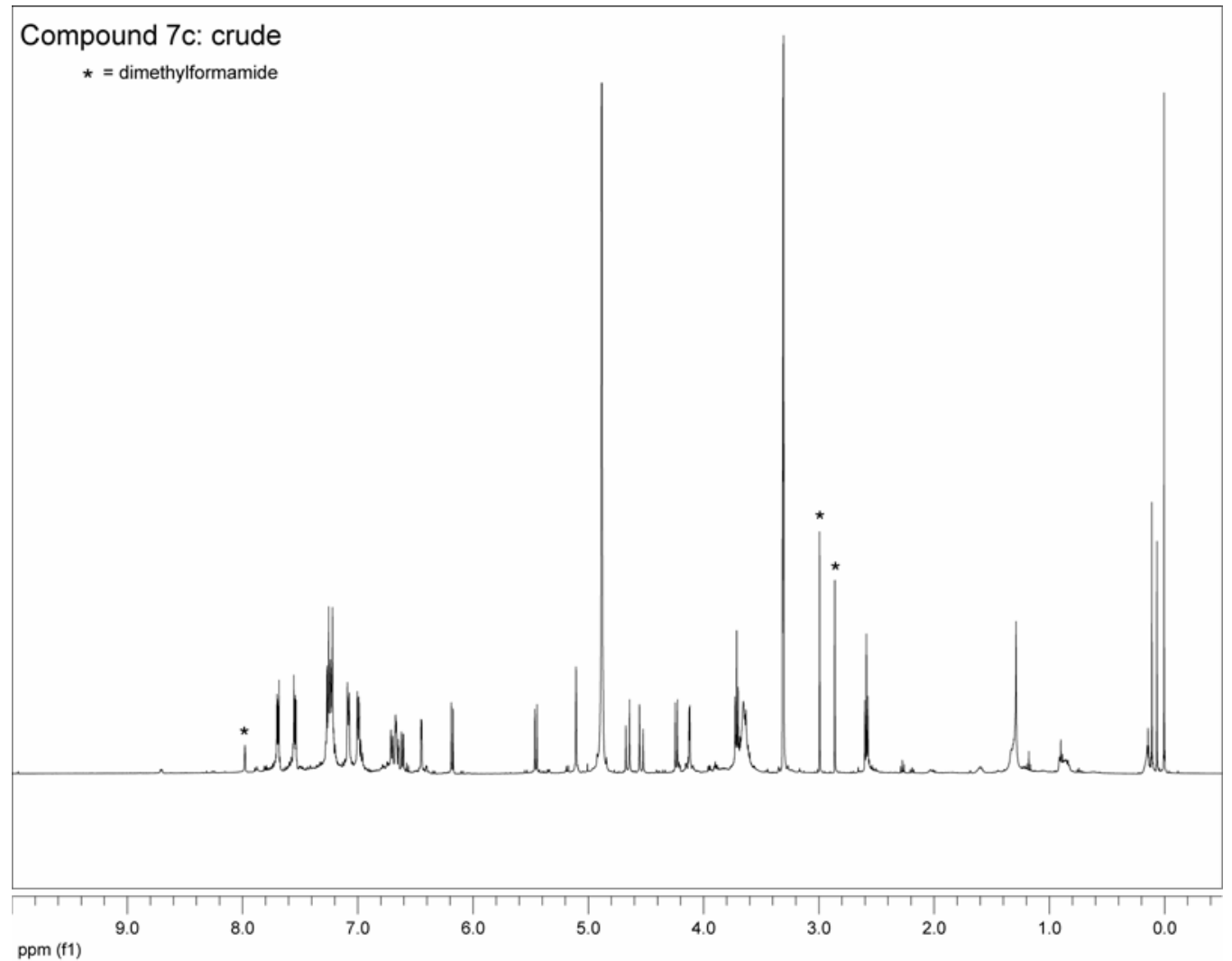

Compound 7c: purified

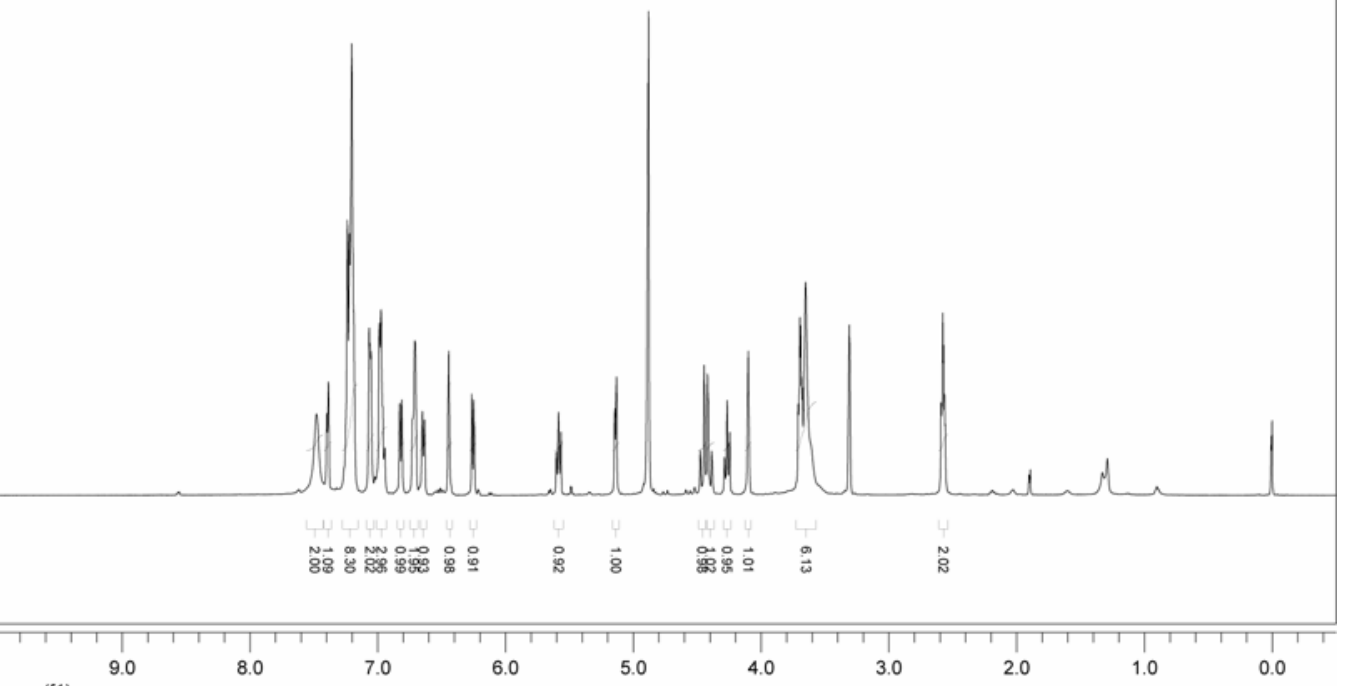

ppm (f1) 


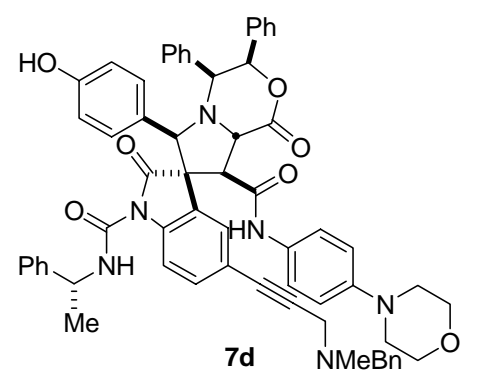

7d. Purification: Reverse phase flash chromatography $\left(0.1 \% \quad \mathrm{HCO}_{2} \mathrm{H} / 64.9 \%\right.$ water $/ 35 \%$ acetonitrile $) \rightarrow 0.1 \% / 59.9 \% / 40 \%) .{ }^{1} \mathrm{H}$ NMR $\left(500 \mathrm{MHz}, \mathrm{CD}_{3} \mathrm{CN}\right): \delta 1.57(\mathrm{~d}, 3 \mathrm{H}, J=6.8), 2.25(\mathrm{~s}, 3 \mathrm{H})$, $3.01(\mathrm{t}, 4 \mathrm{H}, J=4.9), 3.39(\mathrm{~s}, 2 \mathrm{H}), 3.53(\mathrm{~s}, 2 \mathrm{H}), 3.72(\mathrm{t}, 4 \mathrm{H}, J=4.9), 4.14(\mathrm{~d}, 1 \mathrm{H}, J=2.9), 4.50(\mathrm{~d}, 1 \mathrm{H}, J$ $=10.3$ ), 5.02 (quintet, $1 \mathrm{H}, J=7.0), 5.14(\mathrm{~s}, 1 \mathrm{H}), 5.48(\mathrm{~d}, 1 \mathrm{H}, J=10.3), 6.41-6.45(\mathrm{~m}, 3 \mathrm{H}), 6.80-6.86$ (m, 4H), $6.96(\mathrm{~d}, 2 \mathrm{H}, J=6.8), 7.07-7.10(\mathrm{~m}, 2 \mathrm{H}), 7.14-7.35(\mathrm{~m}, 15 \mathrm{H}), 7.39-7.45(\mathrm{~m}, 5 \mathrm{H}), 7.79(\mathrm{~d}, 1 \mathrm{H}$, $J=8.3), 8.91(\mathrm{~d}, 1 \mathrm{H}, J=7.3), 9.54(\mathrm{~s}, 1 \mathrm{H}) .{ }^{13} \mathrm{C} \mathrm{NMR}\left(101 \mathrm{MHz}, \mathrm{CD}_{3} \mathrm{CN}\right): \delta 23.0,42.2,46.2,50.2$, 51.0, 57.5, 57.9, 60.7, 61.8, 62.5, 67.4, 74.8, 78.5, 85.66, 85.72, 115.7, 116.1, 116.7, 119.5, 122.1, 125.7, $126.8,127.4,128.1,128.3,128.8,128.89,128.95,129.21,129.24,129.5,129.7,130.0,131.0,133.1$, $136.7,137.0,139.9,141.3,145.1,149.6,151.3,158.1,165.7,174.0,178.9 . \operatorname{HRMS}_{-E^{+}}{ }^{+}(m / z):[M+$ $\mathrm{H}]^{+}$calcd for $\mathrm{C}_{63} \mathrm{H}_{59} \mathrm{~N}_{6} \mathrm{O}_{7}, 1011.4445$; found, 1011.4421 . 
IV. Reaction Survey and Building Block Selection
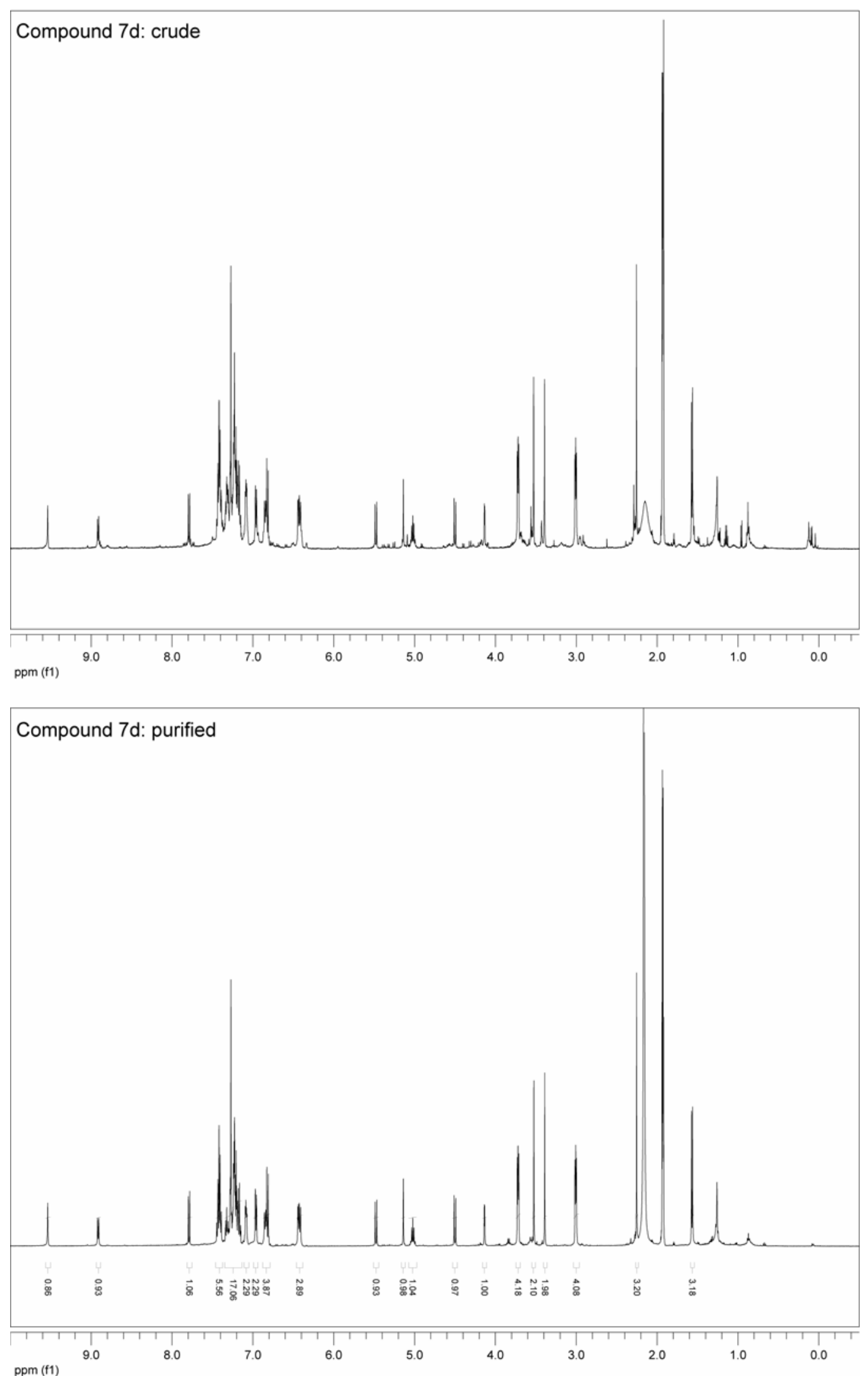


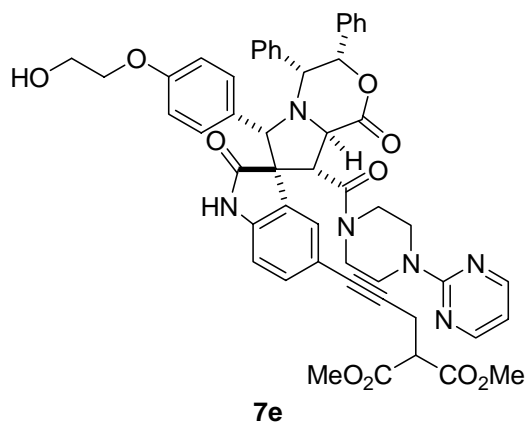

7e. Purification: Flash chromatography (65/35 EtOAc/hexanes $\rightarrow$ 100/0). ${ }^{1} \mathrm{H}$ NMR $(500 \mathrm{MHz}$, $\left.\mathrm{CD}_{3} \mathrm{CN}\right): \delta 2.85-2.93(\mathrm{~m}, 1 \mathrm{H}), 2.90(\mathrm{~d}, 2 \mathrm{H}, J=7.8), 3.07(\mathrm{ddd}, 1 \mathrm{H}, J=3.4,8.3,13.2), 3.19(\mathrm{ddd}, 1 \mathrm{H}, J$ $=3.1,8.5,13.0), 3.35(\mathrm{ddd}, 1 \mathrm{H}, J=3.3,8.1,13.2), 3.43-3.49(\mathrm{~m}, 2 \mathrm{H}), 3.60-3.71(\mathrm{~m}, 12 \mathrm{H}), 3.84(\mathrm{ddd}$, $1 \mathrm{H}, J=3.5,5.5,13.1), 3.94(\mathrm{ddd}, 1 \mathrm{H}, J=3.3,5.2,13.0), 4.14(\mathrm{~d}, 1 \mathrm{H}, J=3.4), 4.51(\mathrm{~d}, 1 \mathrm{H}, J=8.3)$, $5.16(\mathrm{~s}, 1 \mathrm{H}), 5.48(\mathrm{~d}, 1 \mathrm{H}, J=8.8), 6.36(\mathrm{~d}, 1 \mathrm{H}, J=3.4), 6.54(\mathrm{~d}, 1 \mathrm{H}, J=7.8), 6.57(\mathrm{t}, 1 \mathrm{H}, J=4.6), 6.64-$ $6.72(\mathrm{~m}, 3 \mathrm{H}), 6.99-7.04(\mathrm{~m}, 4 \mathrm{H}), 7.07-7.10(\mathrm{~m}, 2 \mathrm{H}), 7.18-7.27(\mathrm{~m}, 7 \mathrm{H}), 8.30(\mathrm{~d}, 2 \mathrm{H}, J=4.9), 8.65$ (s, 1H). ${ }^{13} \mathrm{C}$ NMR $\left(101 \mathrm{MHz}, \mathrm{CD}_{3} \mathrm{CN}\right): \delta 19.9,43.2,44.3,45.1,46.2,51.4,51.8,53.4,60.7,61.2,62.2$, $62.4,70.3,76.7,77.8,83.0,85.5,110.4,111.5,116.6,121.2,126.6,126.8,128.69,128.70,129.1,129.3$, 129.7, 130.0, 132.5, 133.1, 137.3, 137.59, 137.65, 141.8, 158.8, 159.5, 162.6, 166.4, 169.5, 172.0, 177.0. HRMS-ESI ${ }^{+}(\mathrm{m} / \mathrm{z}):[\mathrm{M}+\mathrm{H}]^{+}$calcd for $\mathrm{C}_{51} \mathrm{H}_{49} \mathrm{~N}_{6} \mathrm{O}_{10}, 905.3510$; found, 905.3513 . 
IV. Reaction Survey and Building Block Selection

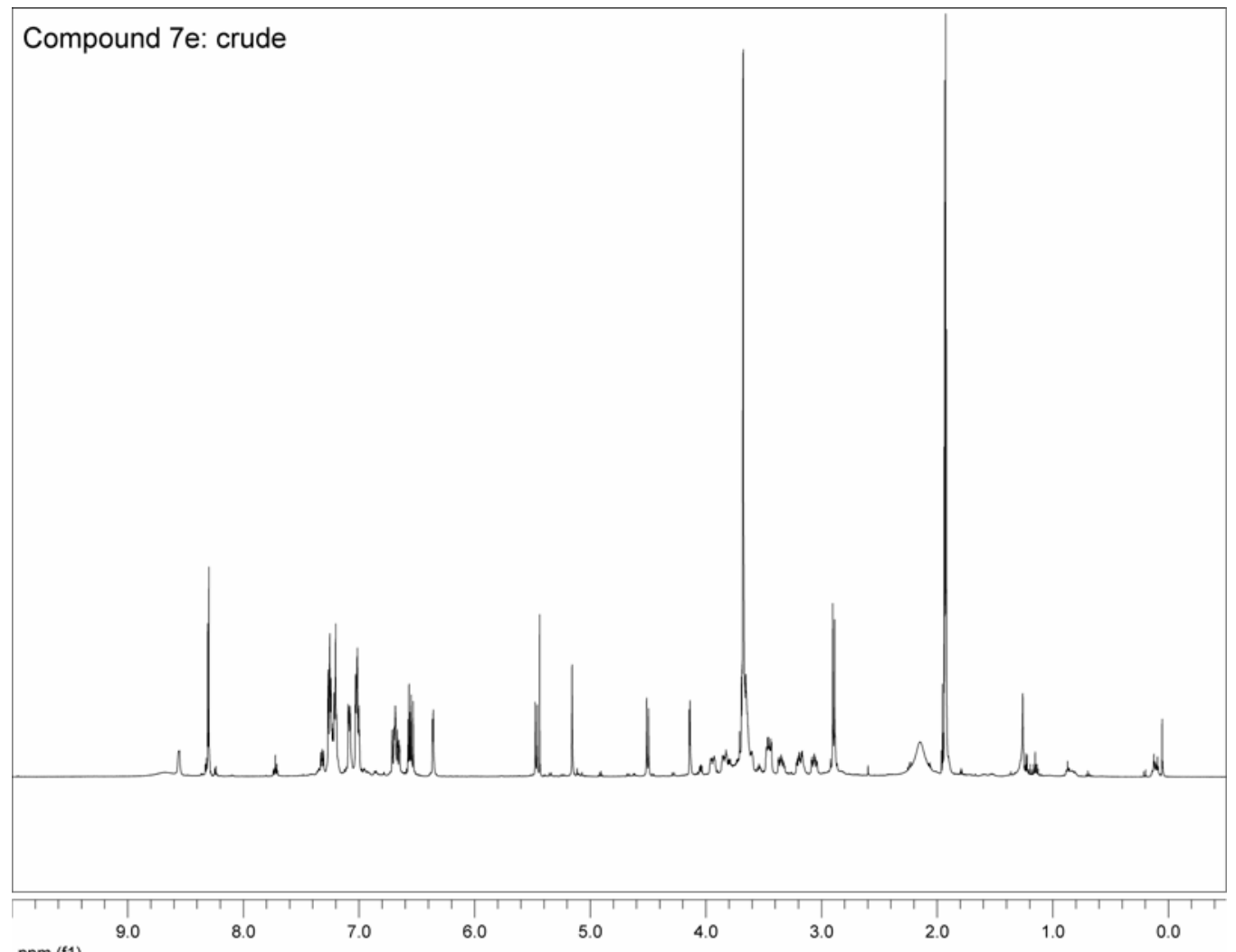

ppm (f1)

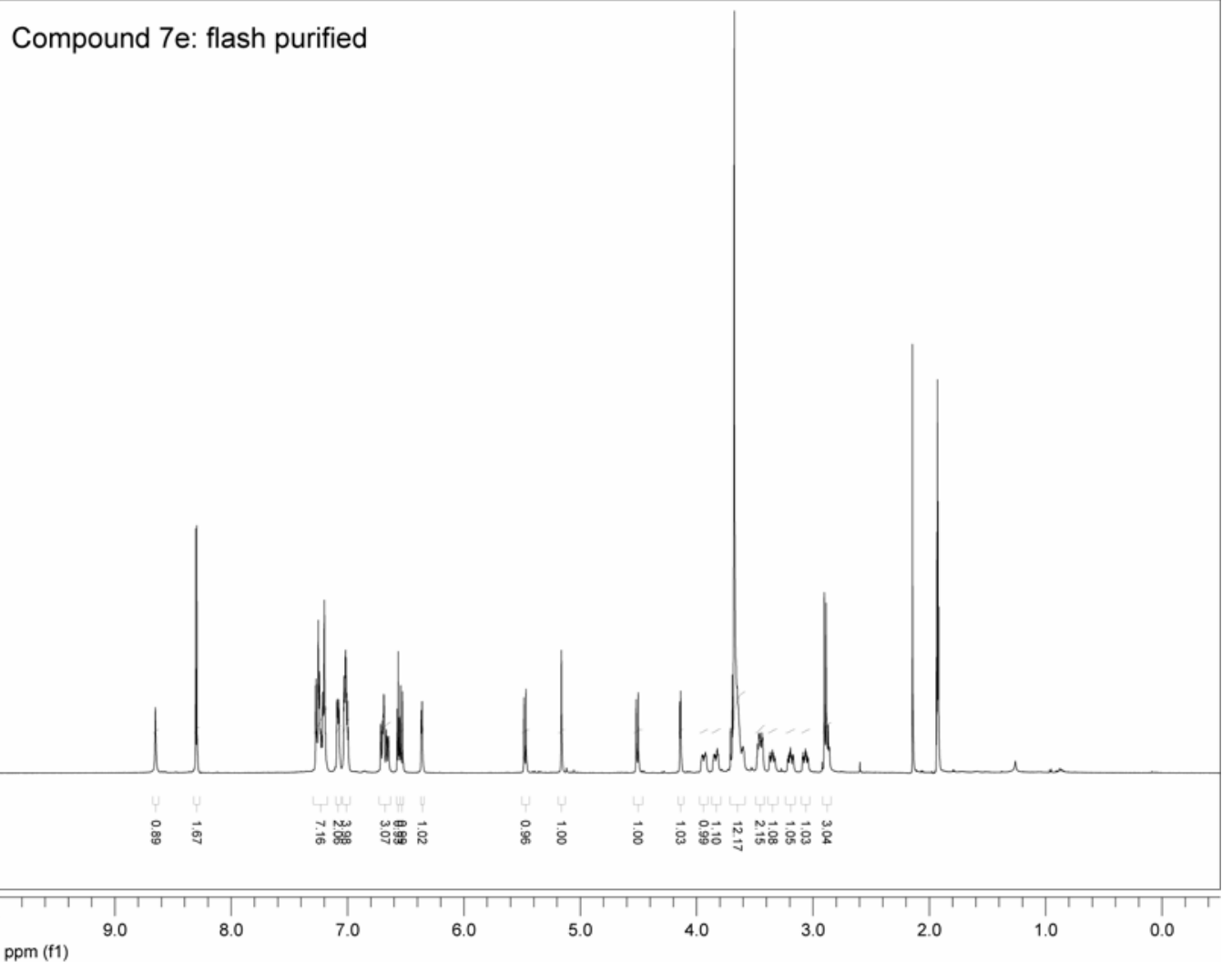


IV. Reaction Survey and Building Block Selection

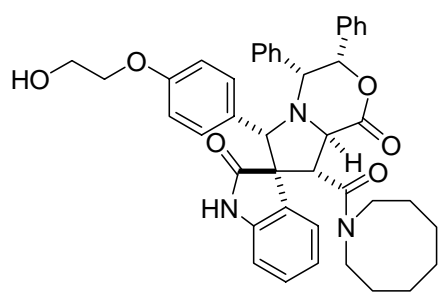

$7 f$

7f. Purification: Flash chromatography $\left(0.1 / 20 / 79.9 \mathrm{NEt} / \mathrm{EtOAc} / \mathrm{CH}_{2} \mathrm{Cl}_{2}\right)$, followed by HPLC (40/60 acetonitrile/water). ${ }^{1} \mathrm{H}$ NMR (500 MHz, $\left.\mathrm{CD}_{3} \mathrm{CN}\right): \delta 1.08-1.16(\mathrm{~m}, 1 \mathrm{H}), 1.24-1.72(\mathrm{~m}, 9 \mathrm{H}), 2.91$ (t, 1H, J=5.9), 2.96-3.02 (m, 1H), 3.15-3.22 (m, 2H), 3.46-3.52 (m, 1H), $3.70(\mathrm{t}, 2 \mathrm{H}, J=4.6), 3.85(\mathrm{t}$, $2 \mathrm{H}, J=4.6), 4.13(\mathrm{~d}, 1 \mathrm{H}, J=3.4), 4.36(\mathrm{~d}, 1 \mathrm{H}, J=8.3), 5.03$ (s, $1 \mathrm{H}), 5.37(\mathrm{~d}, 1 \mathrm{H}, J=8.3), 6.35(\mathrm{~d}, 1 \mathrm{H}$, $J=3.4), 6.57(\mathrm{~d}, 1 \mathrm{H}, J=7.8), 6.62(\mathrm{~d}, 2 \mathrm{H}, J=8.3), 6.85(\mathrm{dt}, 1 \mathrm{H}, J=1.0,7.6), 7.01(\mathrm{dt}, 1 \mathrm{H}, J=1.1,7.7)$, 7.04-7.10 (m, 6H), 7.18-7.24 (m, 6H), $7.37(\mathrm{~d}, 1 \mathrm{H}, J=7.3), 8.52(\mathrm{~s}, 1 \mathrm{H}) .{ }^{13} \mathrm{C}$ NMR $(101 \mathrm{MHz}$ $\left.\mathrm{CD}_{3} \mathrm{CN}\right): \delta 24.4,26.6,26.9,27.4,27.8,47.8,49.5,52.1,61.16,61.25,61.3,62.6,70.3,76.8,77.4,109.9$, 114.6, 122.0, 126.6, 127.6, 128.58, 128.60, 129.20, 129.23, 129.3, 129.8, 130.0, 130.4, 137.56, 137.62, 141.8, 159.9, 167.5, 172.6, 177.6. HRMS-ESI ${ }^{+}(\mathrm{m} / \mathrm{z}):[\mathrm{M}+\mathrm{H}]^{+}$calcd for $\mathrm{C}_{42} \mathrm{H}_{44} \mathrm{~N}_{3} \mathrm{O}_{6}, 686.3230$; found, 686.3239. 
IV. Reaction Survey and Building Block Selection

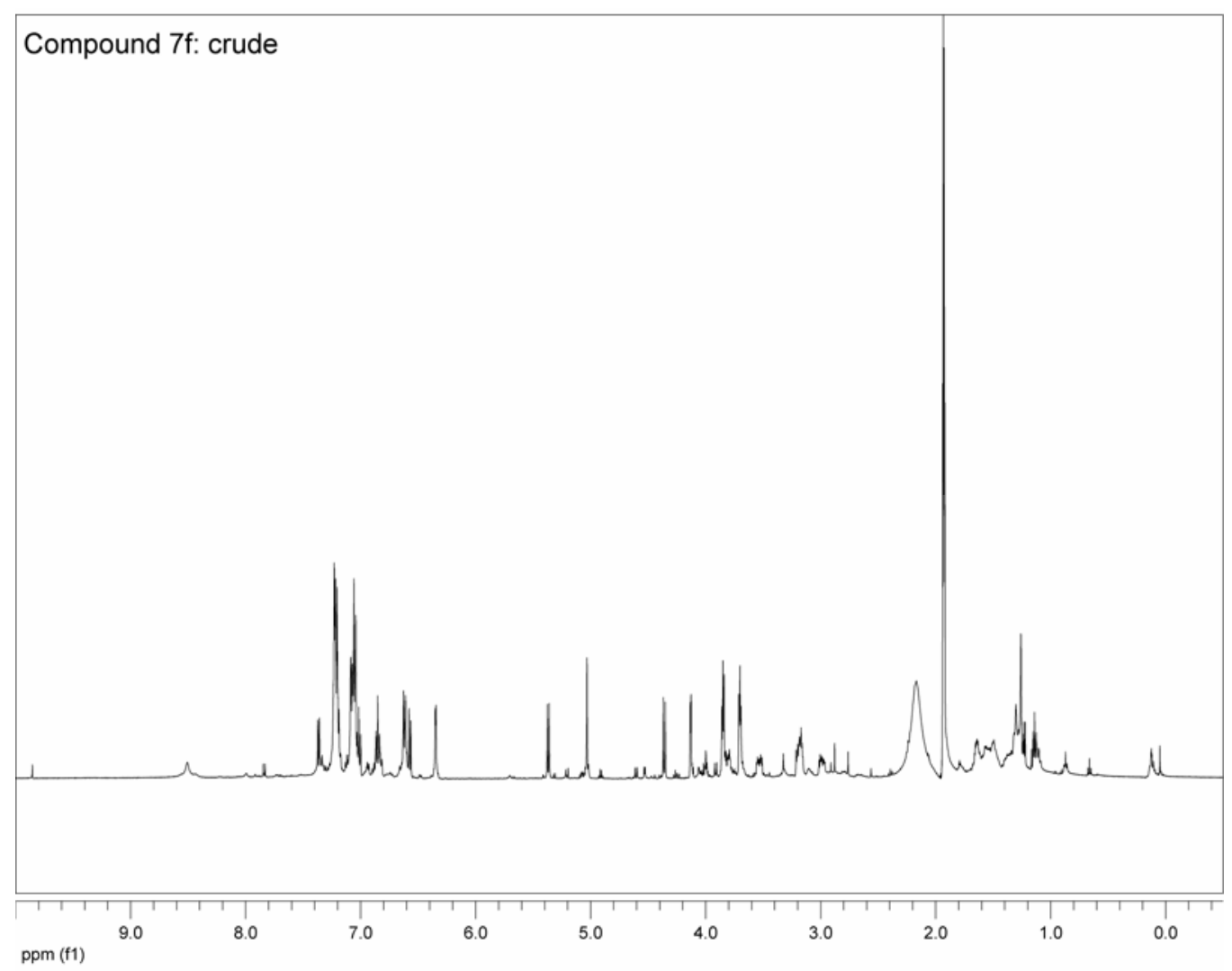

Compound 7f: purified






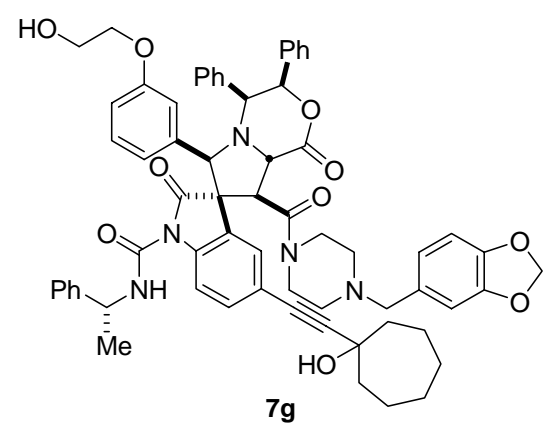

7g. Purification: Flash chromatography (50/50 EtOAc/hexanes $\rightarrow 67 / 33) .{ }^{1} \mathrm{H}$ NMR $(500 \mathrm{MHz}$, $\left.\mathrm{CD}_{3} \mathrm{CN}\right): \delta 1.47-1.71(\mathrm{~m}, 12 \mathrm{H}), 1.79-1.84(\mathrm{~m}, 3 \mathrm{H}), 1.95-2.00(\mathrm{~m}, 2 \mathrm{H}), 2.34-2.37$ (m br, $\left.1 \mathrm{H}\right), 2.49-2.52$ (m br, $1 \mathrm{H}), 3.06-3.11(\mathrm{~m} \mathrm{br}, 2 \mathrm{H}), 3.24(\mathrm{~d}, 1 \mathrm{H}, J=12.7), 3.34$ (d, $1 \mathrm{H}, J=13.2), 3.37-3.58(\mathrm{~m}, 8 \mathrm{H}), 4.20$ (d, $1 \mathrm{H}, J=3.4), 4.59(\mathrm{~d}, 1 \mathrm{H}, J=8.3$ ), 5.03 (quintet, $1 \mathrm{H}, J=7.0), 5.22(\mathrm{~s}, 1 \mathrm{H}), 5.47$ (d, $1 \mathrm{H}, J=8.3), 5.92$ (dd, 2H, $J=1.5,2.9), 6.35(\mathrm{~d}, 1 \mathrm{H}, J=3.4), 6.58(\mathrm{~s} \mathrm{br}, 1 \mathrm{H}), 6.60-6.64(\mathrm{~m}, 2 \mathrm{H}), 6.69$ (dd, $1 \mathrm{H}, J=1.5$, 7.8), $6.76(\mathrm{~d}, 1 \mathrm{H}, J=7.8), 6.78$ (d, 1H, $J=1.5), 6.94$ (t, $1 \mathrm{H}, J=7.8), 7.07$ (dd, $2 \mathrm{H}, J=1.7,7.6), 7.10$ (dd, $2 \mathrm{H}, J=2.0,7.3), 7.13(\mathrm{dd}, 1 \mathrm{H}, J=1.7,8.5), 7.18-7.27(\mathrm{~m}, 6 \mathrm{H}), 7.29-7.33(\mathrm{~m}, 1 \mathrm{H}), 7.38-7.44(\mathrm{~m}$, $5 \mathrm{H}), 7.73(\mathrm{~d}, 1 \mathrm{H}, J=8.8), 8.80(\mathrm{~d}, 1 \mathrm{H}, J=7.3) .{ }^{13} \mathrm{C} \mathrm{NMR}\left(101 \mathrm{MHz}, \mathrm{CD}_{3} \mathrm{CN}\right): \delta 23.06,23.13,28.7$, $43.6,43.8,43.9,46.7,51.1,51.2,53.5,54.0,60.5,61.2,61.6,62.8,63.4,70.2,72.2,77.6,78.1,83.0$, $95.8,101.2,102.2,108.7,110.1,116.1,119.3,120.9,123.1,125.3,126.8,126.9,128.4,128.8,129.2$ $129.4,129.7,130.2,132.1,132.8,133.0,136.7,137.2,137.5,140.4,144.7,147.7,148.7,150.8,159.6$, 165.7, 171.9, 179.0. HRMS-ESI ${ }^{+}(\mathrm{m} / \mathrm{z}):[\mathrm{M}+\mathrm{H}]^{+}$calcd for $\mathrm{C}_{65} \mathrm{H}_{66} \mathrm{~N}_{5} \mathrm{O}_{10}, 1076.4810$; found, 1076.4817. 
IV. Reaction Survey and Building Block Selection
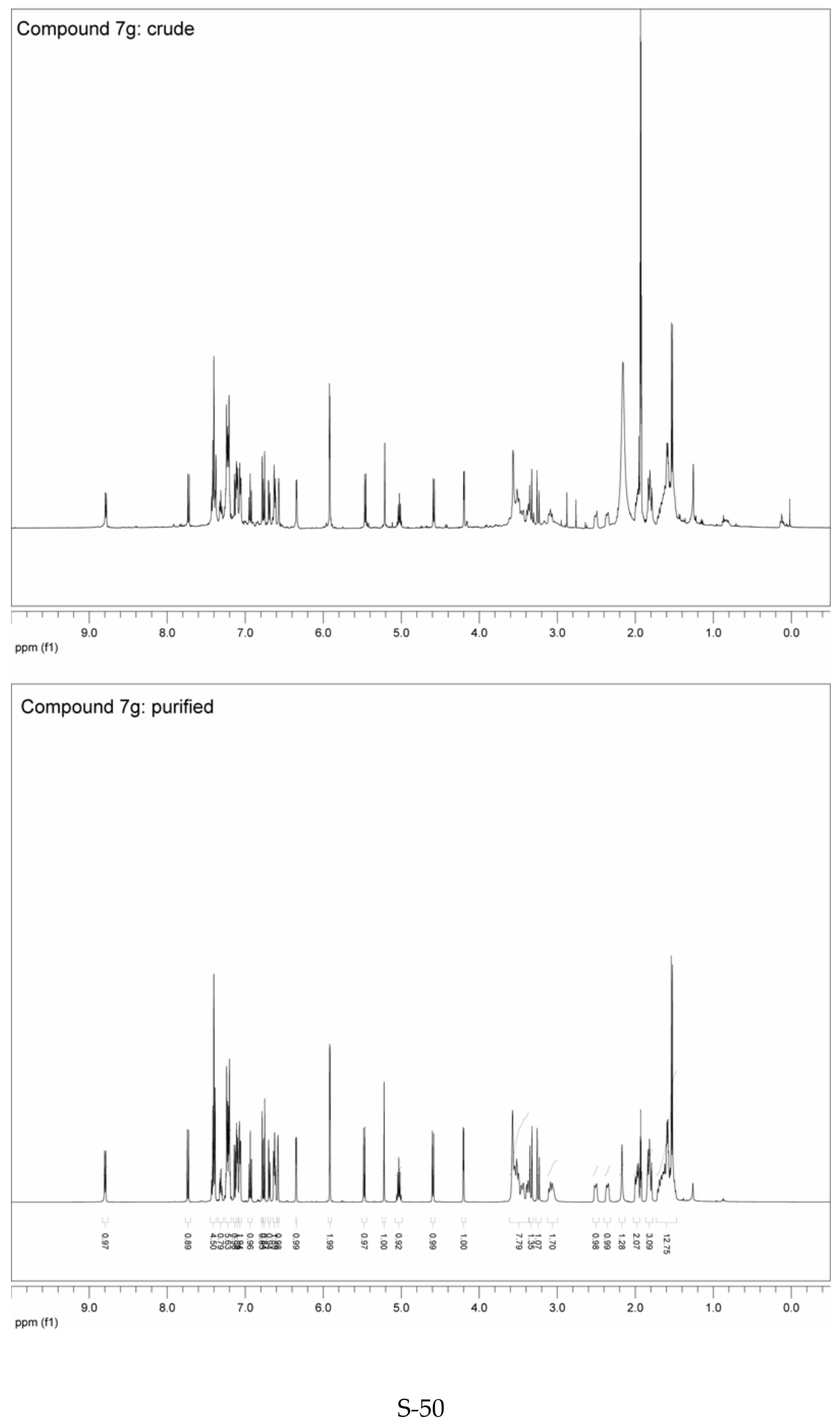


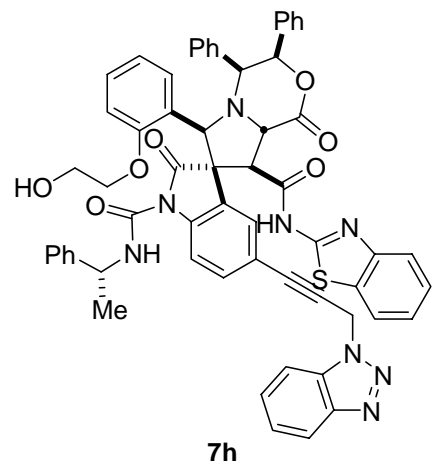

7h. Purification: Flash chromatography (40/60 EtOAc/hexanes $\rightarrow 55 / 45)$, followed by HPLC (80/20 acetonitrile/water). ${ }^{1} \mathrm{H}$ NMR (500 MHz, $\mathrm{CD}_{3} \mathrm{CN}$ ): $\delta 1.59$ (d, 3H, J=7.3), 2.98 (t, 1H, J=6.3), 3.57-3.62 (m br, 2H), 3.71-3.75 (m, 1H), 3.79-3.83 (m, 1H), $4.11(\mathrm{~d}, 1 \mathrm{H}, J=2.9), 4.75(\mathrm{~d}, 1 \mathrm{H}, J=10.3)$, 5.05 (quintet, $1 \mathrm{H}, J=7.0), 5.58$ (d, 1H, $J=10.3), 5.61$ (m, 2H), 5.65 (s, 1H), 6.39 (t, 1H, J=7.3), 6.42 (d, $1 \mathrm{H}, J=2.9), 6.71(\mathrm{~d}, 1 \mathrm{H}, J=8.3), 6.88$ (d, 2H, $J=7.8), 6.93$ (d, 1H, $J=7.8), 6.99$ (dt, 1H, $J=1.5,7.9), 7.04-$ $7.06(\mathrm{~m}, 2 \mathrm{H}), 7.12(\mathrm{dd}, 1 \mathrm{H}, J=1.5,8.8), 7.16(\mathrm{~m}, 2 \mathrm{H}), 7.23-7.27$ (m, 6H), 7.29-7.47 (m, 9H), 7.74 (d, $1 \mathrm{H}, J=8.3), 7.77-7.81(\mathrm{~m}, 3 \mathrm{H}), 7.99(\mathrm{~d}, 1 \mathrm{H}, J=7.8), 8.72(\mathrm{~d}, 1 \mathrm{H}, J=6.8) .{ }^{13} \mathrm{C}$ NMR $\left(101 \mathrm{MHz}, \mathrm{CD}_{3} \mathrm{CN}\right)$ : $\delta 22.7,39.6,51.3,57.4,58.5,61.1,61.5,63.0,68.8,72.0,79.9,82.6,86.0,111.5,113.6,116.3,120.6$, $121.3,122.8,124.2,125.28,125.33,127.3,127.4,127.5,128.6,128.7,129.10,129.11,129.3,129.4$ $129.5,129.67,129.71,129.9,130.6,133.1,133.7,136.5,136.9,142.5,144.9,147.1,151.4,158.5,174.6$ 178.9. HRMS-ESI ${ }^{+}(\mathrm{m} / \mathrm{z})$ : $[\mathrm{M}+\mathrm{H}]^{+}$calcd for $\mathrm{C}_{60} \mathrm{H}_{49} \mathrm{~N}_{8} \mathrm{O}_{7} \mathrm{~S}, 1025.3445$; found, 1025.3457 . 
IV. Reaction Survey and Building Block Selection
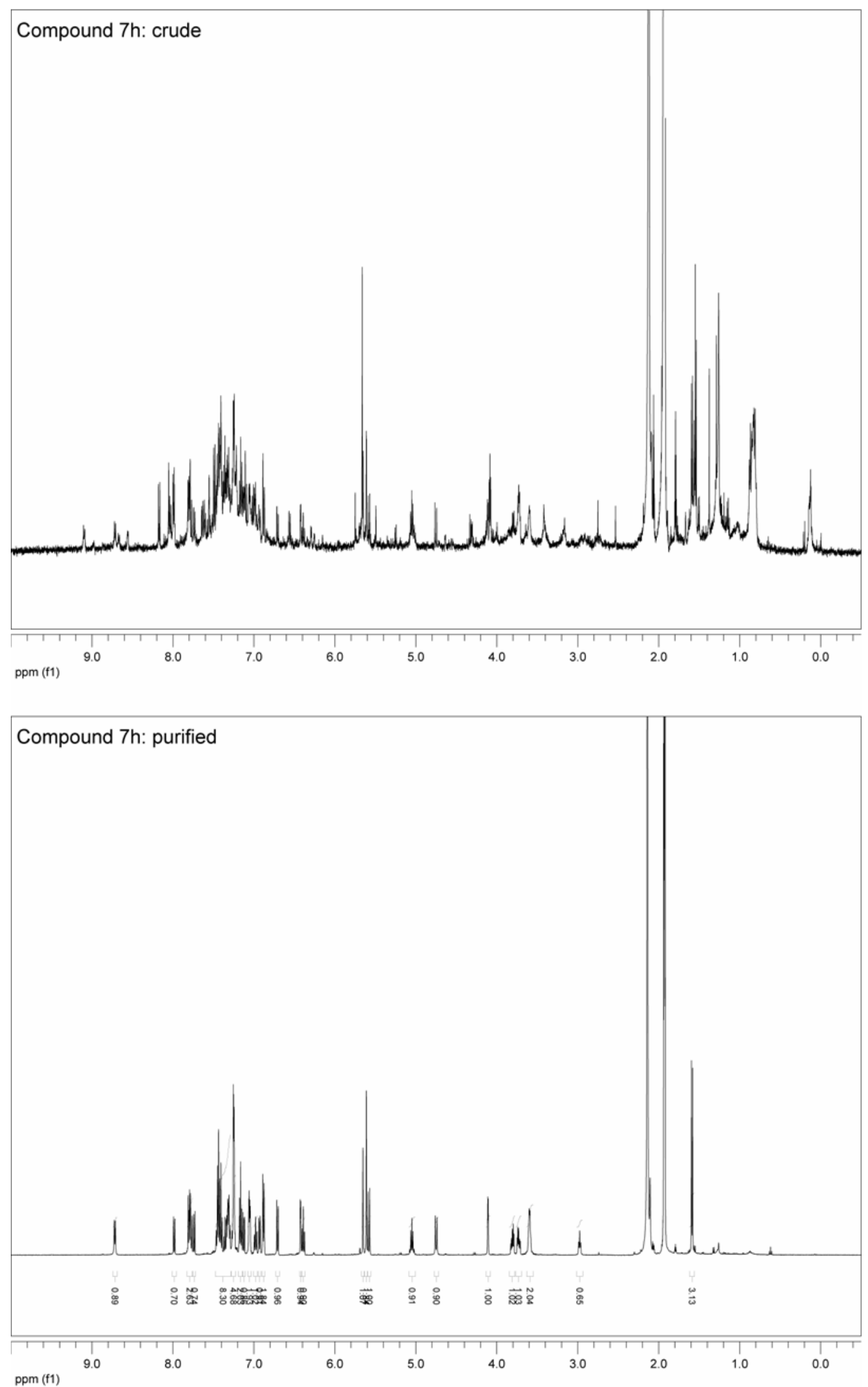


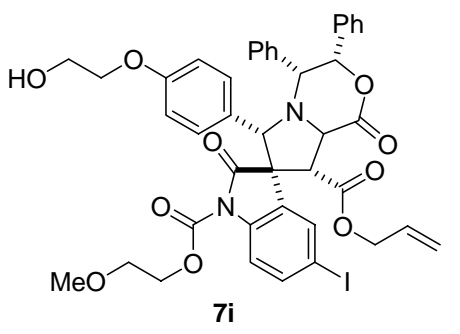

7i. Purification: Flash chromatography (67/33 EtOAc/hexanes), followed by flash chromatography (2/98 $\mathrm{i}-\mathrm{PrOH} / \mathrm{CH}_{2} \mathrm{Cl}_{2} \rightarrow$ 4/96). ${ }^{1} \mathrm{H}$ NMR (500 MHz, $\left.\mathrm{CD}_{3} \mathrm{CN}\right): \delta 2.91(\mathrm{t}, 1 \mathrm{H}, J=5.9), 3.35(\mathrm{~s}, 3 \mathrm{H}), 3.66$ (t, 2H, $J=4.4), 3.75(\mathrm{q}, 2 \mathrm{H}, J=4.9), 3.91(\mathrm{t}, 2 \mathrm{H}, J=4.6), 4.16-4.20(\mathrm{~m}, 4 \mathrm{H}), 4.44(\mathrm{t}, 2 \mathrm{H}, J=4.4)$, 4.97-5.02 (m, 3H), 5.13 (s, 1H), 5.30 (tdd, $1 \mathrm{H}, J=6.2,10.4,17.0), 6.33$ (d, 1H, $J=2.9), 6.70$ (d, 2H, $J$ $=8.8), 7.01(\mathrm{~d}, 2 \mathrm{H}, J=8.8), 7.08-7.28(\mathrm{~m}, 10 \mathrm{H}), 7.39(\mathrm{~d}, 1 \mathrm{H}, J=8.8), 7.56(\mathrm{~d}, 1 \mathrm{H}, J=2.0), 7.59(\mathrm{dd}$, $1 \mathrm{H}, J=2.0,8.8) .{ }^{13} \mathrm{C} \mathrm{NMR}\left(101 \mathrm{MHz}, \mathrm{CD}_{3} \mathrm{CN}\right): \delta 55.7,57.6,59.1,60.4,61.3,62.0,67.0,67.5,70.5$, $70.7,75.5,77.7,87.9,115.3,117.8,119.8,126.2,126.5,127.9,128.7,128.9,129.3,129.5,129.9,130.1$, $131.9,135.7,137.1,137.2,139.2,140.3,150.7,160.4,168.5,171.4,173.5 . \operatorname{HRMS}^{-E_{S I}}{ }^{+}(\mathrm{m} / \mathrm{z}):[\mathrm{M}+$ $\mathrm{H}]^{+}$calcd for $\mathrm{C}_{42} \mathrm{H}_{40} \mathrm{IN}_{2} \mathrm{O}_{10}, 859.1727$; found, 859.1713. 
IV. Reaction Survey and Building Block Selection
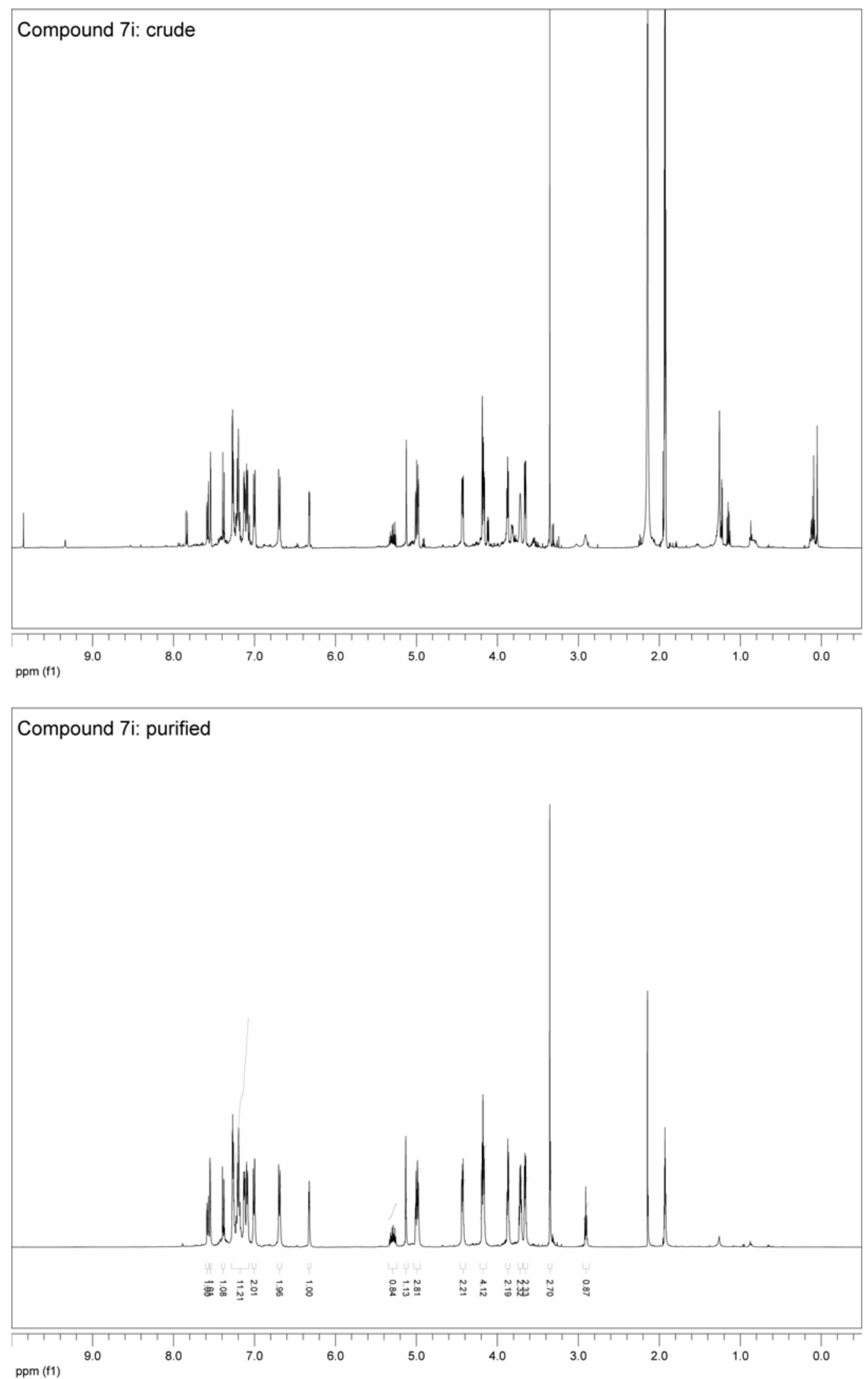


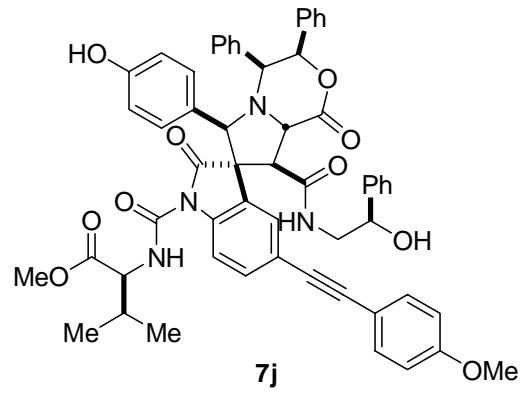

7j. Purification: Flash chromatography (20/80 EtOAc/hexanes $\rightarrow$ 50/50), followed by HPLC (70/30 acetonitrile/water). ${ }^{1} \mathrm{H}$ NMR $\left(500 \mathrm{MHz}, \mathrm{CD}_{3} \mathrm{CN}\right): \delta 1.00(\mathrm{~d}, 3 \mathrm{H}, J=6.8), 1.01(\mathrm{~d}, 3 \mathrm{H}, J=6.8), 2.29(\mathrm{~d}$ sept, $1 \mathrm{H}, J=4.9,6.8$ ), 3.24 (ddd, $1 \mathrm{H}, J=5.9,7.3,13.2$ ), 3.32 (ddd, $1 \mathrm{H}, J=4.4,5.9,13.7$ ), 3.6 (s br, $1 \mathrm{H}), 3.74(\mathrm{~s}, 3 \mathrm{H}), 3.81(\mathrm{~s}, 3 \mathrm{H}), 4.12(\mathrm{~d}, 1 \mathrm{H}, J=3.4), 4.32(\mathrm{~d}, 1 \mathrm{H}, J=9.8), 4.48(\mathrm{dd}, 1 \mathrm{H}, J=4.6,8.1)$, 4.57 (dd, $1 \mathrm{H}, J=4.9,6.3), 5.10$ (s, $1 \mathrm{H}), 5.13$ (d, $1 \mathrm{H}, J=10.3), 6.41$ (d, 1H, $J=2.9), 6.48$ (d, 2H, $J=$ 8.3), $6.85(\mathrm{~d}, 2 \mathrm{H}, J=7.8), 6.95(\mathrm{~d}, 2 \mathrm{H}, J=8.8), 6.97(\mathrm{~d}, 2 \mathrm{H}, J=7.3), 7.07-7.10(\mathrm{~m}, 2 \mathrm{H}), 7.21-7.32(\mathrm{~m}$, 12H), $7.41(\mathrm{~d}, 1 \mathrm{H}, J=1.5), 7.44(\mathrm{~d}, 2 \mathrm{H}, J=8.8), 7.85(\mathrm{~d}, 1 \mathrm{H}, J=8.3), 7.89(\mathrm{t}, 1 \mathrm{H}, J=5.9), 9.01(\mathrm{~d}, 1 \mathrm{H}$, $J=7.8) .{ }^{13} \mathrm{C}$ NMR $\left(101 \mathrm{MHz}, \mathrm{CD}_{3} \mathrm{CN}\right): \delta 18.6,20.0,32.5,48.5,53.6,56.7,57.3,58.6,59.5,62.2,63.1$, $73.7,75.5,78.8,89.2,90.6,115.9,116.35,116.43,116.9,120.5,126.2,127.3,127.5,128.2,129.0$, $129.3,129.4,129.5,129.8,129.85,129.95,130.2,130.3,133.3,134.5,137.4,137.6,141.8,144.0,152.5$,

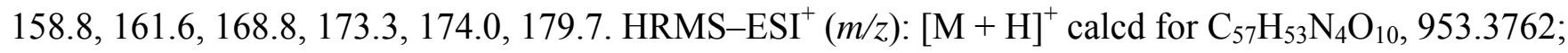
found, 953.3768 . 
IV. Reaction Survey and Building Block Selection

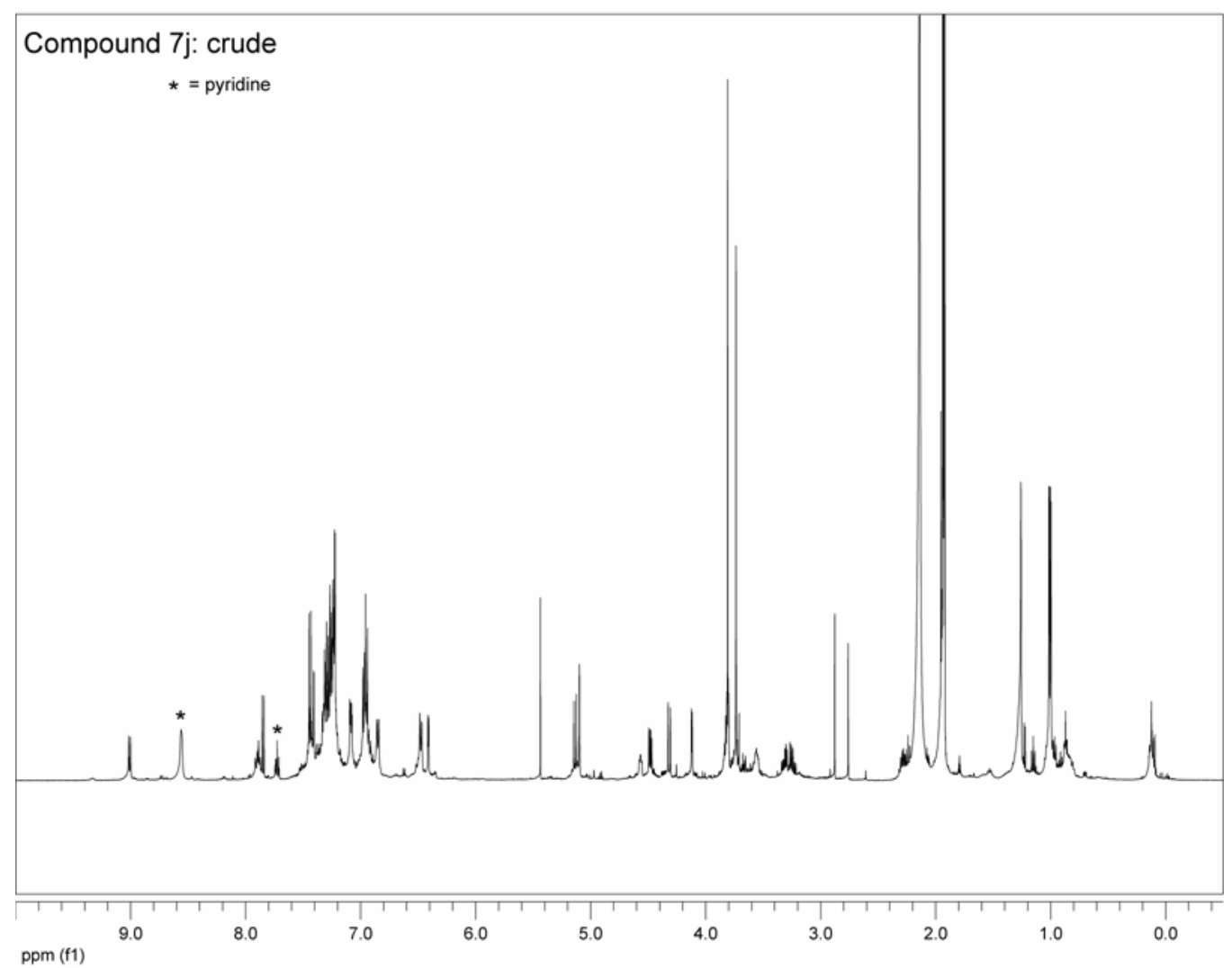

Compound 7j: purified

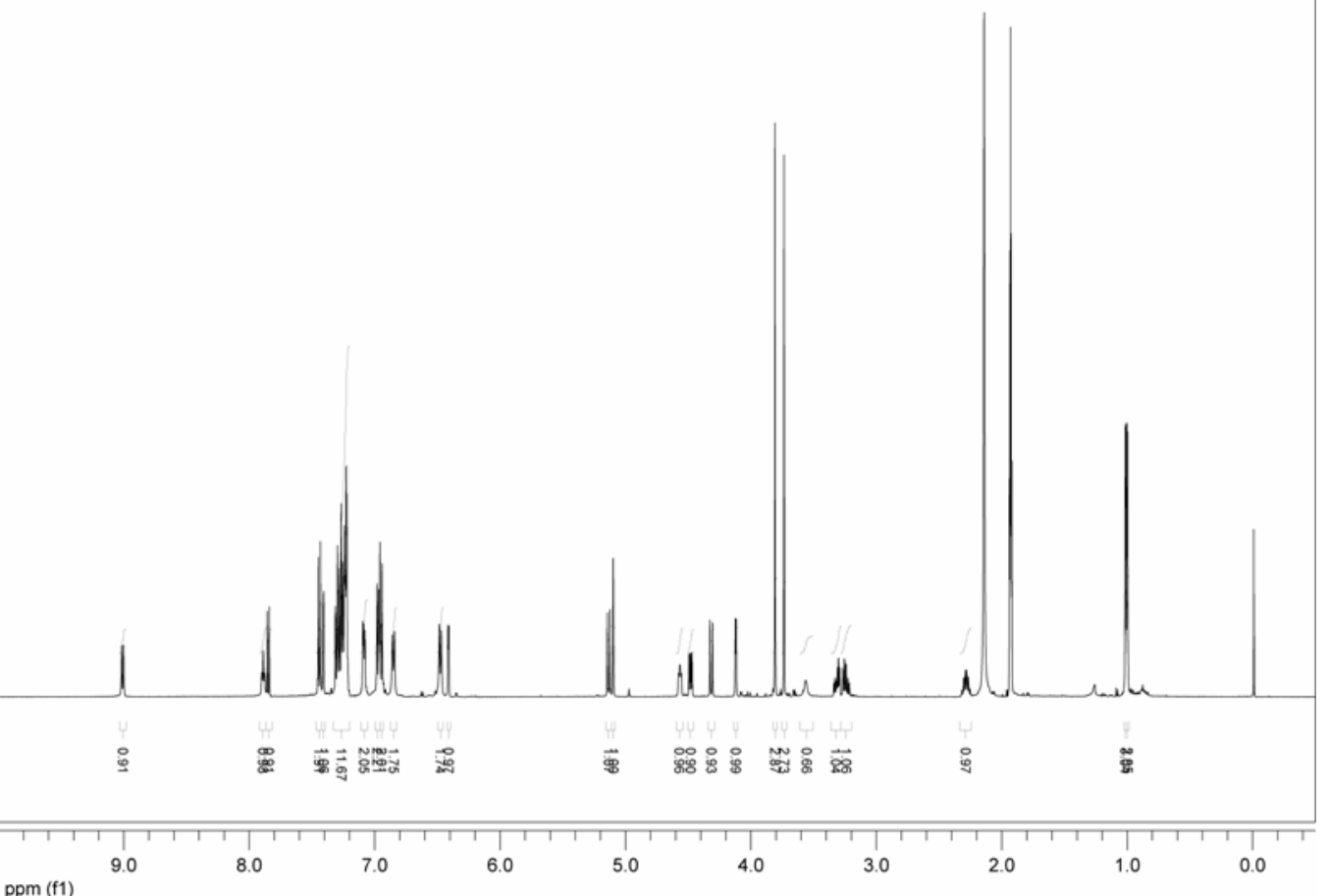

$\mathrm{ppm}(\mathrm{f1})$ 
IV. Reaction Survey and Building Block Selection

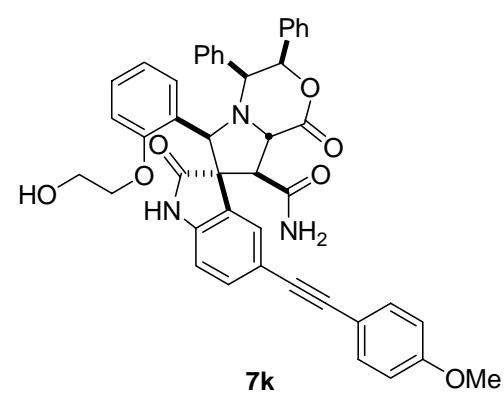

7k. Purification: Flash chromatography (EtOAc), followed by HPLC (23/77 i-PrOH/hexanes $\rightarrow$ 50/50). ${ }^{1} \mathrm{H}$ NMR (500 MHz, $\left.\mathrm{CD}_{3} \mathrm{CN}\right): \delta 3.8(\mathrm{~s}, 3 \mathrm{H}), 3.88-3.98(\mathrm{~m}, 3 \mathrm{H}), 4.00(\mathrm{~d}, 1 \mathrm{H}, J=2.9), 4.20(\mathrm{~d}$, $1 \mathrm{H}, J=10.7), 5.38(\mathrm{~d}, 1 \mathrm{H}, J=10.7), 5.55(\mathrm{~s}, 1 \mathrm{H}), 5.8(\mathrm{~s} \mathrm{br}, 2 \mathrm{H}), 6.34(\mathrm{~d}, 1 \mathrm{H}, J=2.9), 6.50(\mathrm{t}, 1 \mathrm{H}, J=$ 7.1), $6.63(\mathrm{~d}, 1 \mathrm{H}, J=7.8), 6.77(\mathrm{~d}, 1 \mathrm{H}, J=8.3), 6.87-6.95(\mathrm{~m}, 5 \mathrm{H}), 7.01-7.06(\mathrm{~m}, 3 \mathrm{H}), 7.11(\mathrm{dd}, 1 \mathrm{H}, J$ $=1.2,7.6), 7.14-7.26(\mathrm{~m}, 7 \mathrm{H}), 7.38(\mathrm{~d}, 1 \mathrm{H}, J=1.5), 7.43(\mathrm{td}, 2 \mathrm{H}, J=2.4,9.4), 8.8(\mathrm{~s} \mathrm{br}, 1 \mathrm{H}) .{ }^{13} \mathrm{C} \mathrm{NMR}$ $\left(101 \mathrm{MHz}, \mathrm{CD}_{3} \mathrm{CN}\right): \delta 56.1,56.8,59.5,61.1,61.7,63.4,69.2,71.5,78.7,88.9,89.0,110.6,111.9$ 115.3, 117.2, 118.3, 120.6, 124.4, 127.0, 128.7, 128.8, 129.0, 129.1, 129.2, 129.6, 129.9, 130.0, 130.1,

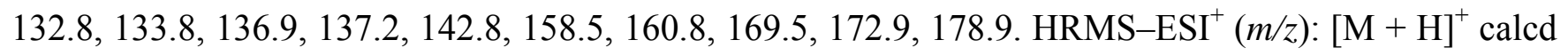
for $\mathrm{C}_{44} \mathrm{H}_{38} \mathrm{~N}_{3} \mathrm{O}_{7}, 720.2710$; found, 720.2717 . 
IV. Reaction Survey and Building Block Selection
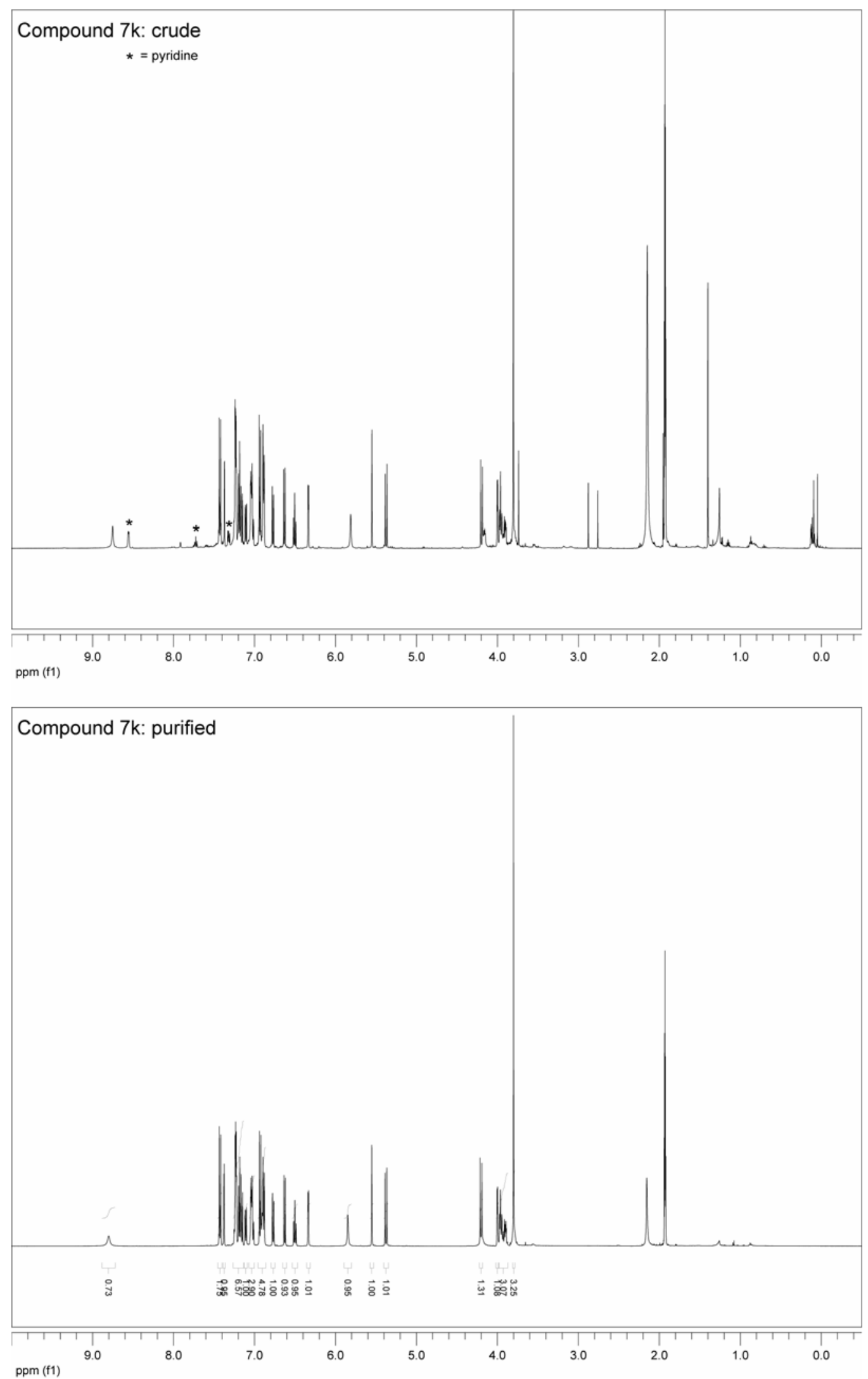

S-58 


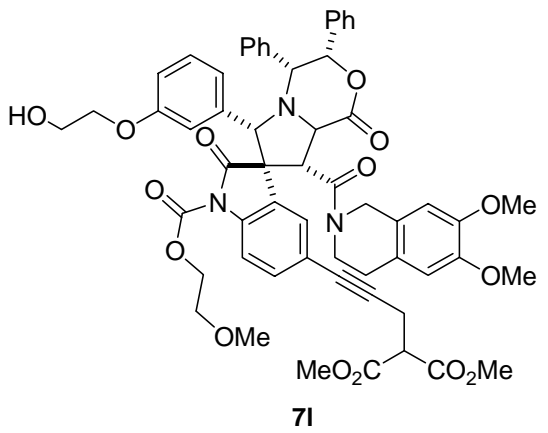

7l. Purification: Flash chromatography (80/20 EtOAc/hexanes $\rightarrow 100 / 0)$, followed by HPLC (60/40 acetonitrile/water). HPLC purified compound was $2.5: 1$ mix of conformational isomers (rotamers) in $\mathrm{CDCl}_{3}$. Peaks in proton spectra are assigned to the major $[\mathrm{A}]$ or minor [B] conformer when possible; integrations of unresolved muliplets are relative to the singlet at $4.96 \mathrm{ppm}$. Peaks in C13 spectra are not assigned to a particular conformer. ${ }^{1} \mathrm{H}$ NMR $\left(500 \mathrm{MHz}, \mathrm{CDCl}_{3}\right): \delta 1.72(\mathrm{ddd}, 1 \mathrm{H}$ [A], $J=5.4,11.7,16.6$ ), 2.07 (s br, 1.5H), 2.22-2.31 (m, 1H [A]), 2.57 (td, 1H [B], $J=5.4,16.1$ ), 2.77$2.88(\mathrm{~m}, 1.6 \mathrm{H}), 2.95-3.03(\mathrm{~m}, 3.3 \mathrm{H}), 3.37$ (s, 2H [A]), $3.42(\mathrm{~s}, 2 \mathrm{H}[\mathrm{B}]), 3.55-3.61$ (m, 2.4H), 3.66-3.76 (m, 12.7H), 3.77-3.84 (m, 10.7H), 3.89 (s, 3H [A]), 4.11 (d, 1H [B], J=17.1), 4.20-4.31 (m, 5.2H), 4.35 (d, 1H [A], J=16.6), 4.46-4.52 (m, 2.0H), 4.54 (d, 1H [A], J=6.3), 4.58 (d, 1H [B], J=7.8), 4.61 (d, 1H [B], J=17.1), 4.96 (s, 1H [A]), 5.04 (s, 1H [B]), 5.52 (d, 1H [B], J=7.8), 5.61 (d, 1H [A], J=6.3), 6.22 (d, 1H [A], J=3.4), 6.24 (d, 1H [B], J=3.4), 6.31 (s, 1H [A]), 6.46 (s, 1H [B]), 6.49 (s, 1H [A]), 6.54 (s, 1H [B]), 6.59-6.72 (m, 4.5H), 6.98 (t, 1H [A], J=7.8), 7.00-7.06 (m, 2.2H), 7.07-7.22 (m, 11.0H), 7.23-7.28 (m, 5.0H), $7.38(\mathrm{~d}, 1 \mathrm{H}[\mathrm{B}], J=8.8), 7.43(\mathrm{~s}, 1 \mathrm{H}[\mathrm{A}]), 7.54$ (s, 1H [B]). ${ }^{13} \mathrm{C}$ NMR (101 MHz, acetone- $\left.d_{6}\right)$ : $\delta 19.9,27.9,41.9,44.2,45.4,47.8,51.6,51.9,52.6,52.9,55.9,56.0,58.91,58.95,60.4,60.6,60.9,61.1$, $61.2,61.7,62.77,62.80,66.9,67.3,70.35,70.43,70.55,77.1,77.4,77.7,78.0,82.7,86.2,86.3,109.8$, 110.7, 112.7, 112.8, 113.3 (br), 114.75, 114.82, 117.2 (br), 119.0, 119.3, 120.7, 120.9 (br), 124.9, 125.0, $125.2,125.5,126.46,126.55,126.7,126.9,128.37,128.49,128.54,128.6,129.0,129.2,129.3,129.6$ 
IV. Reaction Survey and Building Block Selection

$129.8,129.9,132.1,132.5,132.8,133.0,136.3,136.8,137.3,137.43,137.46,137.52,139.3,139.4$ 148.6, 148.9, 149.05, 149.10, 149.5, 150.4, 159.7, 159.8, 165.7, 166.3, 169.2, 171.5, 172.1, 174.7, 175.2. HRMS-ESI ${ }^{+}(\mathrm{m} / \mathrm{z}):[\mathrm{M}+\mathrm{H}]^{+}$calcd for $\mathrm{C}_{58} \mathrm{H}_{58} \mathrm{~N}_{3} \mathrm{O}_{15}, 1036.3868$; found, 1036.3872 . 
IV. Reaction Survey and Building Block Selection

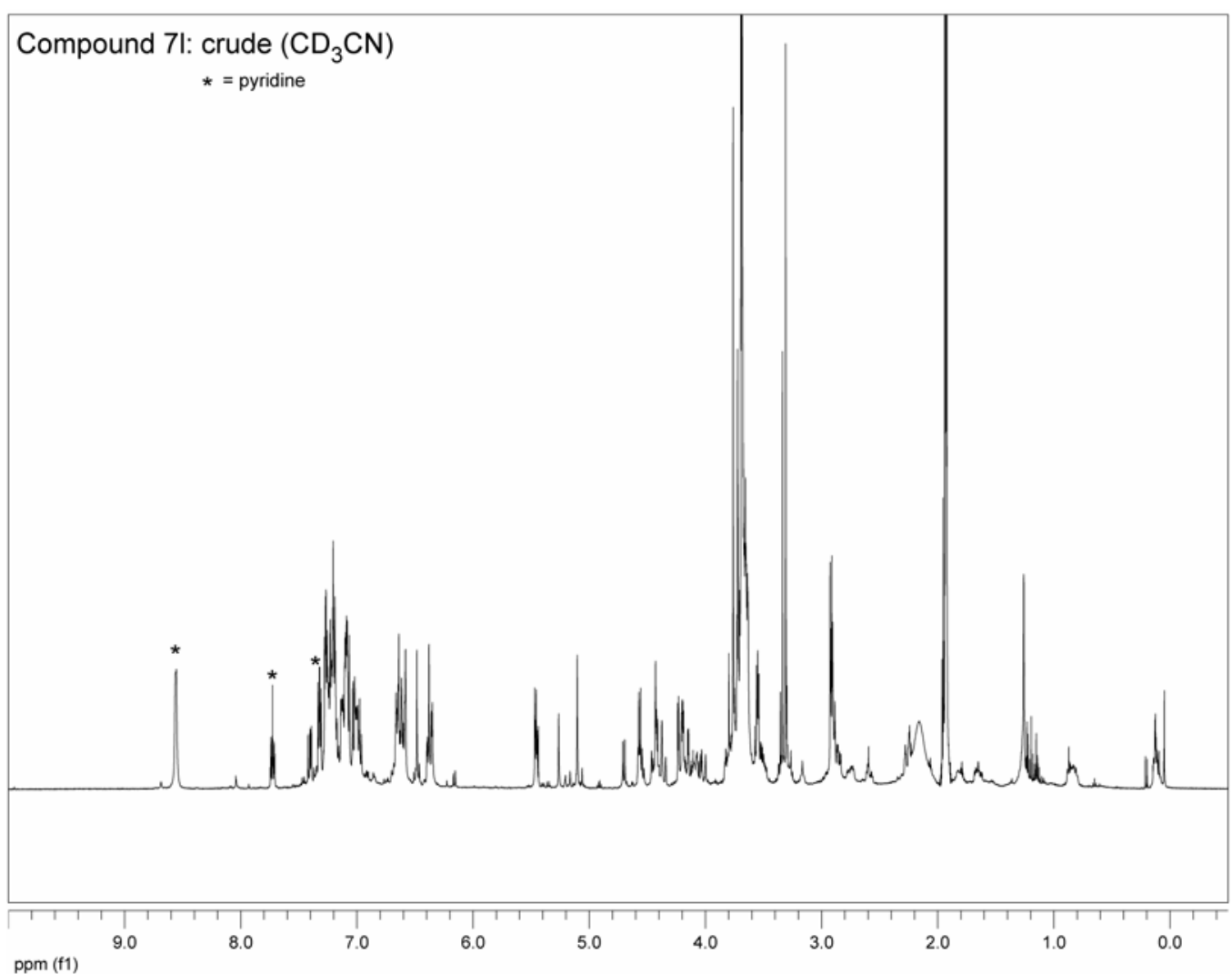

Compound 71: purified $\left(\mathrm{CDCl}_{3}\right)$

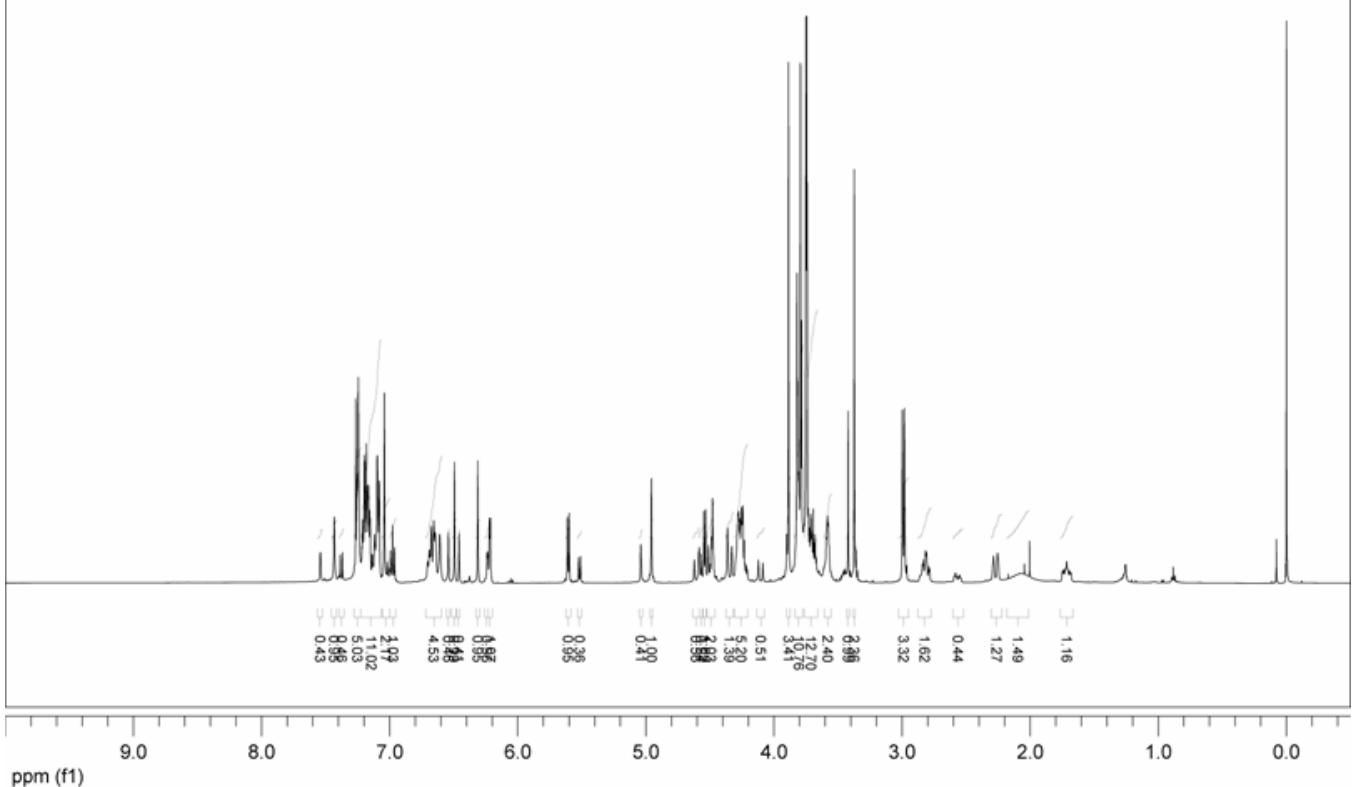


IV. Reaction Survey and Building Block Selection

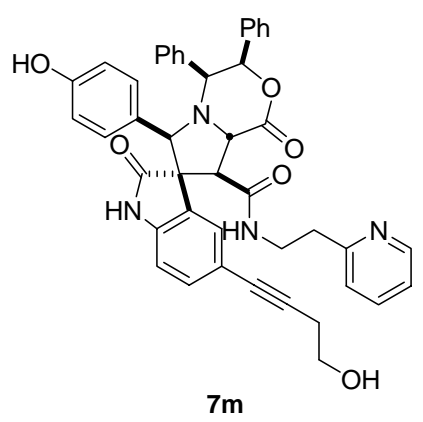

7m. Purification: Flash chromatography (10/90 i-PrOH/EtOAc 50/50), followed by HPLC (35/65 $i$-PrOH/hexanes $\rightarrow$ 55/45). ${ }^{1} \mathrm{H}$ NMR $\left(500 \mathrm{MHz}, \mathrm{CD}_{3} \mathrm{CN}\right): \delta 2.52(\mathrm{td}, 1 \mathrm{H}, J=6.8,14.1), 2.54(\mathrm{t}, 2 \mathrm{H}$, $J=6.8), 2.60(\mathrm{td}, 1 \mathrm{H}, J=6.8,14.1), 2.98(\mathrm{~s} b r, 1 \mathrm{H}), 3.30(\mathrm{td}, 1 \mathrm{H}, J=6.3,19.3), 3.36$ (td, $1 \mathrm{H}, J=6.3,19.5)$, $3.63(\mathrm{~m}, 2 \mathrm{H}), 3.91(\mathrm{~d}, 1 \mathrm{H}, J=9.3), 4.06(\mathrm{~d}, 1 \mathrm{H}, J=2.9), 4.94(\mathrm{~s}, 1 \mathrm{H}), 5.09$ (d, 1H, J=9.3), $6.32(\mathrm{~d}, 1 \mathrm{H}$, $J=2.9), 6.51(\mathrm{~m}, 3 \mathrm{H}), 6.90(\mathrm{~d}, 2 \mathrm{H}, J=8.3), 6.97(\mathrm{~m}, 2 \mathrm{H}), 7.04-7.09$ (m, 4H), 7.16-7.28 (m, 9H), 7.63 (dt, $1 \mathrm{H}, J=2.0,7.8), 8.36(\mathrm{~s} \mathrm{br}, 1 \mathrm{H}), 8.46(\mathrm{~d}, 1 \mathrm{H}, J=4.9) .{ }^{13} \mathrm{C} \mathrm{NMR}\left(125 \mathrm{MHz}, \mathrm{CD}_{3} \mathrm{CN}\right): \delta 24.5,37.9,39.6$, $56.7,58.6,61.7,61.8,62.4,75.3,77.9,82.5,87.5,110.3,115.8,117.5,118.4,122.7,124.4,126.7,126.9$, 128.1, 128.92, 128.94, 129.4, 129.5, 129.9, 130.4, 130.6, 133.2, 137.4, 137.7, 142.6, 150.3, 158.1, 160.5, 167.5, 173.1, 177.2. HRMS-ESI ${ }^{+}(\mathrm{m} / \mathrm{z}):[\mathrm{M}+\mathrm{H}]^{+}$calcd for $\mathrm{C}_{44} \mathrm{H}_{39} \mathrm{~N}_{4} \mathrm{O}_{6}, 719.2870$; found, 719.2867. 
IV. Reaction Survey and Building Block Selection



\section{Library Realization Flowchart}

The following flowchart represents the realized library synthesis. The changes from the planned synthesis are evident in the 4 additional acylation pools.

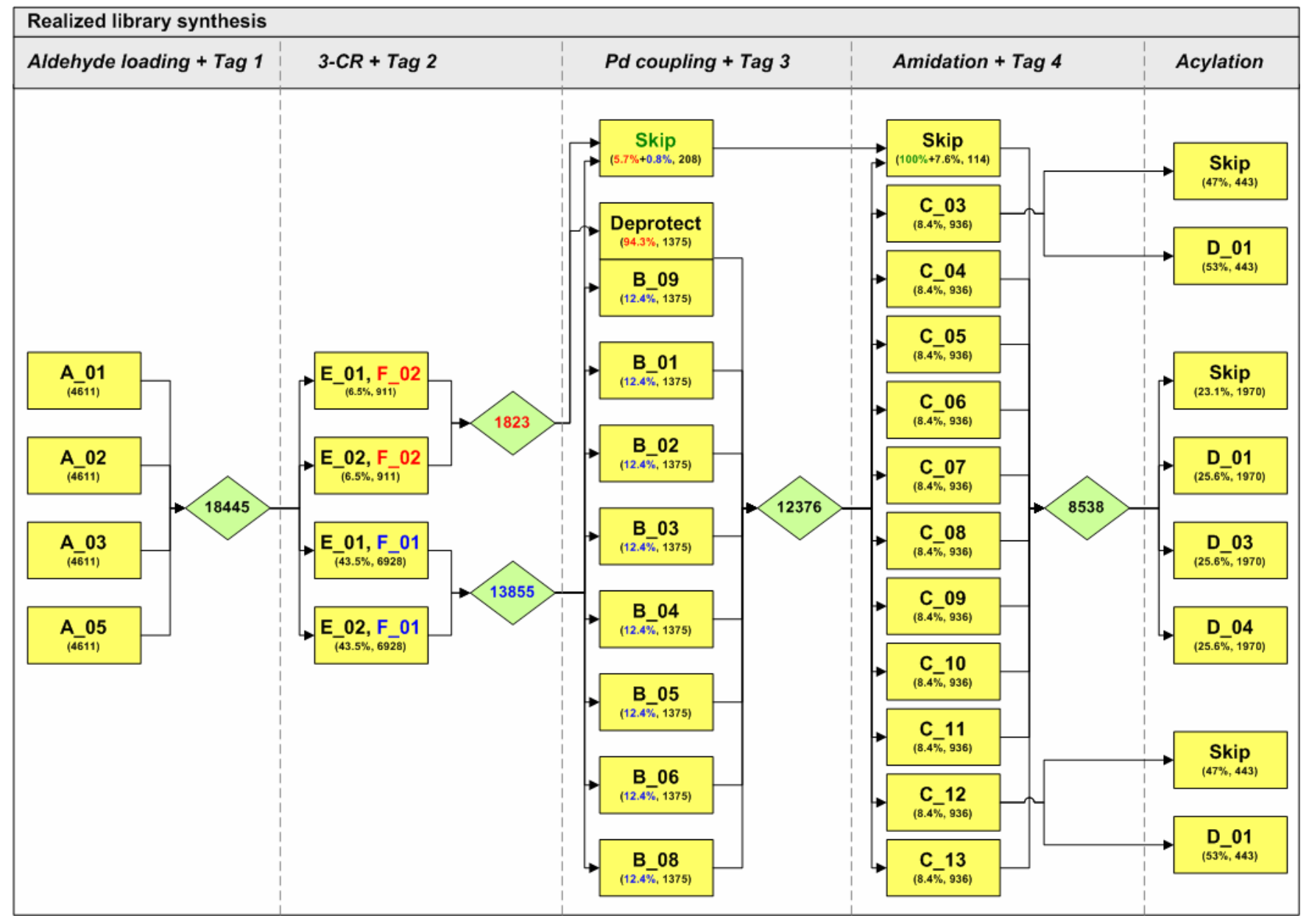




\section{Biological Screening}

A. High-throughput Screen. A yeast culture was inoculated from a single colony of BY4741 (Research Genetics) and grown overnight in YPD media (1\% yeast extract, $2 \%$ peptone, 2\% dextrose) to mid-log phase. A 1:1000 dilution was seeded into 384 well clear bottom NUNC plates (VWR) in a volume of $45 \mathrm{uL}$. Compound $(300 \mathrm{~nL})$ was added by robotic pin transfer. Plates were incubated on the benchtop, and growth was monitored over a window of observation spanning $96 \mathrm{hrs}$. Cells were resuspended by vigorous vortexing of the 384-well plate on a standard benchtop vortexer. Optical density at $600 \mathrm{~nm}$ was measured on a SpectraMax PLUS spectrophotometer (Molecular Devices).

B. Secondary Assay. A yeast culture was inoculated from a single colony of BY4741 and grown to mid-log phase in YPD media. The optical density of the culture was determined. In 96-well plate format, individual wells were seeded with 25,000 cells in $100 \mu \mathrm{L}$ YPD with 1.0 $\mu \mathrm{M}$ Latrunculin B and varying amounts of test compounds. Plates were incubated on the benchtop, and growth was monitored over 24 hours. Cells were resuspended by vigorous shaking on a benchtop orbital shaker. Optical density was measured on a SpectraMax PLUS spectrophotometer. 


\section{Positives from High-Throughput Screen}
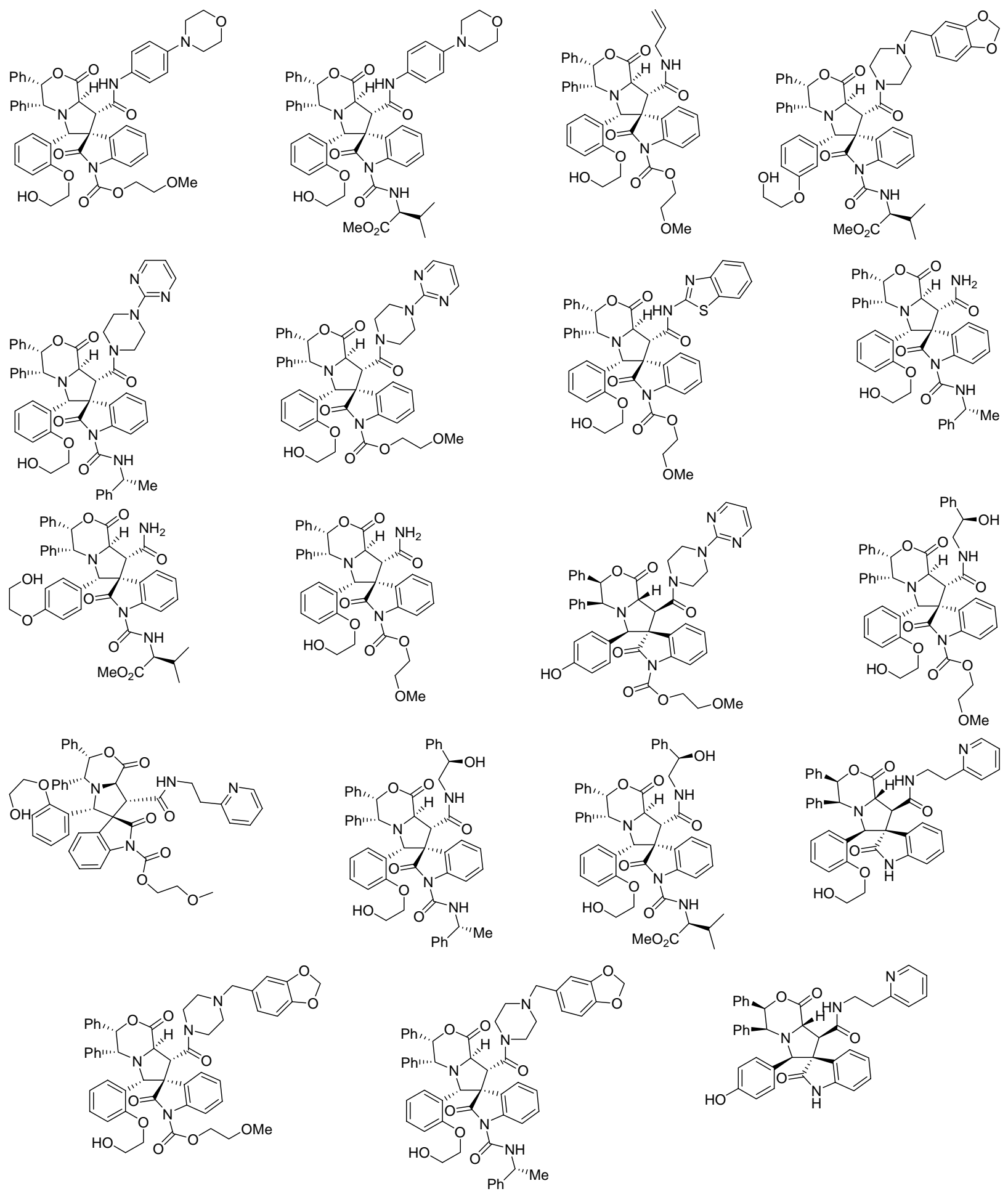